\title{
Cerebrospinal fluid biochemical markers in central nervous system metastasis : clinical applications
}

Citation for published version (APA):

Twijnstra, A. (1986). Cerebrospinal fluid biochemical markers in central nervous system metastasis : clinical applications. [Doctoral Thesis, Maastricht University]. Rijksuniversiteit Limburg. https://doi.org/10.26481/dis.19860516at

Document status and date:

Published: 01/01/1986

DOI:

10.26481/dis.19860516at

Document Version:

Publisher's PDF, also known as Version of record

\section{Please check the document version of this publication:}

- A submitted manuscript is the version of the article upon submission and before peer-review. There can be important differences between the submitted version and the official published version of record. People interested in the research are advised to contact the author for the final version of the publication, or visit the DOI to the publisher's website.

- The final author version and the galley proof are versions of the publication after peer review.

- The final published version features the final layout of the paper including the volume, issue and page numbers.

Link to publication

\footnotetext{
General rights rights.

- You may freely distribute the URL identifying the publication in the public portal. please follow below link for the End User Agreement:

www.umlib.nl/taverne-license

Take down policy

If you believe that this document breaches copyright please contact us at:

repository@maastrichtuniversity.nl

providing details and we will investigate your claim.
}

Copyright and moral rights for the publications made accessible in the public portal are retained by the authors and/or other copyright owners and it is a condition of accessing publications that users recognise and abide by the legal requirements associated with these

- Users may download and print one copy of any publication from the public portal for the purpose of private study or research.

- You may not further distribute the material or use it for any profit-making activity or commercial gain

If the publication is distributed under the terms of Article $25 \mathrm{fa}$ of the Dutch Copyright Act, indicated by the "Taverne" license above, 


\section{CEREBROSPINAL FLUID BIOCHEMICAL MARKERS IN CENTRAL NERVOUS SYSTEM METASTASIS: CLINICAL APPLICATIONS}

\section{Proefschrift}

ter verkrijging van de graad van doctor in de geneeskunde aan de Rijksuniversiteit Limburg te Maastricht, op gezag van de Rector Magnificus, Prof. Dr. F.I.M. Bonke, volgens besluit van het College van Dekanen in het openbaar te verdedigen op vrijdag 16 mei 1986 des namiddags te 16.00 uur

door

Albert Twijnstra

Geboren te Meppel

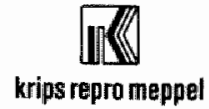


Promotor: Prof. Dr. P.J.M. van der Lugt

Copromotor: Dr. BW. Ongerboer de Visser

Referenten: Dr. G.H. Blijham

Prof. Dr. F.T. Bosman

Prof. Dr. F.J. Cleton 
To the cancer patients 
This study was supported in part by a grant from: BRISTOL-MEYERS B.V.

SANOFI DIVISIE LABAZ 


\section{CONTENTS}

Chapter 1. Introduction

1.1.

General value of biochemical markers in tumours

1.2 Cerebrospinal fluid (CSF) fomation and absorption

1.3. The route of entry of tumour rlarkers into the CSF

1.4. Potential use of cerebrospinal fluid markers in the diagnosis and follow-up of treatment of patients with central nervous system metastases

1.4.1. Screening the general population for presence of CNS tumours

1.4.2. Determining the presence or absence of CNS metastasis in patients at risk

1.4.3. Determining the site of CNS tumours

1.4.4. Classification and grading of CNS tumours 5

1.4.5. Assessment of therapeutic efficacy 6

1.4.6. Prediction of prognosis and long-term evaluation 6 of tumour growth

1.4.7. The value of tumour markers in distinguishing

leptomeningeal metastasis from infectious meningitis

1.5. Classification of tumour markers in CSF 7

1.5.1. Tumour-associated antigens 7

1.5.1.1. Carcinoembryonic antigen (CEA) 7

1.5.1.2. Human chorionic gonadotrophin (HCG) 8

1.5.1.3. Alpha-fetoprotein (AFP) 9

1.5.1.4. Beta-2-microglobul in $(B 2-m) \quad 9$

1.5.2. Enzymes 10

1.5.2.1. Creatine kinase BB isoenzyme (CK BB) 11

1.5.2.2. Enolase 11

1.5.2.3. Beta-glucuronidase $(B-g l u c) \quad$.

1.5.2.4. Lactate dehydrogenase (LDH) 12

1.5.3. Metabolites 14

1.5.3.1. Polyamines 14

1.6. Purpose of this study 14 
1.7. Outtine of the study

1.3. References

Chapter 2. Cerebrospinal Fluid Beta-glucuronidase Activities in Patients with Central Nervous System

Metastases

2.1. Introduction

2.2. Patients and methods

2.2.1. Control group

2.2.2. Patient group

2.2.3. Sample handling

2.2.4. Reagents

2.2.5. Procedures

2.2.6. Statistical methods

2.3. Results

2.4 .

Discussion

2.5 .

Sumary

2.6 .

References

Chapter 3. Cerebrospinal Fluid Beta-2-microglobul in: a Study 35 in Controls and Patients with Metastatic and Non-Metastatic Neurological Diseases

3.1 . Introduction

3.2. Patients and methods

3.2.1. Statistics

3.3. Results 38

3.4 .

Discusiton 39

3.5 . Summary

3.6 . References

Chapter 4. Cerebrospinal Fluid Carcinoembryonic Antigen in

Patients with Metastatic and Nometastatic Neurological Diseases

4.1. Introduction

4.2. Patients and methods

4.3. Statistics 
4.4. Results 49

4.5. Discussion 54

4.6. Summary 55

4.7. References 56

Chapter 5. Serial Lumbar and Ventricle Cerebrospinal Flluid 58 Lactate Dehydrogenase Activities in Patients with Leptomeningeal Metastases from Solid and Hematological Tumours

5.1. Introduction 58

5.2. Patients and methods 59

5.3. Statistics 63

5.4. Resultis 64

5.5. Discussion 66

5.6. Sumary 70

5.7. References $\quad 70$

Chapter 6. Sensitivity and Specificity of single and 75 Conbined Tumour Markers in the Diagnosis of Leptomeningeal Metastasis from Breast Cancer 6.1. Introduction 75

6.2. Patients and methods 76

6.2.1. Samples $\quad 77$

6.2.2. Assay methods $\quad 77$

6.2.3. Statistics 77

6.3. Results 78

6.4. Discussion 80

6.5. Summary 82

6.6. References 82

Chapter 7. Serial Lumbar and Ventricular Cerebrospinal Fluid 85 Biochemical Marker Measurements in Patients with Leptomeningeal Metastases from Solid and Hematological Tumours

7. 1. Introduction 85

7.2. Patients and methods 87 
7.2.1. Cerebrospinal fluid sampling 89

7.2.2. Assay methods 90

7.2.3. Statistical methods 90

7.3. Results 91

7.4. Discussion 98

7.5. Conclusion 100

7.6. Summary 100

7.7. References 101

Chapter 8. Diagnosis of Leptomeningea1 Metastasis 103

8.1. Introduction 103

8.2. Definition of leptomeningeal metastasis 103

8.3. Pathogenesis of leptomeningeal metastasis 103

8.4. Pathology 104

8.5. Clinical incidence and features 105

8.6. Laboratory findings 106

8.6.1. Cytopathology of cerebrospinal fluid 106

8.6.2. The role of CSF biochemical markers in central 107 nervous system (CNS) metastases

8.6.3. The role of monoclonal antibodies in CSF 108 cytology

8.6.4. Cytogenetic studies of cells in the CSF 108

8.7. Radiological studies 109

8.7.1. Computerized tomography of leptomeningea 1 metastasis

8.7.2. Myelography in patients with leptomeningeal 109 metastases

8.8. Clinical investigations and diagnosis in $41 \quad 109$ patients with leptaneningeal metastases

8.8.1. Clinical findings 110

8.8.2. Symptoms and signs of the patients with 111 leptomeningeal metastases

8.8.2.1. Cerebral signs and symptoms 111

8.8.2.2. Cranial nerve signs and symptoms 111

8.8.2.3. Spinal signs and symptoms 111

8.8.3. Laboratory findings $\$ 14$ 
8.8.3.1. Cytology of cerebrospinal fiuid 114

8.8.3.2. Biachenical markers in CSF as a diagnostic a id in 114 leptomeningeal metastasis

8.8.3.3. Autopsy studies 116

8.8.4. Radiological studies 116

8.8.4.1. Computerized tomography of leptomeningeal 116 metastasis

8.8.4.2. Myelography in patients with leptomeningeal $\$ 18$ metastasis

8.8.5. Concluding Remarks 118

8.9. References 119

Samenvatting en Conclusie $\quad 124$

$\begin{array}{ll}\text { Summary and Conclusion } & 128\end{array}$

Acknowl edgements $\quad 132$

Curriculum Vitae 134 

Introduction

1.1. General value of biochenical markers in tumours

Cancer is the second most common cause of death in humans (1), and the incidence of nearly all neoplastic diseases is increasing. The increase in central nervous system (CNS) metastases from systemic cancer has been ascribed to prolonged survival caused by more aggressive forms of therapy and to the inability of most chemotherapeutic agents to cross the blood-brain barrier. Between 18\% and $30 \%$ of all patients who die of systemic cancer have CNS involvement at autopsy (2).

Early detection of cancer may improve the chances of cure and survival; however, about two-thirds of all cancer patients al ready have metastases of the disease before cancer is diagnosed (3). For this reason, an urgent need exists for adequate screening methods which wili permit diagnosis of cancer before the development of metastases. Biochemical markers, al so called "tumour markers", may be important tools; such markers have been studied in various biological fluids, such as urine, plasma, pleural and peritoneal fluids, and cerebrospinal fluid. (CSF) $(4-11)$. Although these tumour markers, in general, have not proved to be very useful in the early diagmosis of cancer in the population at large (the high false positive rate and law true positive rate appear to be serious 1 imitations), it may be different in the screening of subjects who run a high risk of developing cancer. At the moment, it is too early to make any definite conclusions.

Withim this area of research, considerable interest has developed in identifying and measuring tumour-related substances in CSF. Recently, new techniques to measure the concentrations of tumour-specific or tumour-associated materials have been developed, and these techniques are the subject of this thesis.

A substance must meet certain criteria before it can be called a tumour marker. First the "ideal" tumour marker must be a molecule which is exclusively of tumour cell origin and 1 t must be released by the tumour cell in quantities proportional to the tumour burden. For clinical purposes, a tumour marker should not be present in substantial concentrations in body fluids of non-tumour-bearing hosts. Finally, it 
should be detectable before the tumour burden can be demonstrated with simple means or before it has progressed towards an incurable state.

The usefulness of a tumour marker can also be described in terms of parameters which are generally applied for the evaluation of clinical Ilaboratory tests (12). These parameters include: (ii) sensitivity "the abllity of the test to detect all patients with cancer; (ii) specificity "the abillty of the test to identify indiwiduals who do not hawe the disease"; (ifi) positive predictive value "the probability that a person with a positive test actually has the disease"; and (iv) efficiency "the fraction of all results that are correct" Whereas sensitivity and specificity can be calculated directly fir om the data obtained in a clinical study, predictive values are dependent upon prewalence of the disease in the population to which the diagnostic test is administered.

CSF tuntour markers may be divided into enzymes, tumour-associated antigens, and metabolic products. This overwiew will concentrate om the current and future role of tumour markers, particularly in relation to cancer diagnosis and the monitoring of the results of treatment.

\subsection{Cerebrospinal fluid (CSF) formation and absorption}

Cerebrospinal fluid provides the clinician with access to the brain, and variations in its composition allow him to pinpoint pathophysiological changes in brain function (13).

CSF is found in the ventricular system and in the subarachnoid spaces. The fluid is clear and colorless, the valume appraximately $150 \mathrm{ml}$; it contains small amounts of glucose, protein, and potassium, large amounts of sodium chloride, and few or no cellular components (14-17).

The formation and absorption of CSF in humans has been measured by indicator dilution techniques. The rate of formation is approximately $0.35 \mathrm{mll}$ per minute, or $500 \mathrm{ml}$ per day (18). The choroid plexus is the principal source of CSF. The major absorptive sites are the arachnoid granulations (Pachioni), which penetrate the major durat venous sinuises in the cranium and epidural veins.

The chemical milieu of the cNS must be maintained within certain narrow limits to give all neurons the opportunity to function. The blood-brain barrier is directly responsible for this stable physical and chemical milieu. It acts as a differential filter, selectively 
permitting the passage of some substances from the blood into the intracellular fluid. The ept thelium of the choroid plexus may also be invalved, actively secreting certain substances into CSF.

\subsection{The route of entry of tumour markers into the CSF}

Just how biochemical substances produced by malignant neoplasms, enter CSF is unknown. There are, however, several theories about the origin of these tumour products.

(i) Local production and release of tumour products directly into CSF by tumour cells - "This may occur if the tumour cells are localised in the leptomeninges ar are present within the CNS it self $f^{\prime \prime}$.

(ii) Passage of tumour praducts from plasma inta CSF, due to a rupture of the blood-brain barrier - "From electron microscopical studies, it appears that at the site of brain tumours, the blood-brain barrier is frequently open, allowing the free passage of relatively large proteins" (17). However, the obserwation that tumour products can be found in higher concentrations in CSF than in plasma strongly suggests that tumour cells contalned within the subarachnoid space secrete their products directly into spinal fluid, making abnormal permeability of the blood-brain barrier a less plausible explanation.

(iii) Access to CSF through cerebral, extracellular space - "It is known that proteins such as horse radish peroxidase (molecular weight 43,000 Daltons) can pass from the two compartments". Therefore, one cannot rule out the possibility of tumour products diffusing from a turmour deep within the parenchyma to the ventricular or subarachnoidal surface and then being secreted into CSF.

\subsection{Potential use of cerebrospinal fluid markers in the diagnosis and}

\section{follow-up of treatment of patients with central nervous system}

\section{metastases}

1.4.1. Screening the general population for presence of CNS tumours

In order to evaluate a new laboratory test, knowledge of the test characteristics are needed. Sensitivity and specificity, toghether with false negative and false positive rates, are the most important test characteristics to consider when analysing test results (12). Once a 
cut-off limit has been chosen for a laboratory test, the sensitivity and specificity are fired.

Determining the sensituity and specificity of a test is, however, difficult, since an absolute standard (gold standard) against which to measure test performance, must first be chosen. In other words, the usefulness of a test is dependent upon its ability to analyse data to confin the presence or absence of the disease. In our studies, standards were chosen according to the following criteria: In order to confirm a ditagnosis of leptomeningeal metastasis, the presence of tumour cells in the CSF, or an autopsy revealing metastasis, was required. Yet, cytological analyses of CSF have al so posed a serious problem, in that they sometimes give false posttive and fal se negative results. In reviewing the literature, we found that these criteria have not always been used to evaluate a new laboratory test.

The usefulness of a tumour marker test in screening for the presence of absence of a disease can be detemined from its positive or negative predictive value. These values are dependent not only on sensitivity and specificity of the test, but al so on the prevalence of the disease within the population studied. For example, given an estimated prevalence in the general population of 4.5 cases of CNS tumours per 100,000 individuals, a test with a sensitivity and specificity of $99 \%$ would have a positive predictive value of only $0.44 \%$; that is to say, it is quite likely that only one out of every 227 subjects with a positive test would actually have a CNS tumour.

one must bear in mind that a test has to have both a high sensitivity and a high specificity to be of value in this kind of screening* unfortunately, only a few such tests exist.

There are still other factors to consider with regard to mass screening by CSF tests. A test for general screening would have to be given to each member of the population, whether or not the person exhibited symptoms of the disease. Individuals in good health would most likely not agree to a test that involved obtaining CSF by lumbar puncture. 


\section{at risk}

Acceptable predictive walues can be obtained when a test group is limited to a population of patients with neurological diseases who have one or more defined symptoms indicating the possible presence of a cNs tumour.

The advent of computerized tomography (CT) has resulted in a major change in the detection, and follow-up to treatment, of CNS malignancy. However, small tumours and metastases in the posterior fossa and leptomeninges are difficult, if not impossible, to detect on CT scans. In such cases, tumour markers may prove quite helpful. They may also facilitate in the early detection of asymptonatic CNS metastases, such as an increase in the level of human chorionic gonadotrophin (B-HCG) in metastases from uterine chorion carcinoma $(19,20)$. In other words, elevation of tumour markers in CSF may indicate the presence of such tumours earlier than the methods currently available are able to.

\subsubsection{Determining the site of CNS tumours}

B-glucuronidase (B-gluc.) and carcinoembryonic antigen (CEA) in CSF seem to be accurate tumour markers for the detection of leptameningeal metastases, but not for intraparenchymal or epidural metastases (4).

The diagnostic criterion for leptomeningeal metastasis is the presence of tumour cells in CSF, this points to the invasion of the leptomeninges by cancer. In one series of patients, $60 \%$ of the patients with leptomeningeal cancer had a positive cytology, indicating that failure to find malignant cells is relatively common among patients with leptomeningeal metastasis. In that case, other laboratory tests, such as identification of tumour markers within the CSF, can be of help $(4,22$, 23).

\subsubsection{Classification and grading of CNS tumours}

The most reliable method for classifying CNS tumours is histological examination of a biopsy specimen of tumour tissue. However, surgical approaches often carry with them the risk of morbidity or mortality. Some CNS tumours, especially metastases of germ cell tumours (chorion carcinoma), may be highly vascular and prone to spontaneous hemorrhage (24). Surgical manipulation may provoke uncontrollable bleeding and 
contribute to the patient"s death. Measuring biological markers in CSF, such as alpha-fetoprotein (A-F.P.) and human chorionic gonadotrophin (HCG) makes it possible to obviate the need to perform a surgical biopsy. The detection of elevated $A-F$. P. or HCG in the CSF may be sufficient for diagnosis , so that therapy can be started.

Furthermore, some tumour markers may be of value in distinguishing benign from malignant primary CNS tumours (e.g. desmosterol polyamines and adenylate kinase in gllomas $(25,26))$.

\subsubsection{As sessmert of therapeutic efficacy}

Tumour marker measurements of CSF may be useful in monitoring the effects of treatment. Little data is available, however, concerning the serial measurements of biochemical markers during therapy $(7,22,23$, 27-29). In chorion carcinoma, reglular measurements of HCG levels in lunbar CSF are very inpartant in monitoring therapy $(19,20)$.

There is wirtually no information in the literature on usefulness for tumour markers measured simultaneously in ventricular CSF, obtained from the Omaya reservoir, and in lumbar CSF. Moreover, very little information is available concerning the usefulness of tumour marker deteminations in the longitudinal follow-up of patients with leptomeningeal metastases.

\subsubsection{Prediction of prognosis and long-term evaluation of tumour} growth

Changes in CSF marker levels may be more reliable in predicting a decline in the clinical status of a patient, secondary to tumour regrowth, than those methods currently avallable. However, ittle infomation is ayllable on fluctuations in tumour marker levels in relation ta tumour growth. Long-term serial studies on patients who have been treated for CAS tumours are needed to correlate marker levels with clintical status.

\subsubsection{The value of tumour markers in distinguishing leptomeningeal} metastas is from infectious meningit is

Leptomeningeal netastases tend to minic the clinical picture of infectious meningits $(30)$. The CSF findings in leptomeningeal metastasis may al so tend to be identical to those found in cases of mening it is 
arising from tuberculosis, cryptococcus, candida albicans, and sarcoidosis $(31,32)$. In patients with infectious meningitis, the tumour markers B-gluc., B2-microglobul in (B2-m), and lactate dehydrogenase (LOH) are elevated, possibly secondary to the presence of granulocytes in the CSF (33). In the differential diagnosis of leptomeningeal metastases from infectious meningitis, the combined detemination of B-gluc., CEA, and LDH in CSF may be of even greater quantity measured; in meningitis, B-gluc. and LDH will be elevated, whereas CEA will be nomal (20).

\subsection{Classification of tumour markers in CSF}

Tumour markers in CSF can be divided into three groups:

1.5.1. Tumour-associated antigens

1.5.2. Enzymes

1.5.3. Metabolic products

1.5.1. Tumour associated antigens

1.5.1.1. Carcinoembryonic antigen (CEA)

CEA, first isolated in 1965 by Gold and Freedman (34), is a B-1-glycoprotein with a molecular weight of approximately 180,000 Daltons. It is present in normal intestinal tissues, in various biological fluids, such as blood, urine, intestinal secretions, and peritoneal fluids $(5,6,35)$, and in $\operatorname{CSF}(7,36)$.

Raised serum levels of CEA are found particularly in patients with carcinoma of the gastrointestinal tract, breast, lung, ovaries, and pancreas $(31,37,38)$, but have al so been observed in patients with a variety of nommalignant diseases.

In the diagnosis of CNS tumours, measurement of serum CEA appears to be of limited value. Only a small percentage of patients with primary or metastatic brain tumours have shown elevations of serum CEA $(39,40)$, whereas CEA levels are frequently elevated in the serum of patients with neuroblastoma (41).

Since the recent development of new techniques which permit measurement of nanogram concentrations of proteins, CEA has become detectable in CSF. This CEA from CSF is reported to be of value in the detection of CNS metastases of CEA-producing tumours, especially the leptomeninges from lung and breast carcinoma $(7,8,39,40,42)$. There are no reports on CEA elevations in the CSF of patients with 1 ymphoma 
(8). Patients with primary brain tumours have a sight elevation, if any, of CEA in their CSF (7). The same is true of those with infectious. meningitis $(20)$.

\subsubsection{Human choriontc gonadotrophin (HCG)}

HCG is a glycoprotenf produced by the placenta. It has two subunits al pha and beta - which can be detected separatel y by radioimmunoassay methods. In chorion carcinoma, the quantitative assay of urine and/or serum HCG is essential for initial diagnosis and in monitoring the course of the disease; the higher the level, the larger the tumour mass (43). Chorion carcinoma is kmown to metastasize widely and at am early stage, with frequent involvement of the brain.

B-HCG is detectable in the CSF of patients with chorion carcinoma and entibryonal carcinoma.

Analyses of CSF in series of patients with chorion carcinoma (44) showed that, in the absence of brain metastases, the level of HCG found in the CSF is proportional to the serum level. Therefore, a serum:CSF gradient for HCG is gemerally more meaningful than the actual CSF level. By use of this gradient, or ratio, it is possible to distinguish those patients with cerebral metastases from chorion carcinoma from those without it. In patients with cerebral metastases from chorion carcinoma, the serum:CSF gradient is uswally below 60 (44). This method of diagnosing cerebral metastases is now routinely used in all patients with chorion carcinoma. Ance cerebral metastasis has been diagnosed, CSF MCG measurements can be used in monitoring the efficacy of treatment 143 , 44).

The origin of the elevated HCG levels in the CSF of patients with cerebral metastases has been puzzling. The observation that B-HCG is detectable in the CSF of subjects with nomal pregnancy indicates that $B-H C G$ enters the CSF only when a threshold value is excreted. Yet, there is also speculation that HCG from serum may enter an abnormally permeable blood-brain barrier. That this does, in fact, seem to be the case is suggested by the relationship between the HCG level in CSF and that in the serum. At the same time, there is some evidence of direct secretion of HCG from cerebral metastasis, particularly when the level of HCG in the CSF exceeds that found in the serum $(19,42,43)$. 
The HCG from CSF has also been used in the diagnosis and treatment of primary CNS tumours of germ cell origin. The marker profile for chorion carcinoma and embryonal carcinoma in CSF correlates positively with the histological diagnosis, that is to say, both tumours produce HCG (46). Their presence in CSF may be sufficient to confirm the diagnosis of cerebral metastasis, enabiling specific chemotherapy or/and radiotherapy treatment to be started without surgical biopsy. The assessment of HCG in CSF is also a good indicator of the success of therapy (44).

\subsubsection{Al pha-fetoprotein (AFP)}

AFP is an oncofetal antigen found in fetal serum as early as the first month of human embryonic life. AFP is a glycoprotein synthesized by the yolk sac, liver, and gastrointestinal tract of the fetus.

Elevations of AFP levels in serum have been observed in patients with hepatocellular carcinoma, as well as in patients with viral hepatitis and liwer cirrhosis. AFP levels may al so be elevated in germ cell tumours, ovarian cancer, and a variety of gastrointestinal cancers.

Elevated AFP levels have al so been found in cases of endodermal sinus tumour (46). The presence of a CSF:serum gradient of AFP may aid in the diagnosis of surgically inaccessible tumours. In that case, treatment may be started without an histological diagnosis.

The serial detemination of the AFP level in CSF and serum in patients with metastases to the brain from endodermal sinus tumour and embryonal carcinoma may be a useful adjunct in detemining response to therapy (44).

\subsubsection{Beta-2-microglobul in (B2-m)}

B2-m was isolated and described from human urine by Berggärd and Bearn in 1968 (47). It is a protein with a molecular weight of 11,800 Daltons, and it is a small subunit of the human leucocyte antigens (HLA). B2-m is dissociated from the heavy chain of these antigens and is released in free form in extracellular filuid. Lymphacytes and macrophages are particularly rich sources of $B 2-m$.

B2-m is present in various biological fluids, such as serum, urine, amniotic fluid, ascites, and CSF (48-50). Serum levels of B2-m increase in a variety of states, including various neoplastic, inflammatory, and immunologic disarders, and conditions like renal fallure, in which 
Catabolism is diminished $(49,50)$. Raised serum B2-m levels were reported in the serum of patients with multiple myel ona, non-Hodgkin's Iymphona, Hodgkin"s disease, and chronic lymphatic leukemia (51). However, because of the multicude of factors that can affect its concentration, $B 2-m$ levels in serum are not of great diagnostic value (52).

It has been suggested that measurement of $B 2-m$ in CSF may be more promising for the diagnosis of CSF tnvolvement by hematological tumours (28). However, CSF $82-m$ al so appears to be elevated in leptomeningeal metastasts from solid tumours and in bacterial meningitis $(29,50)$. Therefore, the exact contribution of B2-m to the diagnosis of leptomeningeal metatasis remains to be determined.

\subsubsection{Enzymes}

Much attention has been paid to enzymes as tumour markers; nevertheless, the clinical significance of CSF enzynes in the diagnosis of CNS tumours is still poorly defined $(53,54)$.

One observation that has been made regarding CSF enzymes and malignancy is that the level of lysozyme muramidase present in the CSF of subjects with brain tumours appears to be raised (55), not unlike that of serum muramidase in the case of leukemia patients.

Tests have been carried out to detemine the levels of many other enzymes in CSF, such as isocitrate dehydrogenase, aspartate transaminase, alanine transaminase, pyruvate kinase, aldolase, and adenylate kinase (53, 54); unfortunatelly, none of these tests has a high enough degree of specificity to be of real use since raised levels have been observed in both CNS tumours and many nonmalignant diseases, such as vascular and infectious lesions.

Measurements of yet other enzymes in CSF have been proposed as CSF markers of malignancy in the past several years $(56,58)$, among them, creatime kinase BB isoenzyme, enolase, beta-glucuronidase, and lactate dehydrogenase. The significance of the activities of these enzymes, as related to various neurological conditions, has been interpreted in various, and sonetimes conflicting, ways by different investigators $(57-61)$. 
1.5.2.1. Creatine kinase BB isoenzyme (CK BB)

Concentrations of creatine kinase BB isoenzyme in CSF were measured by radioimunoassay and showed striking elevations in acute CNs injury (8, 56). The CSF CK BB levels do not appear elevated in chronic neurological disease (58). Further study is needed to detemine the significance of CSF CK BB measurements in metastatic CNS malignant neoplasms.

\subsubsection{Enolase}

Enollase is a dimeric enzyme with three subunit types: $\alpha$, $B$, and $Y$, which give rise to five isoenzymes: $\alpha \alpha, \beta B, \gamma \gamma, \alpha \beta$, and $\alpha \gamma$, which show differential cellular distributions. Of particular interest are the isoenzymes patterns in the nervous system. Glia cells contain only a enolase, whereas $r$ is confined to the meurons. Outside the nerwous system, $Y$ enolase occurs predominantly in the cells of the neuroendocrinological system. The measurement of isoenzyme levels, rather than of total activities, reflects more precisely the nature of the lesion. Elevated levels of $\gamma$ enolase in CSF reflect neuronal damage.

Alpha and gamma enolase isoenzymes were studied in 212 patients with various neurological diseases. The results showed that these isoenzymes are sensitive markers of tisswe damage and that they were especially raised in the CSF of patients with low grade astrocytomas (58, 62). Assay of the $\alpha$ - and $\gamma$-enolase isoenzymes seemed to reflect damage to glia cells and neurons, respectively. The neuran-specific enolase may also be a useful tumour marker in the diagnosis of CNS metastasis im small cell lung cancer (SCLC), especially in patients with leptomeningeal metastases (63).

\subsubsection{Beta-glucuronidase (B-g)}

B-gluc. is an intracellular enzyme, localized im lysosomes and microsomes, which hydrolyzes the B-glycoside bond between glucuronic acid and an aglucone (60). It is nomally found in the brain, in both the white and the gray matter (59). Relatively high concentrations exist in pia-arachnoid tissue and choroid plexus $(60,64)$. However, the activity of B-gluc. within CNS is lower than in the wiscera.

B-gluC. is usually found in the CSF of individuals without any disease of the nerwous system (nomals) in a concentration below $27 \mathrm{mu} / 1$ (64). 
The cancentration of the B-gluc. enzyme in lumbar CSF is approximately twice that of ventricular CSF (57).

As a result of nalignant transformation, levels of $B-g l u c$. in the brain, as well as in other tissues, may increase (65). Elevated B-gluc. activity in CSF has been found in patients suffering from bacterial meningltis or leptomeningeal metastases $(4,66)$. Malignant cells derived from adenocarcinoma and myelogeneous leukemias are very $r$ ich in $\mathrm{B}-\mathrm{g}$ luc., ymphoma cells maderately so (65).

In patients with leptomeningeal metastases from hematological malignancies, B-gluc. activity was found to be less elevated than in lieptomeningeal spread from solid tumours $(4,23,65)$.

A slight increase in B-gluc. activity in CSF has been obserwed in patients with parenchymal or epidural metastases from solid tumours (59). siight elevations have al so been reported in some primary CNS malignant tumours and in fungal and tuberculous meningitis. Viral meningitis does not appear to cause elevation of B-gluc. activity in $\operatorname{CSF}(64,66)$.

When patients are successfully treated for leptomeningeal metastases, the B-gluc. concentrations approach control levels in both 1 umbar and ventricular CSF (4).

\subsubsection{Lactate dehydrogenase (LDH)}

LDH is an enzyme that catalyzes the final step in the metabolic chain of anaerobic glycolysis. This enzyme has a molecular weight of 135,000 Daltons and is located predominantly intracellularly. In humans, this enzyme exists in five molecular forns, or isoenzymes (61), all of which are tetramers of two different subunits. LDH is a normal constituent of brain tissue, in which the total activity of LDH, as well as the LDH isoenzyme distribution, can be measured. Extracts from brain tumours may show changes in total L.DH and isoenzyme activities, as compared to the acitiwities in a normal brain. Various alterations of LDH isoenzyme patterns have been described in different types of tumours $(67-72)$.

These findings may be of diagmostic significance, since knowledge of the LDH isoemzyme distribution may help in evaluating tumours otherwise difficult to classify.

Low activities of total LDH and of isoenzymes are present in normal CSF and are found to be age-related $(73,74)$. Reports concerning the presence of this enzyme in the CSF of patients with various neurolagical 
diseases first began to appear in 1956, and numerous publications hawe since documented changes in the LDH activity of CSF (10,74-76).

LOH has been found in the CSF of patients suffering from a variety of neurological diseases, including primary and metastatic CNS tumours (72, 74-77). In the 1 iterature, reports on LOH activity in the CSF of control subjects and of patients with CNS tumours are not uniform (8). Several studies have indicated that $L D H$ activity in CSF is nomal in patients with primary tunours $(15,32)$; others have noted a rise in LoH activity in CSF, with benign, as well as malignant, tumours $(10,72,77)$. Although most researchers have found no correlation between increased enzyme activity within CSF and the degree of malignancy of a tumour "the results of some reports do suggest that such a correlation does exist (71, 74). In one study, it was shown that, with time, the tissue culture medium of malignant cells contained ever increasing amounts of LDH, whereas culturing of benign cells did not produce an increase in the LDH content. of the medium (72). The major source of LDH in CSF is almost certainly the tumours themselves. However, the destruction of nervous tissue by cerebral hypoxia caused by cerebral edema and elevated intracranial pressure, associated with very malignant tumours, may very well contribute to greater activities of LDH in CSF.

Much wark has been done on LDH in the CSF of patients with systemic cancer (22) for the express purpose of detecting leptomeningeal metastases. Given their direct contact with the subarachnoid space, one might almost expect CNS tumours to cause a rise in LDH activity in CSF. Earlier studies, however, have reported quite different results (15, 17).

A same high elevation of LDH isoenzymes in CSF was found in patients with leptomeningeal metastases from solid tumours (22), as well as, though to a lesser degree, in patients with leptomeningeal metastases from hematological tumours. Many studies have al so reported high LDH activity in the CSF of patients with cerebral and epidural metastases 18 , 10, 74). Moreover, it is known that LDH activity in CSF increases in a number of nonmalignant conditions. Diagnostic significance has been ascribed to elevations of LDH activity in CSF in cases of cerebrovascular disease $(10,68,71)$, bacterial meningitis $(33,70,75)$, and head injury (10). 
In some studies lead one to conclude that serial measurement of LDH in CSF is reeded, of value in monitoring the efficacy of treatment $(8,22)$.

\subsubsection{Hetabolites}

\subsubsection{Pol:yamines}

The tevel s of the polyamines putrescine, spermidine and spermine have been reported to be elevated in the serum and urine of many patients with cancer (78). The exact function of the polyamines under normal

circumstances has not yet been detemined, but they appear to be related to cellular growth and differentiation. Increases in polyamines in serum and urine have been reported in leukemia, cancer of the ovaries, Iung, colon, rectum, prostate, kidney, testes, and bladder, and malignant melanoma $(78)$.

Polyamines have also been measured in CSF, in neurological patients without CNS neoplasms, and low levels have generally been found. By contrast, the levels of polyamines in the CSF of a group of patients with malignant primary brain tumours have been found to be rather high (76, $79,80)$. The assay of CSF polyamines may be useful in the evaluation of the effectiveness of chemotherapy in patients with primary brain tumours (78).

Monitoring of CSF for polyamines has been reported to allow early diagnosis of meningeal leukemia $(79,80)$. Further studies, particularly those including cases of inflamatory CNS lesions, are required to establish the exact value of polyamines as tumour markers.

\subsection{Purpose of this study}

As has been stated in 1.4.1, CSF tumour markers are not presently being used to screen the population at large for the presence of primary brain tumours. However, the potential role of such tuinour markers in the diagnosis of malignancies in groups of high risk patients may be quite large. Indeed HCG and AFP have al ready been in use for many years as markers for a number of relatively uncommon sorts of cancer, such as chorion carcinoma and germ cell tumours. The serial measurement of these tumour markers in CSF is essential for the diagnosis and management of these diseases, and it has al so appeared to be a useful adjunct in determining response to therapy. 
The routine use of other tumour markers in CSF has been investigated in several studies. However, many of these studies have not included patients with CNS tumours or other neurolagical diseases. Infomation on these patients is necessary in order to evaluate the sensitivity and specificity of the test used; the analytical precision and the time, ease, and cost of the test should also be taken into account.

Little data is available concerning the sensitivity and specificity of the measurement of multiple markers in CSF samples. In many instances, there is no data concerning serial studies of patients undergoing treatment to evaluate the use of markers in predicting the efficacy of treatment. Nor have the effects of prophylactic radiation and chemotherapy on tumour marker levels been studied.

Dur decision to make B-gluc., B2-r, CEA, and $L D H$ the subjects of the present study was, in large part, related to the conflicting and incomplete nature of the results of past studies of these tumour markers in the literature. These markers had never before been studied in populations including patients with malignant and nonmalignant neurological diseases and, until now, no data has been available concerning their sensitivity and specificity. Another reason for choosing these markers was our contention that these four markers belong to routine laboratory determinations, and that they must, therefore, be measured rapidly, precisely, and economically.

\subsection{Outl ine of the study}

In this thesis, we describe the results of other studies on tumour markers in CSF. In chapters 2, 3, 4, and 5, the potential value of the tumour markers B-gluc., B2-m, CEA, and LDH in the diagnosis of CNS. metastases is evaluated.

In these studies, CSF samples were taken from patients with CNS tumours and from patients with a broad spectrum of neuralogical diseases. Levels of the four tumour markers within that CSF were measured simultaneously in order to calculate the sensitivity and specificity of the markers.

In chapter 6 , we evaluate the role of single and combined tumour marker tests in the diagnosis of leptomeningeal metastasis from breast carcinoma. 
In chapter 7 , we measure simultaneously the levels of the four tumour makers in the CSF obtained via lumbar and ventricular (i.e. Omaya) taps. He investigate the levels of these tumour markers in lumbar csf in relation to the extent of leptomeningeal disease. We also attempt to determine the rolle that serial tumour marker patterns in ventricular and spinal fluid have in monttoring the success of therapy in patients with leptomeningeal metastases.

In chapter 8 , we discuss the various ways of diagnosing leptomeningeal metastasis. We summarize the results of several clinical tests which may be relevant to this diagnosis and evaluate the potential contributions of the four tumour markers studied.

In the summary and conclusions, we finally report how our results improve the possibilities of diagnosis and treatment of leptomeningeal metastasis.

\subsection{References}

1. Silverberg $E$. Cancer statistics 1980. CA 30: 23-38.

2. Gonzalez-Vitale JC, Garcia-Bunuel R. Meningeal Carcinomatosis. Cancer $1976 ; 37$; 2906-2911.

3. Posner $\mathrm{JB}$. Clinical manifestations of brain metastasis to the brain. In: Brain Metastasis. Edited by L Weiss, HA Gilbert and JB Posner. The Hague, M. Nijhoff, 1980.

4. Martinez-Vea A, Gatell JM, Segura F, Heiman C, Elena M, Ballesta AM, Ribas Mundo M. Diagnostic value of tumor markers in serous effusions. Cancer 1982; 50: 1783-1788.

5. Fersijn JP, Korsten CB, Batteman al. Chemical significance of urinary CEA estimations during the follow-up of patients with bladder carctnoma or previous bladder carcinoma. J Cl in Biochem 1976; 14: $395-399$.

6. Loewemstein MS, Rittgers RA, Feinerman AE. CEA assay of ascites and detection of malignancy. Ann Int Med 1978; 88: 635-638.

7. Schold SC, Wasserstrom WR, Fleisher M, Schwartz MK, Pasner JB. Cerebrospinal fluid biochenical markers of central nervous system metastases. Ann Neural 1980; 8: 597-604.

8. Wasserstrom WR, Schwartz MK, Fleisher M, Posner JB. Cerebrospinal fluid biochemical markers in central nervous system tumours: a review. Ann Clin Lab. Sci $1981 ; 11$, no. $3 .$. 
9. Berggärd I. Beta-2-microglobul in: Isolation, properties and distribution. Fed Proc 1976; 35: 116i-1170.

10. Dharker SK, Dharker RS, Chaurasia BD. Lactate dehydrogenase and aspartate transaminase of the cerebrospinal fluid in patients with brain tumours, congenital hydrocephalus, and brain abscess. J Neurol Neurosurg Psychiat 1976; 39: $1081-1085$.

11. Seidenfeld J, Marton Ld. Biochemical markers of central mervous system tumours measured in cerebrospinal fluid and their potential use in diagnosis and patient management: a review. $J$ Nat Cancer Inst 1979; 63: 919-931.

12. Galen RS, Gabino SR. Beyond normality: the predictive value and efficiency of medical diagnosis. New York: Wiley, 1975.

13. Davson H. Physiology of the Cerebrospinal fluids. London: Churchill, 1967.

14. Fishman RA. Cerebrospinal fluid in disease of the nervous system. Philadelphia, Saunders, 1980.

15. Wood JH. Neurochemical analysis of cerebrospinal fluid. Neurology (NY), 1980; 30: 645-651.

16. Wood JH. Neurobiology of cerebrospinal fluid. New York, Plenum, 1980.

17. Long DM. Capillary ultrastructure and the blood-brain barrier in human mal ignant brain tumour. J Neurosurg 1970; 32: 127.

18. Milhorat ThH. The third circulation revisited. J Neurosurg 1975; 42: 628-645.

19. Rushworth AG, Orr AH, Bagshaw HO. The cancentration of HCG in the plasma and spinal fluid of patients with throphoblastic tumors in the central nervous system. Brit J Cancer 1968; 22: 253-257.

20. Schold SC, Vugrin D, Golbey RB, Posner UB. Central nervous system metastases from germ-cell carcinoma of testis. Seminar ancol 1978; 6: $102-108$.

21. Glass JP, Melamed M, Chernik ML, Posner JB. Malignant cells in cerebrospinal fluid (CSF): the meaning of a positive CSF cytology. Neurology (NY) 1979; 29: 1369-1375.

22. Fleisher M, Wasserstrom WR, Schold S, Schwartz MK, Posner JB. lactate dehydrogenase isoenzymes in the cerebrospimal fluid of patients with systemic cancer. Cancer 1981; 47: $2654-2659$. 
23. Shuttleworth EC, Allen N. CSF B-glucuronidase assay in the diagnosis of neoplastic mentingitis. Arch Neurol 1980; 37: 684-687.

24. Schmidec HH (ed). Pineal Tumors. New York: Passon, 1977.

25. Ronquist G, Frithz G, Ericsson P, Hugosson R. Malignant brain tumors associated with adenylate kinase in cerebrospinal fluid. Lancet 1977 ; I: 1284.

26. Paoletti $P$, Vandenheuvel FA, Fumagalli $R$, Paolett $\mathbb{R}$. The sterol test for the diagnosis of human brain tumors. Neurology 1969; 19: 190.

27. Yap BS, Yap HY, Benjamin RS, Freirich Fu. Cerebrospinal filuid carcinoembryonic antigen in breast cancer patients with meningeal carcinomatosis. Proc An Assoc Cancer Res/Am Soc Cl in Oncol 1978; 19: 98.

28. Mavligit GM, Stuckey SE, Cabanlllas FF, Keating Mu, Tourtelotte WW, Schold SC, Freirich EJ. Diagnosis of leukemia or 1 Mmphoma in the central nervous system by beta-2-microglobulin determination. N Eng? J Med 1980; 303:718-722.

29. Koch TR, Lichtenfeld KM, Wiernik PH. Detection of central nervous system metastases with cerebrospinal fluid B2-microglobulin. Cancer $1983 ; 52: 101-104$.

30. Morganroth $J$, Deisseroth A, Winakur S, Schein Ph. Differentiation of carcinomatous and bacterial meningitis. Neurology 1972; 22: $1240-1242$.

31. Dhar P, Moore $T$, Zamcheck N, Kupchik Hz. Carcinoembryonic antigen (CEA) in colonic cancer: use in pre- and postoperative dilagmosis and prognosis. JAMA 1972; 221: $31-35$.

32. Spolter $H$, Thompson HG. Factors effecting lactic dehydrogenase and glutamic oxaloacetic transaminase activities in cerebrospinal fluid. Neurology $1962 ; 12: 53-59$.

33. Beaty HN, Oppenheimer S. Cerebrospinal fluid lactic dehydrogenase and its isoenzymes in infections of the central nervous system. New Eng J Med 1968; 279: $1197-1202$.

34. Gold $P$, Freedman SO. Demonstration of tumour-specific antigens in human colonic carcinomata by immunological tolerance and absorption techniques. J Exp Med 1965; 121: 439-462.

35. Kalser MH, Berkin JS, Redlhammer D, Heal A. Curculating carcinoembryonic antigen in pancreatic carcinoma. Cancer 1978; 42 (suppl .): 1468-1471. 
36. Dearnaley DP, Patel S, Powel TJ, Combes RC. Carcinoembryonic antigen estimation in cerebrospinal fluid in patients with metastatic breast cancer. Oncodevel Biol and Med 1981; 2: 305-311.

37. Reynoso G, Chu TH, Hol yoke D, Cohen E, Nemoto $T$, Wang $J$, Chuang $J$, Guinan $P$, Murphy GP. CEA antigens in patients with different cancers. JAMA $1972 ; 220: 361-365$.

38. Ho lyoko ED. Present and probable uses of CEA. CA 1975; 25: 22-26.

39. Snitzer LS, MCKinney EC, Tejada F, Sigel MM, Rosomott HL, Zubrod CG. Cerebral metatases and carcinoembryonic antigen in cerebrospinal fluid. N Engl J Med 1975; 293: 1101.

40. Kido D, Dyse B, Haverback BJ, Rumbaugh C. CEA in patients with untreated central nervous system tumours. Bull Los Angelos Neurol Soc 1976; 41: $47-54$.

41. Helson L, Gahvimi F, Wu CJ, Fleisher M, Schwartz MK. Carcinoembryonic antigen in children with neuroblastoma. J Nat Cancer Inst 1976; 57 : $725-726$.

42. Yap BS, Yap HY, Fritsche HA, Blumenschein G, Bodey GP. Cerebrospinal fluid carcinoembryonic antigen in breast cancer patients with meningeal carcinomatosis. JAMA 1980; 244: 1601-1603.

43. Bagshawe K.D. Recent observations related to the chemotherapy and immunology of gestational choriocarcinoma. Adv Cancver Res 1973; 18: $231-263$.

44. Bagshawe KD, Marland S. Immunodiagnosis and monitoring of gonadotrophin-producing metastases in the central nervous system. Cancer 1976; 38: 112-118.

45. Bagshawe KD, Orr AA, Rushworth AG. Relationship between concentrations of human chorionic gonadotrophin in plasma and cerebral fluid. Nature 1968; 217: 950-951.

46. Allen JC, Nisselbaum $d$, Epstein F, Rosen G, Schwartz MK. Alpha-fetoprotein and human chorionic gonadotrophin determination in cerebrospinal fluid. J Neurosurg 1978; 51: 368-374.

47. Berggärd I, Bearb AG. Isolation and properties of a low molecular weight B2-globulin in human biological fluids. I Biol Chem 1968; 243: 4059-4103.

48. Pippard MJ, Callender ST, Sheldon PWE. Infiltration of central nervous system in adult myeloid leukemia. Br Med J 1974; 1: 227-229. 
49. Wibel IL, Ervin PE, Berggärd J. Serum B2-microglabul in in renal disease. Nephron 1973; 10: 320-331.

50. Starmans JJ, Vos J, Helm van der HJ. The beta-2-microglobulin. J Neurol Sci 1977; 33: 45-49.

51. Child SA, Spati B, 111 ingworth S. Serum beta-2-microglobui in and cancer reactive protein in the monitoring of 1 ymphomas: findings of multicenter study and experience in selected proteim. Cancer 1980; 45: $318-326$.

52. Frankl in EC. Beta-2-microglobul in - big role? N Engl J Med 1975; 293: $1254-1255$.

53. Stiffel M, Dittmann $J$, Faul hauer K, Loew F. Enzymes in cerebrospinal fluid in nomal samples, samples from patients with brain tumors, and other neurollogical diseases. Wien Z Nervenheilk 1973; 31: 325.

54. Hildebrand al, Levin $S$. Enzymatic activities in cerebrospinal fluid in patients with neurological diseases. Acta Neural Belg 1968; 73: 229.

55. Barone A. Liattivata lisozimica actuale del liquor nelle malatti nervose. Acta Neurol Italia 1984; 3: 434.

56. Maes AIR. Cerebrospinal fluid enzymes in acute brain injury. Thesis 1977.

57. Anlyan A and Starr A. B-glucuronidase activity of spinal and ventricular fluids in humans. Cancer 1952; 5; 578-580.

58. Royds JA, Timperley WR, Tayl or CB. Levels of enolase and other enzymes in the cerebrospinal fluid as indices of pathological change. J Neurol Neurosurg Psychiat 1981; 44: 1129-1135.

59. Fishman W, Anlyon A. B-glucuronidase activity in human tissue, some correlation with rocesses of malignant growth and with the physiology of reproduction. Cancer Res 1947; 7: 808-817.

60. Allen $N$ and Reagan E. B-glucuronidase activities in cerebrospinal fluid. Arch Neurol 1964; 11: 144-154.

61. Kaplan NO. Symposium on mul tiple forms of enzymes and control mechanisms: multiple forms and enzymes. Bacterial Rev 1963; 27 : $155-169$.

62. Royds JA, Dawies-Jones GB, Lewt as NA, Timperley WR, Tayl or CB. Enolase isoenzymes in the cerebrospinal fluid of patients with diseases of the nervous system. J Neurol Neurosurg Psychiat 1983; 46: $1031-1036$. 
63. Pedersen AG, Marangos A, Gazdar A, Bach F, Hansen H. Bun p Jf. Asco Abstracts 1984: C-25.

64. Al len N. B-glucuronidase activities in tumors of the rervous system. Neurology (Minm.) 1961; 11: 578-596.

65. Ta Iman RO, Kimbraugh SM, O'Brien JE, Goelener JR, Kanagihara T. Assay for B-glucuronidase in cerebrospinal fluid: usefuness for the detection of neoplastic meningitis. Mayo Clin Proc 1985: 60: $293-298$.

66. Shutt leworth E. Allen . Ealy diferentiation of chronic meningitis by enzyme assay. Neurology 1978; 4: 175.

67. Gerhardt W, CTausen 3, Christensen E, Rijshede J. Changes of LDH-isoenzymes, esterases and acid phosphatases and proteins in malignant and benign human tumors. Acta Neurol Scand 1963; 39 : $85-111$.

68. Jakoby RK, Jakoby WB. Lactic dehydrogenase of cerebrospinal fluid in the differential diagnosis of cerebrovascular disease and brain tumour. J Neurosurg 1958; 15: 45-51.

69. Rawbow L. Kristensson K. Changes in lactic dehydrogenase isoenzyme patterns in patients with tumours of the central nervous system. Acta Neurochirurgica $1977 ; 36 * 71-81$.

70. Wroblewski F, Decker B, Wroblewski R. Activity of lactic dehydrogenase in spinal fluid. Am J Clin Pathol 1957; 28: 269-271.

71. Green JB, 01 dwurtel HA, ODoherty DS, Forster FM. Cerebrospina fluid transaminase and lactic dehydrogenase activities in neurologic disease. Arch Neurol psychiat 1958; 80: 148-156.

72. Wroblewski $F$, Decker $B$, Wroblewski $R$. The clinical implications of spinal fluid lactic dehydrogenase activity. N Engl J Med 1958; 258: $635-639$.

73. Hain RF, Nutter d. Cerebrospinal fluid enzymes as a function of age. Arch Neurol 1960; 2: 331-337.

74. Davies-Jones GAB. Lactate dehydragenase and glutamic oxalacetic transaminase of the cerebrospinal fluid in tumours of the central nervous system. J Neurol Neurosurg Psychiat 1969; 32: 324-327.

75. Nelson PV, Carey WF, Pollard AC. Diagnostic significance of source and lactate dehydrogenase and its isoenzymes in cerebrospinal fluid of children with a wariety of neurological disorders. J clin Pathol 1975; 28: 828-833. 
76. Marton LJ, Heby 0 , Wil son CG. Increased polyamines concentration in the CSF of patients with brain tumors. Int J Cancer 1974; 14 : $731-735$.

77. Goldman KO, Kaplan NO, Hall TC. Lactic dehydrogenase in human neoplastic tissues. Cancer Res 1964; 24: 389-399.

78. Durie BGM, Salmon SE, Russel1 DH. Polyamines as markers of response and disease activity in cancer chemotherapy. Cancer Res 1977; 37: 214.

79. Marton LJ, Heby O, Levin VA, Lubich WP, Crafts CS, Wil son CG. The relationship of polyamines in cerebrospinal fluid to the presence of central nervous system tumor. Cancer Res 1976; 36: 973-977.

80. Marton LJ. Polyamines and brain tumors. J Nat Cancer Inst Monograph $1977 ; 46: 127-131$. 
Chapter 2

Cerebrospinal Fluid Beta-glucuronidase Activities in Patients with Central Nervous System Metastases *

Anton P. van Zanten, Al bert Twijnstra, Vrouwkjen van Benthem, Augustinus A.M. Hart and Bram W. Ongerboer de Visser.

\subsection{Intraduction}

The micro- and lysosomal enzyme beta-glucuronidase (EC 3.2.1.31) is found in relatively high concentrations in the arachmoid and the choroid plexus. However, in cerebrospinal fluid (CSF) it occurs only in low concentration. Because leptomeningeal involvement in brain diseases often increases the CSF activity of beta-glucuronidase, its determination may be used as a marker $(1-4)$, but there are insufficient data available concerning sensitivity and specificity of beta-glucuronidase when used as a marker in this context.

In the present study, beta-glucuronidase and the more conventional determinations of CSF levels of lactate dehydrogenase (LDH, EC 1.1.1.27) activity and total protein and glucose concentrations mere investigated in a group of patients with metastatic and nonmetastatic diseases of the central nervous system (CNS). A group of patients with normal CNS and suffering from diseases other than malignancy served as a control group.

\subsection{Patients and methods}

2.2.1. Control group

The control group consisted of 73 subjects with an average age of 51.3 years, range 23-85 years (Table 1). There were 19 females and 54 males. None had structural lesions of the CNS or symptoms of polyneuropathy. Sixteen controls had low back pain or brachialgia without disc prolaps. In 16 out of the 73 controls CSF levels of protein were elevated (mean $0.61 \mathrm{~g} / 1$, range $0.52-0.84 \mathrm{~g} / 1)$, in one patient CSF LDH activity was elevated $(32 \mathrm{U} / 1)$ and in four CSF levels of glucose were subnomal (mean $2.3 \mathrm{mmol} / 1$ ), range $2.2-2.4 \mathrm{~mol} / 1$ ).

* Published in: Cl in Chim Acta 1985; 147: 127-134. 
Table 1. GsF beta-glucuronidase levels in groups of control subjects and patients.

\begin{tabular}{|c|c|c|c|c|c|c|}
\hline \multirow{3}{*}{ Group } & \multirow[b]{3}{*}{ H } & \multicolumn{4}{|c|}{ Balucuronidase } & \multirow{3}{*}{$\begin{array}{c}\text { Significance } \\
(p)\end{array}$} \\
\hline & & \multicolumn{2}{|c|}{ Activity $(\mathrm{mll} / 1)$} & \multicolumn{2}{|c|}{ Log activity } & \\
\hline & & $\bar{x}$ & range & $\bar{x}$ & \$D & \\
\hline Contral subjects & 73 & 16.0 & $8-38$ & 1.1875 & 0.1201 & \\
\hline Patient groups & & & & & & \\
\hline Solid tumours: & & & & & & \\
\hline without nervous system metastasis & 23 & 16.8 & $11-30$ & 1.2079 & 0.1268 & \\
\hline with brain metastasis & 26 & 20.4 & $8-40$ & 1.2806 & 1.1612 & $<0.0005$ \\
\hline With epidural metastasis & 17 & 20.1 & $12-39$ & 1.2779 & 0.1494 & $<0.01$ \\
\hline with leptomeningeal metastasis & 25 & 89.3 & $17-318$ & 1.8288 & 0.3451 & $<0.001$ \\
\hline Henatological tumours: & & & & & & \\
\hline without nervous system metastas is & 8 & 13.1 & $6-18$ & 1.0962 & 0.1576 & \\
\hline with epidural metastasis & 2 & 20.0 & $14-25$ & 1.2806 & 0.1901 & \\
\hline with leptomeningeal metastasis & 9 & 34.2 & $15-70$ & 1.4689 & 0.2473 & $<0.001$ \\
\hline Viral meningitis & 4 & 16.8 & $8-24$ & 1.1923 & 0.2036 & \\
\hline Bacterial meningitis & 4 & 61.5 & $30-81$ & 1.7579 & 0.2009 & $<0.001$ \\
\hline Cerebrovascular accident & 29 & 16.3 & $4-42$ & 1.18 .23 & 0.9673 & \\
\hline Neuropa thy & 6 & 16.0 & $11-21$ & 1.1964 & 0.0912 & \\
\hline Cerebral concussion & 4 & 18.2 & $\mid 2-31$ & 1.2287 & 0.1857 & \\
\hline Various meurological diseases & 19 & $i 7.7$ & $9-26$ & 1.2347 & 0.1102 & \\
\hline
\end{tabular}

\subsubsection{Patient group}

The patient group consisted of 176 patients with an average age of 56.3 years, range 14-92 year (Table 1). There were 106 females and 70 males. One hundred ten had mal ignant diseases consisting of sol id tumours in 91 and hematological malignancies in 19 patients. In 23 patients of the solid tumour group and in eight of the hematological tumour group neither neurological examinations, including CSF analyses, nor CT brain scans were indicative of CNS metastases. In 26 patients with solid tumours the $c 1$ inical diagnosis of cerebral metastasis was confirmed by CT brain scans. In 17 patients with solid tumours and in two with hematological malignancies myelography confirmed the diagnosis of spinal cord compression by epidural metastasis.

In 34 patients, 25 with solid and nine with hematological tumours, demonstration of tumour cells in lumbar CSF confirmed the diagnosis of leptomeningeal metastasis. Histopathology of the brain was obtained in 14 autopsies and confirmed the clinical diagnosis of leptomeningeal metastasis in five and brain metastasis in nine patients. 
Patients with malignancies were admitted to the Antoni wan Leeuwemhoekhuis during 1981-1983. Patients without malignancies were admitted to the Department of Neurology of the Slotervaart Hospital during $1981-1982$.

Table 2. Within run and day-to-day imprecision.

\begin{tabular}{|c|c|c|c|c|}
\hline Activity & N & \multicolumn{2}{|c|}{$\begin{array}{r}\text { mean } \pm S D \\
(\mathrm{mU} / 1)\end{array}$} & $\begin{array}{l}\mathrm{CV} \\
(\%)\end{array}$ \\
\hline Intra-assay & 29 & 254.9 & $(4.6)$ & 1.8 \\
\hline Inter-assay & 11 & 260.1 & $(16.7)$ & 6.4 \\
\hline \multirow[t]{2}{*}{ Analysis of duplicates } & 20 & 13.8 & $(0.61)$ & 4.4 \\
\hline & 20 & 70.6 & $(1.84)$ & 2.6 \\
\hline
\end{tabular}

\subsubsection{Sample handling}

CSF was removed by puncture and centrifuged for $10 \mathrm{~min}$. at $1.500 \times \mathrm{g}$. CSF total protein, glucose and LDH were determined immediately after centrifugation. For CSF beta-glucuronidase measurement supernatants were frozen at $-20^{\circ} \mathrm{C}$ until they were analysed, within 1 week after the date of sampling .

\subsubsection{Reagents}

A1) chemicals used were of the highest purity obtainable and were stored according to the manufacturer's instructions.

For the determination of CSF beta-glucuronidase the following solutions were used:

1. Acetate buffer solution $0.15 \mathrm{~mol} / 1, \mathrm{pH} 4.5\left(37^{\circ} \mathrm{C}\right)$.

2. Acetate buffer solution $0.10 \mathrm{~mol} / 1$, pH $4.5\left(37^{\circ} \mathrm{C}\right)$.

3. Gl ycine buffer solution $0.40 \mathrm{~mol} / 1, \mathrm{pH} 10.7\left(25^{\circ} \mathrm{C}\right)$.

4. Phenalphthalein glucuronide solution $0.010 \mathrm{~mol} / 1$. This solution was prepared freshly each day, by dissolving the calculated amount of phenolphthalein-mono-beta-glucuronic acid in $10.0 \mathrm{ml}$ of distilled water. Note: the water content of phenol phthalein-mono-beta-glucuronic acid may vary depending upon 
storage conditions, so deterinlination of water content by the Karl-Fisher titration is recommended.

5. Working substrate solution, 65.0 m solution 1 was added to $10.0 \mathrm{~m}$ solution 4 (prepared also freshly).

6. Phenophthalein standard solutions: (a) stack standard (108 umol/1); $34.4 \mathrm{mg}$ phenophthalein was dissolwed in $10.0 \mathrm{ml}$ ethanol $96 \%(\mathrm{w} / \mathrm{v})$ and made up to 1 litre with solution 2; (b) working standard 5olutions (54, 27, 18, 10.8 and 4.3 umol/1). The stack standard was dituted with solution 2 to the given concentration.

\subsubsection{Procedures}

CSF beta-glucur onldase 2 tubes were used for each sample to be assayed, one labeled "blank", the other "test". To the tubes labellad "test" $1.5 \mathrm{ml}$ working substrate solution (5) was added and $0.5 \mathrm{ml}$ CSF. To the tubes labeled "blank" 1.5 ml working substrate solution (5) was added. The tubes were sealed, incubated in a water bath at $37^{\circ} \mathrm{C}$ for exactly $18 \mathrm{~m}$. Immediately after the incubation period $2.0 \mathrm{~m} 1 \mathrm{~g}$ ycine solution (3) was added to each tube labeled "test" and $2.0 \mathrm{ml}$ glycine buffer sollution (3) and $0.5 \mathrm{ml}$ CSF to the tubes labeled "blank". The absorbances of the "blanks" and "tests" were read against distilled water at $555 \mathrm{~nm}$, and using the corrected absorbance readings (A test-A Blank) the beta-glucuronidase activity was determined using the calibration curve. Each analysis was performed in duplicate.

Cal ibration curve $2.0 \mathrm{ml}$ working standard solution (6b) was added to 2.0 mi glycine buffer solution $(3)$.

Blank 2.0 ml acetate buffer solution (2) was added to $2.0 \mathrm{ml}$ glycine buffer solution (3). After mixing the absorbances were read at $555 \mathrm{~nm}$ vs the blank. A calibration curve of absorbance readings was plotted against beta-glucuronidase activities. The standard solution of $54 \mu m o l / 1$ corresponds with $200 \mathrm{mu} / 1$.

Beta-glucuronidase activities in serum were assayed, using phenolphthalein glucuronide as substrate according to fishnan (5). Total pratein and lactate dehydrogenase was determined in CSF using the test methodologies of the ACA (Dupont Company, Clinical Systems Div., Wilmington, DE, USA). The LDH methodology was calibrated to give values 
similar to results obtained with the methodology of the German Society for Clinical Chemistry (6). Glucose was detemined using a Beckman glucose amalyser (Beckman Instruments Inc., Fullerton, CA. USA). Spectrophotometric readings for the deternination of beta-glucuronidase activities were made with Zeiss DMA spectrophotometer (Carl Zeiss, aberkochen, FRG).

\subsubsection{Statistical methods.}

Standard methods of statistical analysis were used to evaluate the results, including Student's t test and analysis of variance and covariance. Before analysis CSF beta-glucuronidase activities were log-transformed. The sensitivity, specificity and the receiver-operator characteristics (ROC) curve were calculated according to Griner et al (7). Nomal values for CSF glucose, total protein and LDH were estimated in patient data using a Bhattacharya pi at as described by Naus et al (8).

Table 3. Reference values for CSF beta-glucuronidase activities.

\begin{tabular}{|c|c|c|c|c|}
\hline Control subjects & $\mathbb{N}$ & $\begin{array}{l}\text { Reference }^{\mathrm{a}} \\
\text { range } \\
(\mathrm{m} \cup / \mathrm{l})\end{array}$ & $\begin{array}{l}\text { Mean } \\
(\mathrm{m} U / 1)\end{array}$ & Ref. \\
\hline Patients without CNS disease & 42 & $8-34^{b}$ & 17.2 & 9 \\
\hline $\begin{array}{l}\text { Patients undergoing spinal } \\
\text { anaes thesia }\end{array}$ & 30 & $7-23$ & 14.8 & $1-3$ \\
\hline $\begin{array}{l}\text { Patients with systemic cancer } \\
\text { but without CNS metastasis }\end{array}$ & 50 & $0-43$ & 24.3 & 4 \\
\hline $\begin{array}{l}\text { Patients without CNS disease } \\
\text { (for details, see text) }\end{array}$ & 73 & $9-27$ & 16.0 & This study \\
\hline
\end{tabular}

${ }^{a}$ A unit of enzyme activity is expressed in terms of umol phenolphthale in 1 iberated/min.

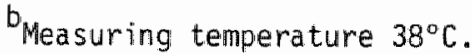




\section{3. Results}

Linearity of the assay system was evaluated by determining betaw glucuronidase activities in serial dilutions of the beta-glucuronidase preparation 51 gma $\mathrm{G}-0258$. A Tinear range up to 1.000 nU/ 1 was found. The imprecision of the CSF beta-glucuronidase assay was evaluated by calculation of the standard deviation from duplicates and from repeated assays of a frozen preparation $\left(-20^{\circ} \mathrm{C}\right)$ of beta-glucur onidase (Sigma G-0258) in a solution containing 1 mol/1 1 disodium EDTA and 1 mol/l $L(+)$ cysteine (Table 2). Reference values for CSF beta-gllucuronidase activity were estimated from the results in the control group. Results appeared to be reasonably log nomally distributed. No statistically significant differences $(p<0.10)$ between beta-glucuronidase activities in controls with or without elevated CSF total protein content could $\mathbb{d}$ be demonstrated. Therefore, all patient data from this controll group were used for estimating the reference range of CSF beta-glucuronidase activities. No relationship was found between log (beta-glucuronidase activity) and age or sex. The reference range was established as 9-27 mu/1, based on mean log (beta-glucuronidase activity) $\pm 2 \mathrm{SD}$.

The mean CSF beta-glucuronidase level was increased in patients with leptomeningeal metastases from solid tumours (mean 89.3, range 17-318 mu/1) and hematological malignancies (mean 34.2, range 15-70 mU//1). Abnomally high values were al so found in patients with bacterial meningitis. The mean value of beta-glucuranidase was silightly incireased in patients with brain or epidural metastases. The remaining patients showed nomal CSF beta-glucuronidase activities (Table 1 ).

In 15 patients with various neurological diseases beta-glucuronidase activities were measured in serum as mell as CSF. No correlation could be demonstrated.

Normal values for CSF glucose, total protein and LDH were estimated from the results of routine analysis of CSF from patients admitted to the Sloterwart Hospital during the past 2 years. We found glucose 2.5-4.2 numol/1 ( $n=1997)$, total protein $0.14-0.51 \mathrm{~g} / 1 \quad(n=2784)$ and LDH $0-26 \mathrm{U} / 1$ $(n=1949)$. 


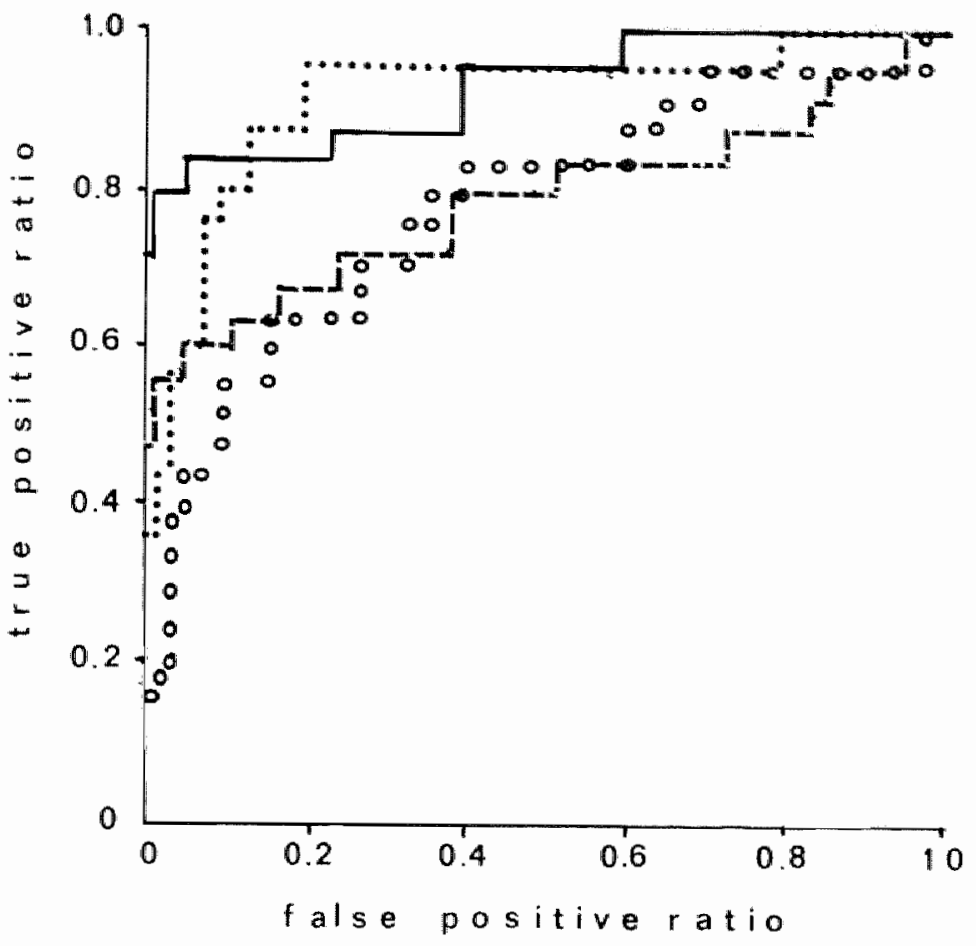

Fig. 1

Receiver operator characteristic curves for beta-glucuronidase , LDH ......., glucose -....--, and total protein oooo

for patients at risk for developing leptomeningeal metastasis from solid tumours.

\subsection{Discussion}

The determination of beta-glucuronidase in CSF has already been described by Anlyan and Starr (9), using a method developed by fishman et a) (10). At the present, the glucuronides of $p$-nitrophenol, 8 hydroxyquinol ine and phenolphthalein are widely used as substrate in the assay of beta-glucuronidase (5). We adapted the assay of Talalay and Fishman (11) using phenolphthalein glucuronide as substrate. Our reference range agrees rather well with those reported by other groups using phenolphthalein glucuronide as substrate (Table 3 ).

Dur results confirm the previous findings of high CSF levels of beta-glucuronidase activities in patients suffering from bacterial meningitis or leptomeningeal metastases. A small but significant increase 
In CSF beta-glucuronidase activities was observed in patients with parenchymal or epidurat metastases from solid tumours.

The most inpressive result of this investigation was the discriminative value of this assay in cases of leptomeningeal spread from solid tumours. In analysing the usefulness of the beta-glucuronidase assay in this respect, ROC curves of the different tests, i.e. CSF beta-glucuronidase, glucose, total protein and LoH were calculated in the group of patients at risk for developing leptomeningeal metastases from solid tumours (Fig. 1 ).

Table 4. Sensitiwity and specificity for different chemical tests in CSF, used in a patient group at risk in developing leptomeningea 1 spread from lymphoma and leukemia.

\begin{tabular}{|l|c|c|}
\hline \multicolumn{1}{|c|}{ Test } & sensitivity & specificity \\
\hline Beta-glucuronidase & 0.4 & 1.0 \\
LDH $^{\mathrm{a}}$ & 0.8 & 0.9 \\
Glucose $^{\mathrm{b}}$ & 0.6 & 1.0 \\
Total protein $^{\mathrm{a}}$ & 0.7 & 0.6 \\
\hline
\end{tabular}

Test criteria for a pasitive test:

$$
\begin{aligned}
& \text { a result above upper } 1 \text { imit of norma } \\
& b_{\text {result below lower } 1 \mathrm{imit} \text { of nomal. }}
\end{aligned}
$$

These RoC curves correlate true and false positive ratios (sensitivity and 1 minus specificity) for a series of cutoff points for the respective test. Good clinical performance of a test is characterized by a high true positive value and a low false positive value. In this way, Fig. 1 as well as the frequency distribution of test results in the patients groups "leptomeningeal dissenination from solid tumours" and "no meningeal dissemination from solid tumours" (Fig. 2), as calculated from the patient data incorporated in Table I show the value of the determination of CSF beta-glucuronidase activities in the diagnosis of leptomeningeal metastasis from solid tumours. At the manent, diagnosis of leptomeningeal metastasis is based on clinical signs and symptoms. 
suggesting neoplastic infiltration of the leptomeninges and the finding of tumour cells in the $\operatorname{CSF}(3,13,14)$. Our patients with leptomeningeal metastasis met these criteria. The diagnosis of bacterial meningitis can be confimed by the demonstration of the micro organism involved.
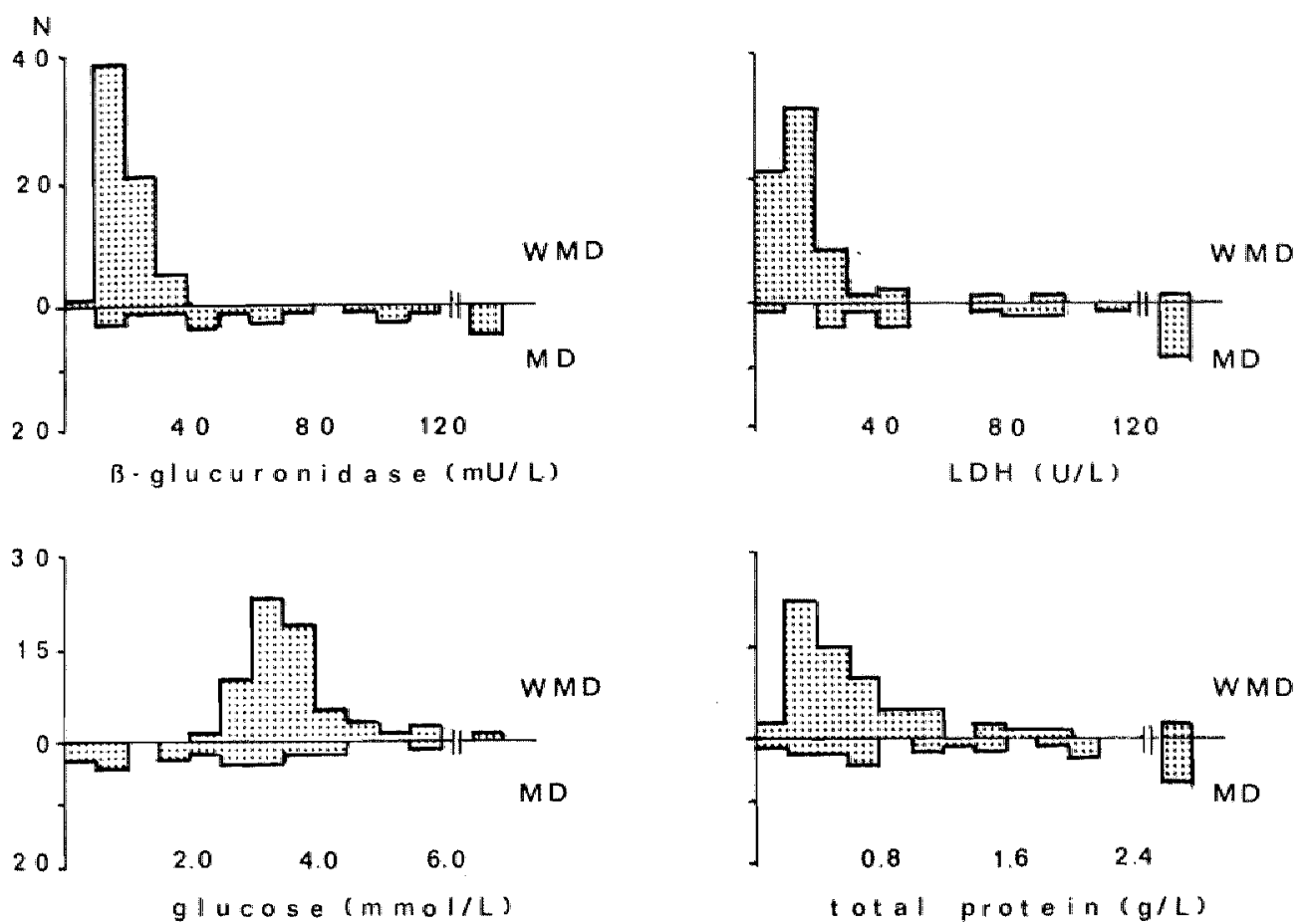

glucose ( $\mathrm{mmol} / \mathrm{L})$

total protein $(\mathrm{g} / \mathrm{L})$

Fig.2: Frequency distributions of results of different tests for patients at risk for developing leptomeningeal metastasis from solid tumours. WMD, patients without meningeal dissemination; $M D$, patients with meningeal dissemination.

For meningeal dissemination from tumours arising from the hemopoetic system, we could not make reliable receiver operator characteristic curves, due to the 1 imited number of patients. Our results regarding sensitivity and specificity for this patient group are summarized in Table 4. They show the 1 imited walue of CSF beta-glucuronidase activities with respect to other tests in use, especially CSF LDH. In some cases, we were able to monitor CSF beta-glucuronidase during treatment. A representative curve is demonstrated in $\mathrm{Fig}$. 3 . 
In conclusion. based on the data presented we recomend the detemination of CSF beta-glucuronidase activities in the diagnosis of patients with leptoneningeal metastases from solid tumours. Serial measurements of beta-glucuronidase may prove valuable in assessing the efficacy of treatment. However, the number of patients represented is very small. Therefore, additional cinical trials are necessary.
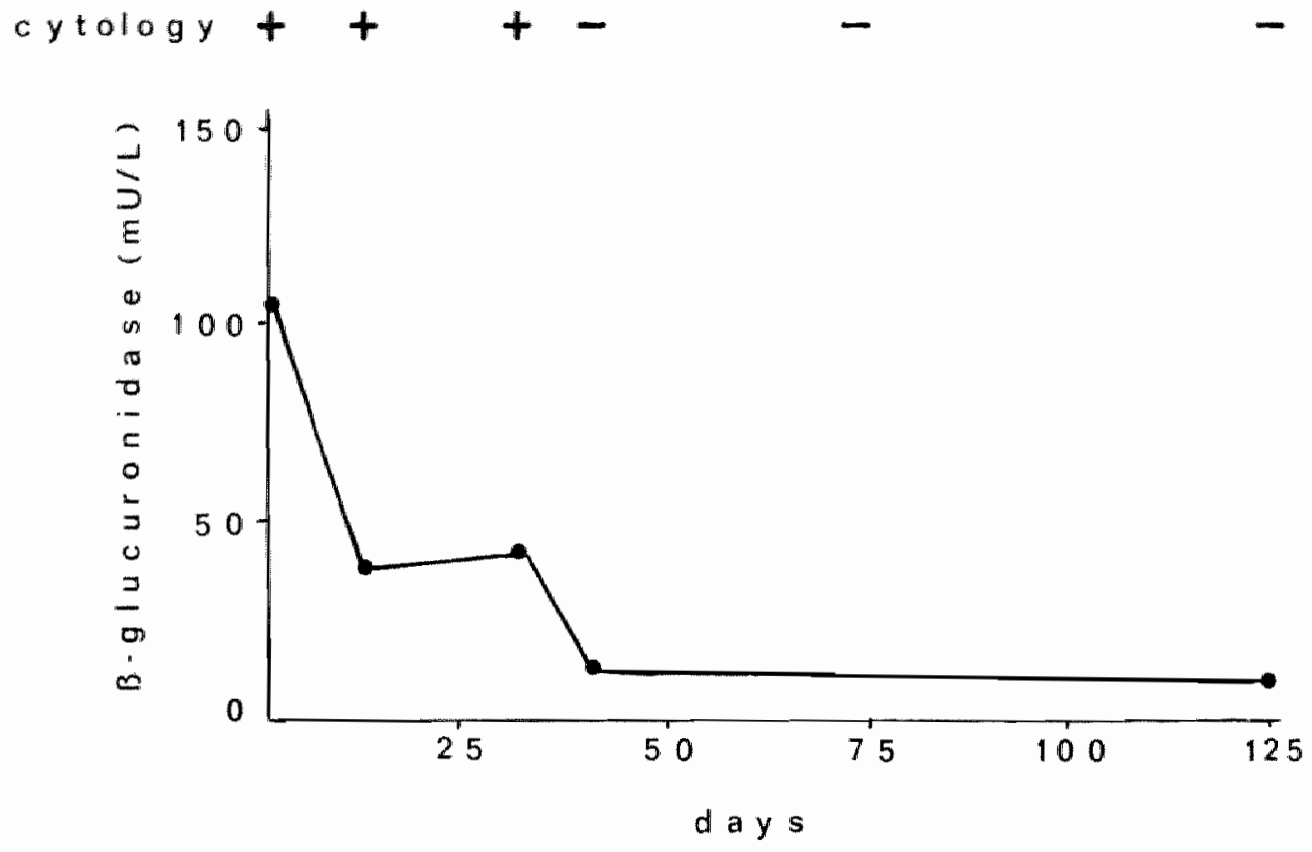

Fig.3: Time course of CSF beta-glucuronidase activities in a patient with breast cancer after diagnosis of leptomeningeal metastasis has been made and treatment started.

\subsection{Sumary}

Beta-glucuronidase activities were determined in cerebrospinal fluid from 249 patients suffering from various neurological diseases. Reference values were established as 9-27 mU/1. Marked elevations of cerebrospinal beta-glucuronidase activities were observed in patients with bacterial and carcinomatous meningitis. Slight elevations of cerebrospinal beta-glucuronidase activities were observed in epidural and parenchymal metastases from solid tumours. Comparison was made with the determination 
of total protein, glucose and lactate dehydrogenase in cerebrospinal fluid. Cerebrospinal beta-glucuronidase activity appeared the most useful test in monitoring patients at risk in developing meningeal metastases from solid primary tumours.

\subsection{References}

1. Allen $N$, Reagan $E$. Beta-glucuronidase activities in cerebrospinal fluid. Arch Neurol 1964; 11: 144-154.

2. Shuttleworth EC, Allen N. Early differentiation of chronic meningitis by enzyme assay. Neurology 1968; 18: 534-542.

3. Shuttleworth EC, Alien N. CSF beta-glucuronidase assay in the diagnosis of neoplastic meningitis. Arch Neurol 1980; 37: 684-687.

4. Schold SC, Wasserstron WR, Fleisher M, Schwartz MK, Posner JB. Cerebrospinal fluid biochemical markers of central nerwous system metastases. Ann Neurol 1980; 8: 597-604.

5. Fishman WH. Beta-glucuronidase. In: Bergmeyer HU, ed. Methods of enzymatic analysis. Vol.2. New York: Academic Press, 1974: 929-943.

6. Empfehl ungen der Deutschen Gesel1schaft für Kl imische Chemie. Standardisulerung won Methoden zur Bestimnung von Enzymaktivitäten im biologischen Flüssigkeiten. Experimentelle Begründung der optimierten Standard Bedingungen. J Clin Chem Clin Biochem 1972; 10: 182-189.

7. Griner PF, Mayewski Ru, Mushlin AI, Greenland P. Selection and interpretation of diagnostic tests and procedures. Ann Intern Med $1981 ; 94: 553-592$.

8. Naus AJ, Borst A, Kuppens PS. The use of patient data for the calculation of reference values for some hematological parameters. J C1 in Cherr $\mathrm{Cl}$ in Biachem 1980; 18: 621-625.

9. Anlyan AJ, Starr A. Beta-glucuronidase activity of spinal and ventricular fluids in humans. Cancer 1952; 5; 578-580.

10. Fishman WH, Springer B, Brunetti R. Application of an improved glucuronidase assay method to the study of human blood beta-glucuronidase. w Biol Chem 1948; 173: 449-456.

11. Talalay P, Fishman WH, Huggins C. Chromogenic substrates. II. Phenolphthalein glucuronic acid as a substrate for assay of glucuronidase activity. J Biol Chem 1946; 166: 757-772.

12. Zweig $M H$, Robertson $E A$. Why we need better test evaluations. Clin Chem $1982 ; 28 ; 1272-1276$. 
13. Wasserstrom WR, Glass JP, Posner JB. Diagnosis and treatment of leptomeningeal metastases from solid tumours. Cancer 1982; 49 : $759-772$.

14. Ongerboer de Visser BW, Somers $R$, Nooyen WH, van Heerde P, Hart AAM, McVie JG. Intraventricular methotrexate therapy of leptomeningea? metastasis from breast carcinoma. Neurology 1983; 33: 1565-1572. 
Cerebrospinal Fluid Beta-2-Micraglobul in: a Study in Controls and Patients with Metastatic and Non-Metastatic Neurological Disease *

Albert Twijnstra, Anton P. van Zanten, Will lem J. Nooyen, Augustinus A.M. Hart and Bram $W$. Ongerboer de Wisser.

\subsection{Introduction}

Beta-2-microglobul in (B2-m) has been isolated and characterized from human urine by Berggärd and Bearn in 1968 (1, 2). It is a small subunit of the Human Leucocyte Antigens. (HLA) on the surface of nucleated cells. $B 2-m$ is dissociated from HLA heavy chain and released in free form in extracellular fluid. Lymphocytes and macrophages are particularly rich in B2-m.

B2-m is present in various biological fluids, such as serum, urine, amniotic fluid, ascites, and cerebrospinal fluid (CSF) (3-6).

From blood B2-m is removed by glonerular filtration. The serum concentration may increase in various circumstances such as in newborns, in the elderly, in renal disorders, in malignancies, in auto-immune and inflamatory disorders (7).

The multiple factors that affect $82-m$ concentration in the serum, make it questionable in diagnostic procedures (8). Raised serum B2-m values nevertheless are to occur reported in serum of patients with multiple myeloma, non-Hodgkinn"s 1 ymphoma, Hodgkin's disease and chronic 1 ymphatic leukemia (9).

Measurement of CSF B2-m seems promising in the diagnosis of CNS involvement by hematological tumours (5). Recently it has been reported that CSF B2-m may increase before the CSF becomes positive for tumour cells $(9,10)$. This ma lead to earlier and more specific diagnosis of CNS leukemia and 1 momoma. As little data are available concerning: (i) CSF B2-m values in nomal subjects, (ii) CSF B2-m values in metastatic and nometastatic diseases, (iii) the sensitiwity and specificity of CSF

*To be published in: Eur J Cancer Clin Oncol, 1986. 
B2-m, we set up this present study, to investigate the possible application of this assay. Without knowledge of the CSF 82-m from patients with neoplastic and non-neoplastic neurological diseases, cks involvement by solid and hematological tumours cannot be diagnosed with reasonable confidence.

other investigators reported high level CSF B2-m in bacterial meningitis $(5,10)$. Because this infiltration can be diagnosed by culture, bacterial meningitis was excluded from this study.

\subsection{Patients and methods}

We collected CSF samples from 197 patients with nomal renal function. The CSF specimen were coded and 5 tored at $-20{ }^{\circ} \mathrm{C}$ until analyzed by radioimunoassay. We performed lumbar puncture as a part of clinical diagnostic procedures, and never for the measurement of B2-m only. CSF exaninations included protein concentration, glucase content, LDH, culture and cytology with the cytacentrifuge technique. We compared the CSF B2-m level in 10 patient groups (Table 1 ). The 48 patients with 1 ow back pain with or without leg pain served as a control group. They were otherwise healthy. Myelography was normal in 36 of them and showed a lumbar disc herniation in 12 subjects. Age and sex distributions of the controls and patients are given in Table 1. Patients with malignancies were admitted to the Antoni van Leeuwenhoekhuis during 1981-1983, and patients without malignant diseases to the Department of Neurology of the Slotervaart Hospital during 1981-1982. The criteria used for the diagnosis leptomeningeal metastases was the presence of tumour ceils in the CSF. In 12 patients B2-m levels were measured in serum as well as in CSF. We determined total protein and lactate dehydrogenase (LDH) in cerebrospinal flutd using the test methodologies of the ACA (Dupont Company, Clinical Systens Division, Willmington, DE 19898, USA). LDH methodology was calibrated to give values similar to results abtained with the method of the German Society for clinical chemistry (11). Glucose was detemined using a Beckman gl ucose analyzer (Beckman Instruments inc., Fullerton, CA 92634, USA).

We measured both serum and CSF B2-m by radioimmunoassay using the Phadebas B2-m microtest (Pharmacta Diagnostics, Uppsala, Swedeni). Briefly, aliquots of 200-fold diluted serum and CSF were incubated for 3 hours at room temperature with 125-1 1 abeled $B 2-m$ and ant $1-B 2-m$ 
antibodies coupled to sephadex particles. Thereafter, the bound and firee B2-m were separated by centrifugation. The radioactivity bound to sedinented sephadex particles was then measumed. This radioactive uptake varied inversely with the quantity unlabeled 32 -m present.

From the results obtained in the controls, we calculated reference values far CSF B2-m (Table 1$)$.

Table 1. CSF Beta-2-Microglobul in levels (mo/1) in groups of control subjects and patients.

\begin{tabular}{|c|c|c|c|c|c|c|c|c|}
\hline \multirow[t]{2}{*}{ Group } & \multirow[t]{2}{*}{ N } & \multicolumn{2}{|c|}{ Age } & \multirow[b]{2}{*}{ Male/Fenale } & \multirow{2}{*}{$\bar{x}$} & \multirow[b]{2}{*}{$\$ 0$} & \multirow[b]{2}{*}{ skewness } & \multirow[b]{2}{*}{ kurtosis } \\
\hline & & Mean & SD & & & & & \\
\hline Low back pain (controls) & 48 & 48 & 16 & $34 / 14$ & 1.33 & 0.48 & 0.77 & 1.17 \\
\hline Trauma capitis & 4 & 38 & 26 & $3 / 1$ & $\Uparrow .85$ & 1.12 & 1.11 & -0.70 \\
\hline Neuropathy & 6 & 52 & 18 & $5 / 1$ & 1.56 & 0.55 & 0.98 & -0.41 \\
\hline Cerebrovascullar accident & 29 & 71 & 12 & $17 / 12$ & 1.74 & 0.48 & -0.21 & -0.28 \\
\hline Epidural metastases & 19 & 58 & 11 & $1 / 18$ & 1.85 & 0.97 & 1.38 & 1.39 \\
\hline Brain metastases & 26 & 52 & 17 & $11 / 15$ & 1.49 & 0.67 & 2.69 & 8.55 \\
\hline $\begin{array}{l}\text { Leptomeningeal metastases } \\
\text { sol id tumours }\end{array}$ & 25 & 53 & 11 & $6 / 19$ & 3.22 & 1.79 & 0.93 & 0.55 \\
\hline $\begin{array}{c}\text { Leptomeningeal metastases } \\
\text { hematological tumours }\end{array}$ & 9 & 49 & 17 & $7 / 2$ & 4.42 & 2.13 & 0.45 & -1.16 \\
\hline $\begin{array}{l}\text { Solid tumours without } \\
\text { CNS metastases }\end{array}$ & 23 & 55 & 16 & $3 / 20$ & 1.57 & 0.70 & 2.47 & 5.92 \\
\hline $\begin{array}{l}\text { Hena tological metastases } \\
\text { without CNS metastases }\end{array}$ & 8 & 46 & 22 & $5 / 2$ & 1.43 & 0.86 & 1.61 & 1.37 \\
\hline
\end{tabular}

\subsubsection{Statistics}

From the results of a preliminary analysis, it was decided to transfom the B2-m lagarithnically prior to the final analysis in order to get a closer approximation of the vartation of observed values by the nomal distribution in all groups. Ordinary linear regression analysis was used to determine the relationship between 109 B2-m and sex and age. To test the statistical distribution of values for nomality the test of Shapiro and Wilk was used (11).

Skewness indicates that data distribution was not symmetrical. Kurtosis indicates the degree of steepness of the middle part of the data distribution; it measures the concentration around the mean value. 


\subsection{Results}

In Table 1 we show the mean and SD of CSF B2-m levels, as well as skewness and kurtosis. The skewness and kurtosis indicate measurements for the shape of the distribution. In the contral group a relationship was found between CSF $\log B 2-m$ and age $(p<0.0001)$ (Fig. I). We found no difference between females and males with respect to the slope of $10 \mathrm{~g}$ B2-m against age $(p=0.45)$ nor with respect to the intercept $(p=0.91)$. Because of the age dependence of $\log B 2-m$, age standardization is needed in comparing the different groups. From the regression equation in the control group we defined the following quantity as standardized log B2-m at 50 years:

$-\log (B 2-m) A S=\log (B 2-m)-0.00595$ (age - 50).

We found no deviation from nomal in groups at a level of $p<0.10$. Deviation from normal occurred in the patient groups with cerebrovascular accident ( $\left.V_{A}\right)(p<0.05)$, brain metastases $(p<0.02)$, and sol id tumour $s$ without metastases $(p<0.01)$. We defined the reference range of $B 2-m$ standardized at the age of 50 as $0.65-2.20 \mathrm{mg} / 1$.

From Table 2 it can be seen that B2-m used as the sole diagnostic tool leads to a sensitivity of $70 \%$ (95\% confidence interval: $47-87 \%$ ) for leptomeningeal metastases from solid tumours and of $90 \%(52-99 \%)$ for leptomeningeal metastases from hematological tumours. Adding all groups with leptomeningeal metastases together we would find a specificity of 93\% $(87-96 \%)$. Counting only the tumour group without leptomeningeal involvement would lead to a specificity of $87 \%(76-94 \%)$. Al tour patients with spinal epidural metastases and raised CSF B2-m showed a gross elevation of CSF protein and a complete block by myelography, so clinically seeding was suspected. Of the 2 patients with intraparenchymal metastases and elevation of CSF B2-m levels, the metastases were on $\mathrm{CT}$-scans adjacent to leptomeningeal surface, but we did not find tumour cells in the CSF. The serum B2-m and CSF B2-m levels did not correlate in twelve patients of the different groups. 
Table 2. Beta-2-Microglobul in in Cerebrospinal Fluid. Elevated Values in Different Groups.

\begin{tabular}{|c|c|c|c|}
\hline Group & Total & $\begin{array}{l}\text { B2-microglobut in } \\
\text { elevated }\end{array}$ & $\begin{array}{l}\text { total } \\
\text { elevated }\end{array}$ \\
\hline Control subjects & 48 & 0 & 0 \\
\hline Trauma capitis & 4 & 1 & 25 \\
\hline Neuropa thy & 6 & 1 & 17 \\
\hline Cerebrovascular accident & 29 & 0 & 0 \\
\hline Epidural metastases & 19 & 4 & 21 \\
\hline Brain metastases & 26 & 2 & 8 \\
\hline $\begin{array}{l}\text { Leptomeningeal metastases } \\
\text { sol id tumours }\end{array}$ & 25 & 17 & 68 \\
\hline $\begin{array}{l}\text { Leptomeningeal metastases } \\
\text { hematological tumours }\end{array}$ & 9 & 8 & 89 \\
\hline $\begin{array}{l}\text { Sol id tumours without } \\
\text { CNS metastases }\end{array}$ & 23 & 2 & 9 \\
\hline $\begin{array}{l}\text { Hematological tumours } \\
\text { without CNS metastases }\end{array}$ & 8 & 2 & 25 \\
\hline Tatals & 197 & 37 & \\
\hline
\end{tabular}

\subsection{Discussion}

In recent years malignant disease appears to be more frequenti y diagnosed (12-14). This increase has generally been attributed to longer survival of patients because of more effective drug treatment of the primary tumour and the failure of almost all currently used chemotherapeutic agents to cross the blood-brain barrier.

Early diagnosis of leptomeningeal metastases is a comon diagnostic problem $(12,15,16)$. The fal se negative rate of CSF cytology vartes from 5 to $40 \%$ of the patients with leptomeningeal tumours. The yield of positive cytology may be enhanced by examination of successive CSF samples $(6,17)$. We found raised CSF B2-m in 2 autopsy proven cases with leptomeningeal tumours, with negative cytological findings in CSF. Tumour associated proteins in CSF, or so-called tumour markers, have been 
described previous y $(6,9,10,12-20)$, for the early identification of metastases to the leptomeninges.

Fram these studies insuffichent data are avaliable on patients with parenchymal and epidural metastases and non-neoplastic neurological diseases. Such homation is necessary to evaluate sensitivity and speciftcity of the CSF B2-m assay for the diagnosis of leptomeningeal tumours $(21,22)$. In our control group CSF B2-m increased significantly with increasing age. This complicates the comparison of different groups of diseases. To overcone this difficulty we standardized CSF B2-m values for age using the regression equation found in the control group. We defined the reference range of $82-m$ standardized at the age of 50 from 0.65 to $2.20 \mathrm{mg} / 1$. Other investigators described similar $\mathrm{y}$ reference ranges $(2,10)$.

Like Schaub et al. we have not observed any correlation between corresponding serum and CSF B2-m levels in a group of neoplastic patients, wich suggests an autonomous production of $B 2-m$ in the two compartments $(23)$.

Both Maviligit et al (9) and Kach et al (10) recently published results of a study about CSF B2-m in CNS metastasis. They did not mention an effect of age on CSF B2-m.

We found that $B 2-m$ as a sole diagnostic tool leads to a sensitivity of $70 \%$ for leptomeningeal carcinomatosis and of $90 \%$ for leptomeningea dissemination of hematological tumours $(21,22)$. A specificity of $93 \%$ was calculated adding all patients together with nomalignant and malignant neurological diseases, but without malignant leptomeningeal dissemination. We detected a raised $B 2-m$ level in two patients with cerebral and four with epidural metastases. These elevations may be due to the invasion of submeningeal or subependymal parenchym, so that malignant cells may not be detected. On CT-scan we noted subependymal brain metastases in two patients.

From the present study we conclude that the determination of age standardized B2-rn in CSF affords a valuable adjunct in the diagnosis for leptomeningeal tumour, more appropir iate for lymphoma than for solid tumours.

Further studies will be needed ta determine the validity of the test in monitoring progression of the disease and evaluating tumour response to therapy. 


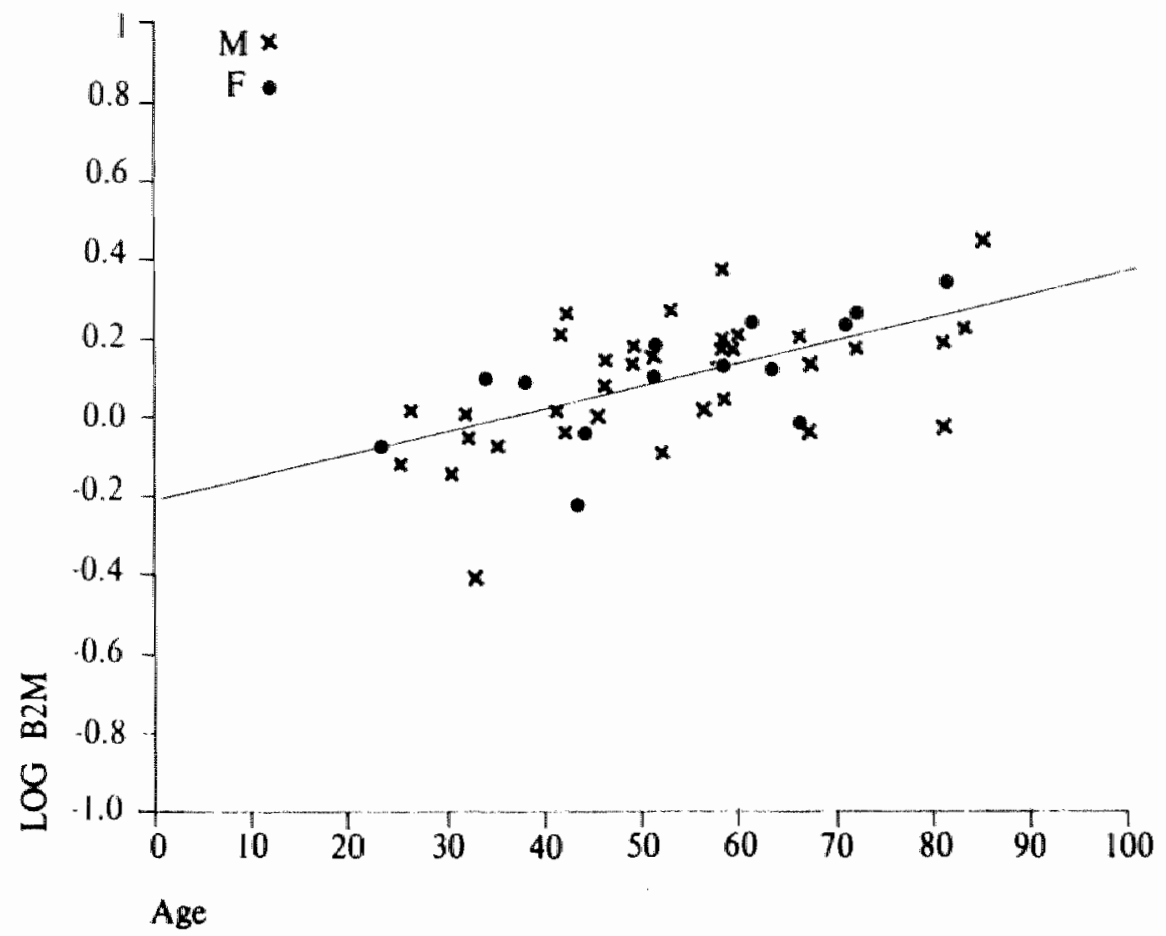

Fig. 1: The relationship between $\log B 2-m$ in CSF and age of the 48 control subjects.

Log $B 2-m$ levels increased significantly with age for the averall group $(p=0.0004)$ independent of sex difference $(p=0.86)$. Regression equation: $\log \mathrm{B} 2-\mathrm{m}=3.081-0.00595$ (age: 50 ).

\subsection{Summary}

We studied cerebrospinal fluid beta-2-micraglobulin (CSF B2-m) in 197 patients with a variety of neurological diseases to evaluate the usefulness of B2-m in the detection of meningeal dissemination of malignancy. In the control group we found a relationship between CSF 109 B2-m and age $(p<0.0001)$.

Age standardized reference values were established as $0.65-2.2 \mathrm{mg} / 1$. The results show that CSF $82-m$ was elevated in the majority of cases with leptomeningeal metastases from solid and hematological tumours. 
We obserwed slight elevations of CSF $2-m$ in epidural and parenchym metastases from solud tumours. Dur study shows that B2-m in CSF is a sensitive marker for leptomeningeal metastases especially from hemopoletic tumours.

\subsection{Reterences}

1. Berggäd I, Bearb AG. Isolation and properties of a low molecular weight B2-globulin in human biological fluids. J Biol Chem 1968; 243: $4059-4103$.

2. Berggärd $\mathbb{1}$. Beta-2-microglobul in: Tsolation, properties and distribution. Fed Proc 1976;35: 1167-1170.

3. Pippard MU, Callender ST, Sheldon PWE. Infiltration of central nervous system in adult myeloid leukemia. Br Med J 1974; 1: 227-229.

4. Wibel $1 \mathrm{~L}$, Ervin PE, Berggärd J. Serum B2-milicroglobul in in renal disease. Nephran 1973; 10: 320-331.

5. Starmans Ju, Vas $\mathrm{J}$, Helm Hd van der. The beta2-micraglobul in content of the cerebrosipinal fluid in neurological disease. J Neurol Sici $1977 ; 33: 45-49$.

6. Glass JP, Melamed $N$, Chernik NL, Posner JB. Malignant cells in cerebrospinal fluid (CSF). The meaning of a positive CSF cytology. Neurology (NY) 1979; 29: 1369-1375.

7. Child SA, Spati B, IIlingworth S. Serum beta-2-microglobulin and cancer reactive protein in the monitoring of lymphomas: findings of multicenter study and experience in selected protein. Cancer 1980; 45: $318-326$.

8. Franklin EC. Beta-2-riticroglobul in - big role? N Engl J Med 1975 ; 293: $1254-1255$.

9. Mawligit CM, Stuckey SE, Cabanillas FF, Keating MJ, Tourtelotte WW, Schold SC, Frelrich EJ. Diagnosis of leukemia or 1 jmphona in the Central Nervous System by Beta-2-microglabul in determination. N Engl J Med 1980: 303: 718-722.

10. Koch Th R, Lichtenfeld KM, Wiernik PH. Detection of central nervous system metastases with cerebrospinal fluid B2-microglobulin. Cancer 1983 ; $52: 101-104$.

11. Shapiro SS, Wi $7 k$ MB. An analysis of variance test for normality (complete samples). Biometrika 1965; 52: 59l-596. 
12. Wasserstrom MR, GlasS JP, Posner JB. Diagnosis and treatment of leptomeningeal metastasis from solid tumors * Cancer 1982; 49 : $759-772$.

13. Nugent JL, Bunn PA, Matthews MJ, Ihde OC, Cohen MH, Gazdar A. CWS metastases in small cell bronchogenic carcinona: Increased frequency and changing pattern with survival lengthening. Cancer 1979; 44: $1885-1893$.

14. Ongerboer de Visser BW, Somers R, Nooyen WH, Heerde P van, Hart AAM, McVie $J G$. Intraventricular methotrexate therapy of leptaneningeal metastasis from breast carcinoma. Neurology 1983; 33: 1565-1572.

15. Seidenfeld J, Marton Lu. Biochemical markers of central nervous system tumours measured in cerebrospinal fidid and their potential use in diagnosis and patient managment: a review. J Nat Cancer Inst 1979; 63: $919-931$.

16. Yap BS, Yap HY, Fritsche HA, Blumenschein G, Bodey GP. Cerebrospinal fluid carcino-embryonic antigen in breast cancer patients with meningeal carcinomatosis. JAMA 1980; 244: 1601-1603.

17. 01 son HE, Chernik HL, Posner JB. Infiltration of the leptameninges by systemic cancer. A clinical and pathological study. Arch Neurol 1974 ; $30: 122-137$.

18. Wasserstron WR, Schwartz NK, Fleisher M, Posner JB. Cerebrospinal fluid biochemical markers in central nervous system turnours: a review. Ann Clin Lab Sci 1981; 11; 3: 239-251.

19. Zanten AP van, Twijnstra $A$, Benthem $V$ van, Hart AAM, Ongerboer de Visser BW. Cerebraspinal fluid B-glucuronidase activities in patients with central nervous system metastases. Clin Chim Acta 1985; 147: $127-134$.

20. Twijnstra A, Nooyen W, Zanten AP van, Ongerboer de Wisser BW, Hart AAM. Cerebrospinal fluid carcino-embryonic antigen in patients with metastatic and non-metastatica neurological diseases. Arch Neurol 1986 (in press).

21. Griner PF, Mayewski RJ, Mushl in AJ, Greenland P. Selection and interpretation of diagnostic tests and procedures. Ann Int Med 1981; 94: $553-592$.

22. Zweig MH, Robertson EA. Why we need better test evaluations. Cl in Chem $1982 ; 28: 1272-1276$. 
23. Schaub C, Buet Pajot MT, Szikla G, Lomet-Videau C, Mounier F, Tolairach J. Distribution of beta-2-microglobulin in CSF and cystic fluid of brain tumours. A preliminary study. Path Biol 1978; 26; 6: $381-385$. 
Cerebrospinal Fluid Carcinoembryonic Antigen in Patients with Metastatic and Non-Metastatic Neurological Diseases *

Albert Twijnstra, Willem $d$. Nooyen, Anton P. van Zanten, Augustinus A.M. Hart and Bram W. Ongerboer de Visser.

\subsection{Introduction}

Carcinoembryonic antigen (CEA), first isolated in 1965 by Gold and Freedman (1), is a beta-1-glycoprotein with a molecular weight of approximately 180,000 Daltons. It is present in normal intestinal tissues, in various biological fluids such as serum, urine, intestinal secretions, pleural and peritoneal fluids $(2-4)$ and in the cerebrospinal fluid (CSF) $(5,6)$.

Raised serum levels of CEA are found particularly in patients with carcinoma of the gastrointestinal tract, breast, lung, ovaries, and pancreas $(7-9)$, but have also been established in patients with a variety of nommalignant diseases.

The CSF CEA level is valuable in the detection of CNS metastases of CEA producing tumours especially to the leptomeninges $(5,10-12)$. There are few data available concerning CSF CEA values in normal subjects, CSF CEA values in metastatic and nonmetastatic diseases, the sensitivity and specificity of the CSF CEA test, and the CSF CEA relation to the CSF protein, glucose, and lactic dehydrogenase (LDH) levels. Therefore, the present study was set up to investigate further this possible application of the assay.

\subsection{Patients and methods}

Cerebraspinal fluid was obtained by lumbar puncture that was performed as a part of the regular clinical diagnostic procedure and never for the measurement of the CEA level alone. The CSF examinations included protein concentration and glucose content measurements, $10 H$, culture, and cytologic studies with the cytocentrifuge techrique.

* To be published in: Arch Neurol, 1986. 
The control group consisted of 45 patients (11 men and 34 women) with an average age of 53 years (range, 23 to 85 years). They had low back pain with or without leg pain and were otherwise healthy. Myelography showed a lumbar disc herniation in 35 subjects and no abnomalities in the rematining ten subjects.

Table 1. Distribution of patients with malignant and nonmalignant diseases

\begin{tabular}{|l|c|c|}
\hline \multicolumn{1}{|c|}{ Diseases } & No \\
\hline Malignant (solid tumours) & 96 \\
Epidural metastases & 19 & \\
Brain metastases & 28 & \\
Leptomeningeal metastases & 26 & \\
Without central nervous system involvement & 23 & \\
Malignant (hematological tumours) & & 19 \\
Epidural metastases & 2 & \\
Leptomeningeal metastases & 8 & \\
Without central nervous system metastases & & \\
Nonmalignant & 40 \\
Trauma capitis & 30 & \\
Neuropathy & & \\
Cerebrovascular accident &
\end{tabular}

The patient group consisted of 155 patients with an average age of 56.1 years (range, 16 to 92 years) (Table 1). There were 98 female and 57 male patients. The CNS metastases were diagnosed by conputerized tomographic brain scans, myelography and the presence of tumour cells in the CSF. The demonstration of malignant cells in the CSF was a requisite for the diagnosis of leptomeningeal metastases. In two patients with clinical signs and symptoms of leptameningeal involvement the CSF remained persistently clear of tumour cells. The diagnosis was confimed at a postmortem examination. Histopathologic studies of the brain were obtained at 15 autopsies and confirmed the clinical diagnosis of brain metastases in nine and leptomeningeal metastases in six patients, respectively. 
Patients with malignant neoplasms were admitted to the Antoni van Leeuwenhoekhuis during 1981-1983, and patients without malignant diseases were admitted to the Department of Neurology of the Slotervaart Hospital, Amsterdam, during $1981-1982$.

Total protein and LDH level were determined in CSF using commercially ayailable tests. The LOH measurement was calibrated to give values similar to results obtained by the method of German Society for Gimical chemistry (13). The glucose level was detemined using a commercially available glucose analysis. The CSF CEA levels were estimated by the method of Egan et al (14), with several modifications. The $4 \mathrm{~cm}$, plastic incubation tubes (inside diameter $8 \mathrm{~mm}$ with a round bottom) contained a sample of $50 \mathrm{\mu l}$ of CSF and $20 \mu \mathrm{Hl}$ of goat antiserum diluted with phosphate buffered saline solution $(0.07 \mathrm{M}: \mathrm{pH} 7.4)$ containing rabbit serum dilution $(1: 150,000)$.

After overnight incubation at $37^{\circ} \mathrm{C}, 20$ wl of radioactive iodine $125 \rrbracket \mathrm{CEA}$ solution ( $3 \mu \mathrm{g} / 1)$ was added. Incubation was continued for two hours at $37^{\circ} \mathrm{C}$. Separation of antibody bound CEA from unbound CEA was performed as follows: $50 \mu 1$ of nomal goat serum at the appropriate dilution (with phosphate buffered saline solution containing rabbit serum), followed by 50 ul of rabbit antigoat serum (usually diluted with phosphate buffered saline solution containing rabbit serum) was added. The tubes were stored overnight at $4{ }^{\circ} \mathrm{C}$.

After the addition of $300 \mu 1$ of polyethylene glycol solution, centrifugation was carried out. The supernatant was carefully removed by aspiration, and the residue was counted. For the construction of standard inhibition curves, aliquots $(50 \mu l)$ of diluted CEA solutions were used.

\section{3. Statistics}

From the results of a preliminary analysis, we decided to transfom the CEA wallues prior to the final analysis. Ordinary 1 inear regression amalysis was used to determine the relationship between the log CEA level and sex and age. To test the statistical distribution of values for normal ity, the Shapiro and Wi lk test (15) was used. Skewness indicates that the data distributions are not symetric. Kurtosis indicates the degree of steepness of the middle part of the data distributions. It measures the concentration around the mean value. 


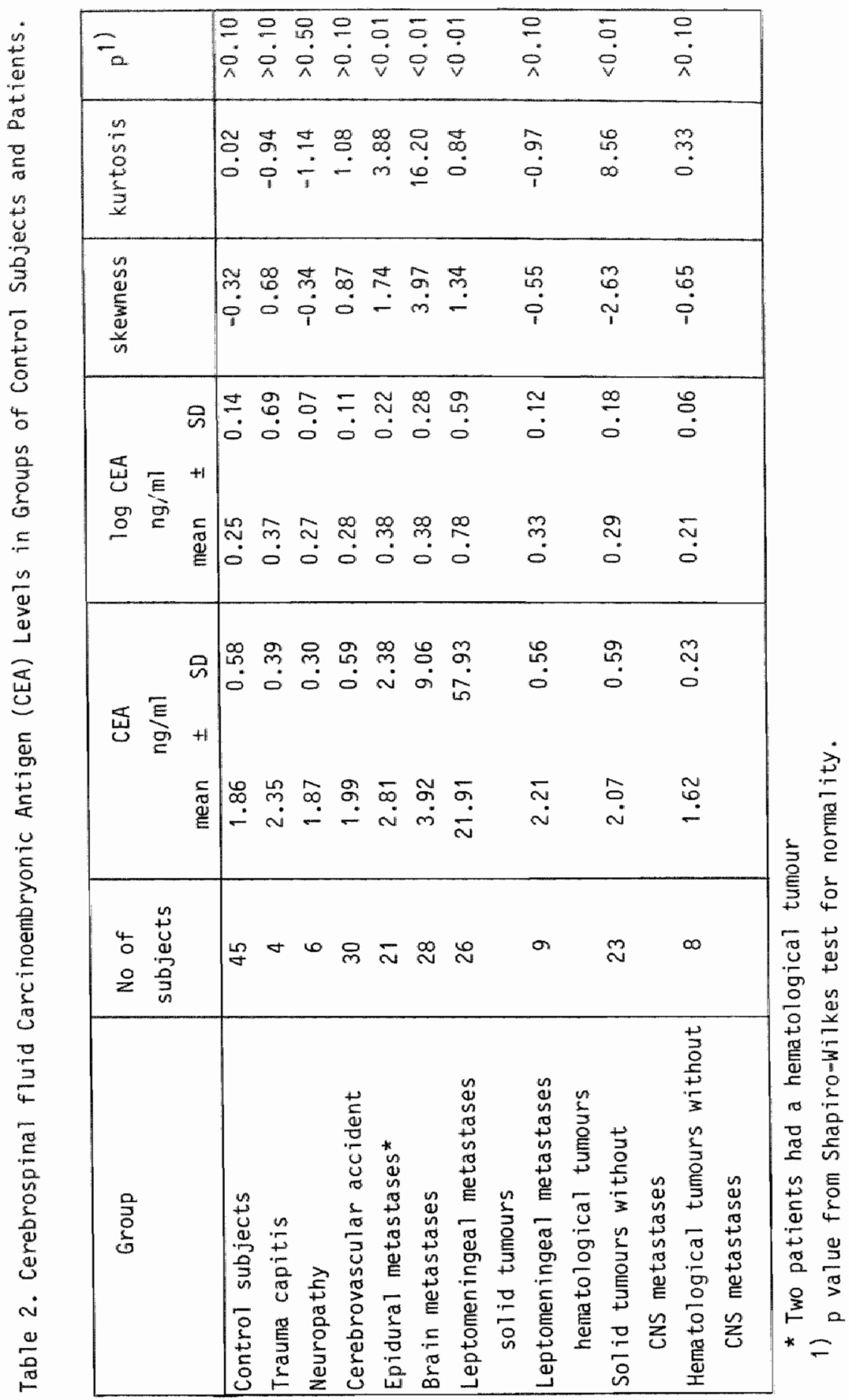




\section{4. Results}

Reference values for CSF CEA levels were calculated from the results obtained in the control subjects. Ho difference in the mean and distribution of CSF CEA levels were observed in control subjects with a nomal total protein content $(<0.51 \mathrm{~g} / 1$ ) or abnomal protein content ( $>$ $0.51 \mathrm{~g} / \mathrm{l}$. Therefore, we used all data of the controls for the calculation of the reference range of CSF CEA levels .

Table 3. Control subjects and patients with elevated cerebrospinal fluid Carcinoembryonic Antigen (CEA) levels.

\begin{tabular}{|l|c|cr|}
\hline \multicolumn{1}{|c|}{ Group } & $\begin{array}{c}\text { No of } \\
\text { subjects }\end{array}$ & No $(\%)$ with abnorma \\
CEA & \% \\
\hline Control subjects & 45 & 1 & $(2)$ \\
Trauma capitis & 4 & 0 & $(3)$ \\
Neuropathy & 6 & 0 & $(14)$ \\
Cerebrovascular accident & 30 & 1 & $(42)$ \\
Epidural metastases & 21 & 3 & 2 \\
Brain metastases & 28 & 11 & \\
Leptomeningeal metastases & 26 & 0 & \\
solid tumours & & 9 & 0
\end{tabular}

* CEA level > $4 \mathrm{ng} / \mathrm{ml}$ was considered abnormal.

We found no relationship between the CSF $10 \mathrm{~g}$ CEA level and age $(p=.62)$. No difference between female and male subjects was found with respect to the slope of the $\log$ CEA level against age $(p=1.00)$, nor with respect to the intercept $(p=.09)$. The mean $I S D$ of the CEA level and the $\log$ transfomation of the mean, 50 , skewness, and kurtasis are given in Table 2. The skewness and kurtosis indicate measurements for the shape of the distribution. 
Nomal probability curves of the log CEA level for the different groups are given in the Figures (1-3). From these data an upper 1 imit of $4 \mathrm{ng} / \mathrm{m}$ l was chosen for the normal range of CSF CEA levels. Raised levels $\geqslant 4$ $\mathrm{ng} / \mathrm{ml}$ of CEA) were detected in 18 of 200 subjects (controls and patients) (Table 3 ). Eleven of the 18 subjects were in the group with leptomeningeal spread from solid tumours. None of the nine patients with leptomeningeal metastases from hematological tumours had CSF CEA values of $\geqslant 4 \mathrm{ng} / \mathrm{ml}$. Three patients with spinal epidural metastases and two patients with cerebral metastases had CSF CEA levels of $\geqslant 4 \mathrm{ng} / \mathrm{ml}$. In 23 patients with leptomeningeal seeding, the CEA level was measured in serum as well as in CSF. No correlation could be demonstrated. The CSF CEA level correlated with LDH, glucose, and protein levels in patients with leptomeningeal metastases from solid tumours. There was also a relationship between CSF CEA and the histologic type of the primary tumour. Metastatic lung and breast cancer showed the highest CSF CEA levels.

From Table 3 it can be seen that the use of the CEA level as the sole diagnostic tool leads to a sensitivity of $31 \%$ for leptomeningeal metastases from solid and hematological tumours, for only solid tumours we found a sensitivity of $42 \%$. Adding all groups without leptomeningeal metastases together, we found a specificity of $90 \%$. Counting only the tumour group without leptomeningeal involvement would lead to a specificity of $91 \%$. 


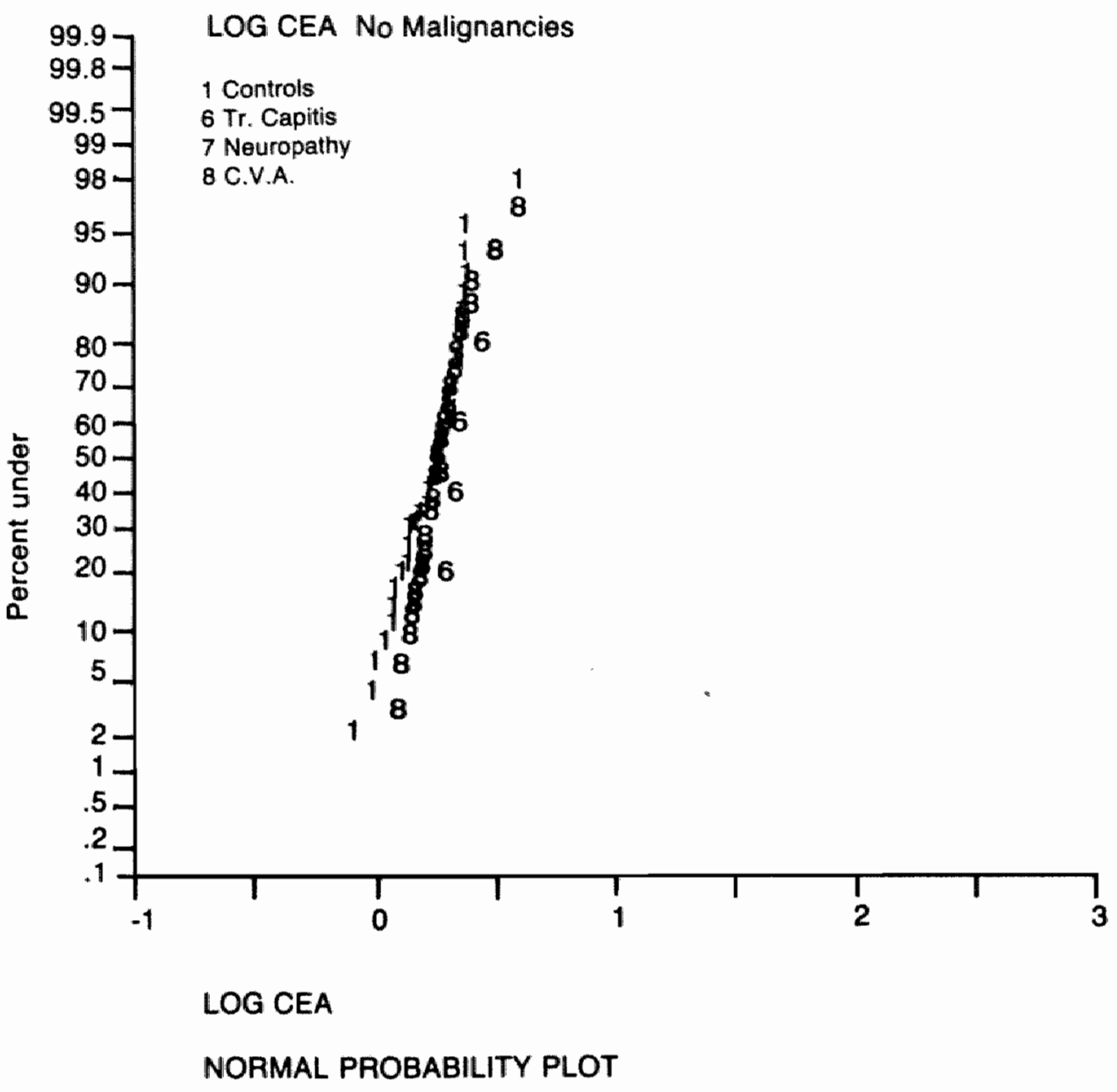

Fig. 1: Normal probability plots of carcinoembryonic antigen (CEA) concentration in cerebrospinal fluid: no malignant neoplasms. 


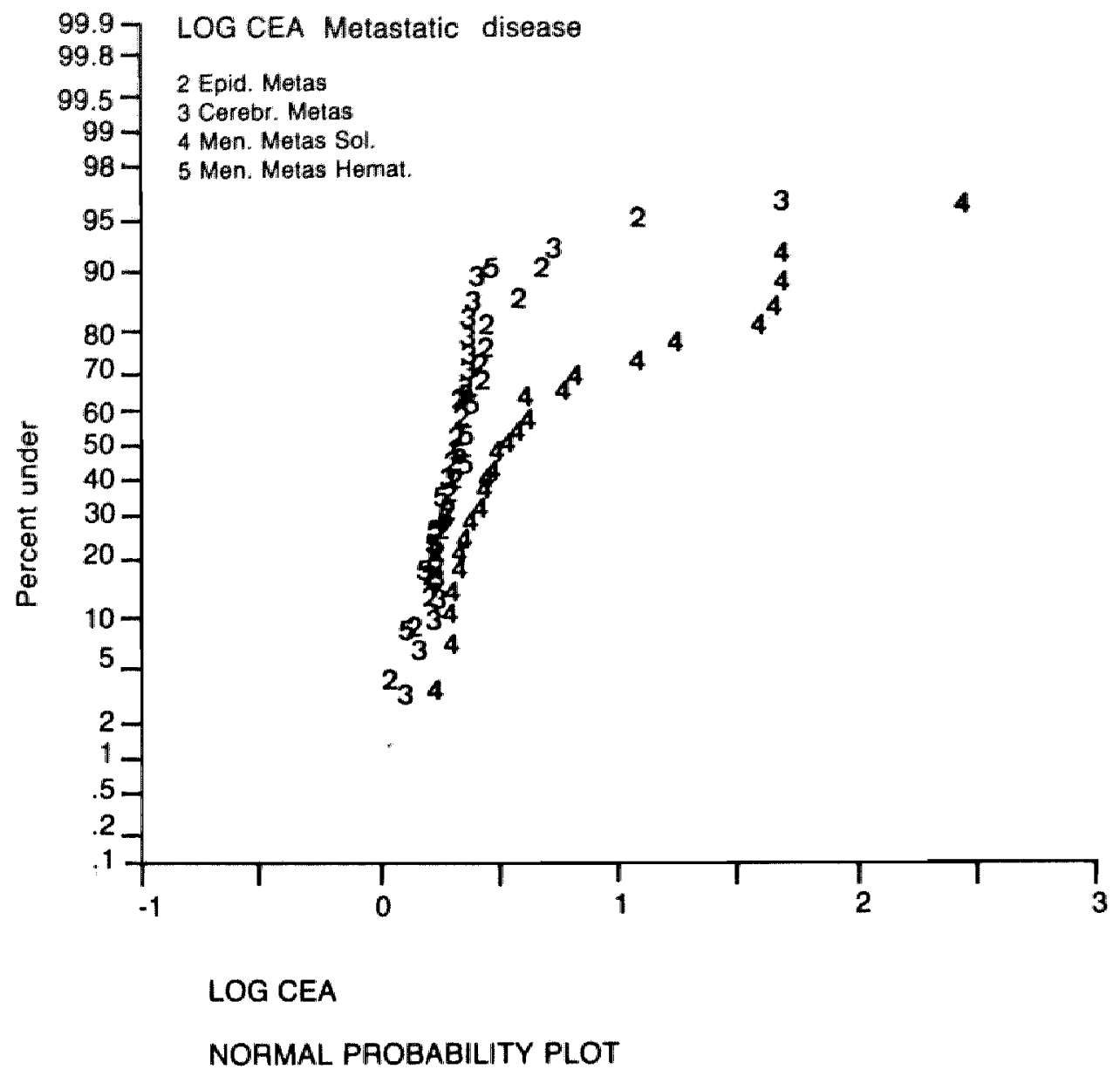

Fig.2: Normal probability plots of carcinoembryonic antigen (CEA) concentration in cerebrospinal fluid: metastatic disease. 


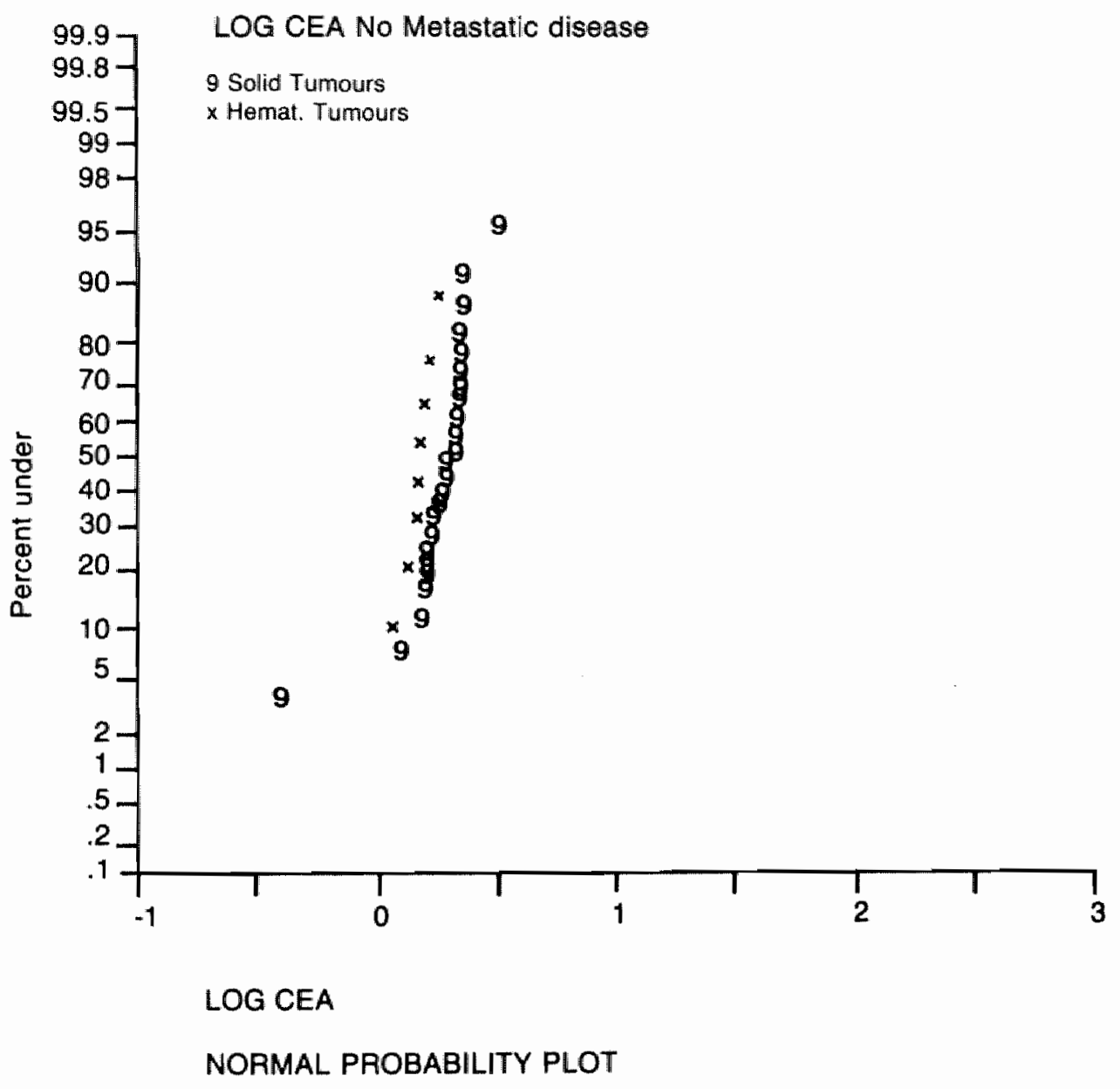

Fig.3: Norma 1 probability plots of carcinaembryonic antigen (CEA) concentration in cerebrospinal fluid: no metastatic disease. 
Carcinoembryonic antigen is the most studied and the best known of the circulating tumour-associated antigens, which can be measured in warious biological fluids by means of radioimmunoassay techniques $(2,7,9)$. Contrary to previous findings $(5,6)$, in the CSF of most control subjects. we found detectable levels of CER using an assay obtained by the directed technique (14).

The explanation for the mode of entry of CEA into CSF from patients with leptomeningeal disease has been widely discussed in the literature $(5,6,10-12,14)$. Some authors argue that CSF CEA originates from a local production of CEA by metastatic tissue, while others suspected a leakage of plasma CEA through the blood CSF barrier (5). In the present study we found no elevated levels of CEA in the CSF of patients with cerebrovascular diseases with raised plasma CEA 1 ewels of up to $26 \mathrm{ng} / \mathrm{m} 1$, suggesting that production of CEA rather than opening the blood CSF barrier is a causative factor of abnormal CEA levels.

In some studies, cutoff levels have not been used to define abnomal levels. There is alsa insufficient information concerning the levels of CSF CEA in populations that included both metastatic and nommetastatic neurological diseases, which is necessary to evaluate the sensitivity and specificity of tumour associated antigen (16).

We selected a CSF CEA cutoff point of $4 \mathrm{ng} / \mathrm{ml}$ to differentiate nomal ignant firom malignant neurological diseases. Only a high cutaff point was specific of malignamt CNS involvement. However, in this case the sensitivity will decrease (15). In our study, using $4.0 \mathrm{ng} / \mathrm{ml}$ as the upper limit of normal, two $(2 \%)$ patients of those with nonmalignant neurological diseases and $16(14 \%)$ of the patients with cancer with or without CNS metastases had elevated CSF CEA levels.

Our results confirm previous findings of raised CSF levels of CEA in patients suffering from leptomeningeal carcinomatosis (5, 6, 12, 17), the highest in patients with leptomeningeal metastases from lung and breast carcinoma. A small but significant increase in CSF CEA levels was observed in two patients with parenchymal and three patients with epidural metastases from solid tumours without CSF tumour cells. These elevations may have resulted from submeningeal or subependymal infiltration of tumour cells. The CSF CEA level correlated positively 
with protein, glucose, and LDH levels in patients with leptomeningeal carcinomatosis.

Early diagnosis of leptomeningeal metastases is a common diagnostic problem $(11,16-19)$, because of false negative results of cytologic studies of CSF samples. We found raised CSF CEA levels in two autopsy-proved cases with leptomeningeal metastases from solid tumour, in which the cytology study results remained persistently negative. This finding indicates that CEA level measurement may be valuable when CSF cytology fails to confirm the presence of malignant cells.

In other work, CEA level elevations in plasma are related to the extent of metastatic disease (20). We al so found the highest CSF CEA levels in our patients with leptomeningeal spread at all levels of the neuraxis.

We conclude that CSF CEA assays do possess a low sensitivity (31\%) to establish the diagnosis of leptomeningeal seeding from solid tumours. However, the Clinical use of CSF CEA assay should be undertaken when CSF cytological studies fall to confirm the presence of malignant cells. The CSF CEA level seems to be of limited value as a marker of leptomeningeal infiltration from 1 ymphoma.

\subsection{Summary}

Cerebrospinal fluid (CSF) carcinoembryonic antigen (CEA) values were determined in 200 patients suffering from various neurological diseases. We found no relationship between CEA levels and age or sex. A positive test was defined as an upper 1 imit of at least $4.0 \mathrm{ng} / \mathrm{ml}$ of CEA. We found raised CSF CEA levels in patients with leptomeningeal spread from carcinoma, but not in some patients with leptoneningeal metastases from 1 ymphoma. We also found high values of CSF CEA in three of 21 patients with epidural and in two of 28 patients with cerebral metastases from solid tumours. Comparison was made wilt th the CSF levels of toal protein, glucose, and lactate dehydrogenase. The sensitivity of the CSF CEA determination in patients for the presence of leptomeningeal involvement of solid tumours is $42 \%$ and the specificity is $90 \%$. 


\subsection{References}

1. Gold $P$, Freedman S0. Denonstration of tumour-specific antigens in human colonic carcinomata by imnunological tollerance and absorption techniques. J Ep Med 1965; 121: 439-462.

2. Persijn JP, Corstem CB, Batteman JJ. Chemical significance of urinary CEA estimations during the fol low up of patients with bladder carcinoma or previous bladder carcinoma. J Clin Biochem 1976; 14: 395-399.

3. Kalser MH, Berkin JS, Redlhammer D, Heal A.-Circuliating carcinoembryonic antigen in pancreatic carcinoma. Cancer 1978; 42 (supp1.): 1468-1471.

4. Loewenstein MS, Rittgers RA, Feimerman AE. CEA assay of ascites and detection of malignancy. Ann Int Med 1978; 88: 635-638.

5. Schold SC, Wasserstrom WR, Fleisher.M, Schwartz MK, Posner JB. Cerebrospinal fluid biochentical markers of central nervous system metastases. Ann Neurol 1980; 8: 597-604.

6. Dearnaley DP, Patel S, Powels TJ, Coombes R.C. Carcinoembryonic antigen estimation in cerebrospinal fluid in patients with metastatic breast cancer. Oncodevelopmental Biology and Medicine 1981; 2: 305-311.

7. Reynoso G, Chu TH, Holyoke D, Cohen E, Nemoto T, Wange JJ, Chuang J, Guinan P, Murphy GP. CEA antigens in patients different cancers. JAMA 1972; 220: $361-365$.

8. Dhar $P$, Moore $T$, Zamcheck $N$, Kupchik HZ. Carcinoembryonic antigen (CEA) in colonic cancer: use in pre- and postoperative diagnosis. JAMA $1972 ; 221: 31-35$.

9. Holyoke ED: present and probable uses of CEA. CA 1975; 25: 22-26.

10. Snitzer LS, MCKinney EC, Tejada F, Sigel MM, Rosomott HL, Zubrod CG. Cerebrat metastasis and CEA in CSF. N Engl J Med 1975; 293: 1101.

11. Kido D, Dyse B, Haverback BJ, Rumbaugh C. CEA in patients with untreated central nervous system tumours. Bull Los Angelas Neurol Soc 1976; 41: 47-54.

12. Wasserstrom WR, Schwartz MK, Fleisher M, Posner JB. Cerebrospinal fluid biochemical markers in central nervous system tumours: a review. Ann $\mathrm{Cl}$ in Lab Sci 1981 ; 11: no. 3.

13. Empfehlungen der Deutschen Gesell schaft für KI inische Chemie. Standardisierung von Methoden zur Bestimmung von Enzymaktivitäten in 
biologischen Flüssigkeiten. Experimentelle Begründung der optimierten Standard Bedingungen. J Clin Chen $\mathrm{Cl}$ in Biochem 1972; 10: 182-189.

14. Egan ML, Lautenschleger JT, Coligan JE, Todd CW. Radioimume assay of carcinoembryonic antigen. Immunochemistry 1972; 9: 289-299.

15. Shapiro SS, Wilk MB. An analysis of variance test for normality (complete samples). Bianetrika 1965; 52: $591-596$.

16. Seidenfeld J, Marton LJ. Biochemical markers of central nervous system tumours measured in cerebrospinal fluid and their potential use in diagnosis and patient management: a review. J Nat Cancer Inst 1979; 63: 919-931.

17. Yap BS, Yap HY, Benjamin RS, Freirich FJ. Cerebrospinal fluid carcinoembryonic antigen in breast cancer patients with meningeal carcinomatosis. Proc Am Assoc Cancer Res/Am Soc Cl in Oncol 1978; 19: 98.

18. Ongerboer de Visser BW, Somers R, Nooyen WH, van Heerde P, Hart AAM, McVie JG. Intraventricular methotrexate of leptomeningeal metastasis from breast carcinoma. Neurology 1983; 33: 1565-1572.

19. van Zanten AP, Twijnstra $A$, van Benthem $V$, Hart AAM, Ongerboer de Visser BW. Cerebrospinal fluid B-glucuronidase activities in patients with central nervous system metastases. Clin Chim Acta 1985; 147: $127-134$.

20. Swanson MA. Correlation of quantitative CEA determinations and estimations of tumour burden. J Nucl Med 1978; 19: 718-719. 
Serial Lumbar and Ventricle Cerebrospinal Fluid Lactate Dehydrogenase Activities in Patients with Leptomeningeal Metastases from Solid and Hematologica! Tumours*

Albert Twijnstra, Anton P. van Zanten, Augustinus A.M. Hart and Bram $W$. ongerboer de Visser.

\subsection{Introduction}

Changes of biochemical markers in tissues, body fluids and serum may be used in the diagnosis of some types of cancer ( $1-3)$. However, the clinical significance of biochemical marker tests in the cerebrospinal fluid (CSF) in the diagnosis of central nervous system (CNS) tumours is still poorly defined (4). Moreover, various CSF biomarkers were found to be elevated in a substantial number of non malignant disorders.

In this article we will discuss the change in the lactate dehydrogenase enzyme (LOH) activity in the CSF, found in patients with metastatic and non metastatic diseases of the CNS. The choice to study the CSF LDH enzyme is related to the fact that LDH belongs to routine laboratory determinations and with modern equipment, the catalytic activity of LDH in the CSF can be measured rapidly, precisely and econamically.

LDH is an enzyme that catalyzes the final step in the metabolic chain of anaerobic glycalysis. Its molecular weight is 135,000 Daltons and it is predominantly located intracellular. LOH is a normal constituent of brain tissue and low activity can be measured in nomal CSF. CSF LDH activity may increase in a number of conditions. Diagnostic significance has been ascribed to elevations of CSF LDH activities in cases of cerebrovascular diseases (5-7), bacterial meningitis (8-10), head injury (6), primary brain tumours $(7,11,12)$ and CNS metastases from solid (7, $8,11,12)$ or hematological malignancies $(8,9)$. Little is known, however, about the quantitative meaning of such elevations, especially regarding the usefulness of this marker in the diagnosis of lepto-

* Manuscript submitted for publication, 1986. 
meningeat metastases.

To our knowledge the serial measurements of LoH in lumbar and ventricular CSF before, during and after treatment. have hitherto been unreported. In the present study we analyzed the results of CSF LDH measurements at different levels of the neuraxis in patients with metastatic and non metastatic neurological diseases to deternine: (i) the sensitivity, specificity and the predictive values of the LDH level in the CSF as tumour marker test, (ii) the relationship between the pretreatment level of LOH in the CSF and the extent of the disease, and between that level and the histological type of the primary tumour, (iii) the concentrations of the LDH in lumbar CSF related to ventricular CSF simultaneous $y$, and (iv) the correlation of serial ventricular CSF LDH changes with changes in the clinical disease status.

\subsection{Patients en methods}

CSF was obtained by lumbar puncture, which was performed as a part of the regular clinical diagnostical procedure, and never for the measurement of the LDH activity only. All the CSF examinations included protein concentration and glucose content, bacteriological culture, and cytological studies with the cytocentrifuge technique. The 350 patients (Table 1) with an average age of 54.4 years, range $15-92$ years, were admitted to the Department of Neurology of the Slotervaart Municipal Hospital and to the Antori van Leeuwenhoekhuis, both in Ansterdam, during 1981 to 1983. There were 198 females and 152 males. The CNS metastases were diagnosed by computerized tomagraphy (CT) brain scans, myelography and the presence of tumour cells in the CSF. The demonstration of malignant cells in the CSF was required for the ditagnosis of leptomeningeal metastasis. In two patients, with characteristic clinical manifestations of leptoneningeal metastases, repeated 1 umbar CSF examinations failed to demonstrate malignant cells. The diagnosis was confimed at a postmortem examination. In two other patients cSF cytology became positive later on in the course of the disease. Histopathological studies of the brain were obtained at 15 autopsies and did confirm the clinical diagnosis of brain metastases in nine patients and leptomeningeal metastasils in six patients, respectively.

In 23 patients of the solid turour group and in eight patients of the hematological tumour group, neither neurological examinations including 


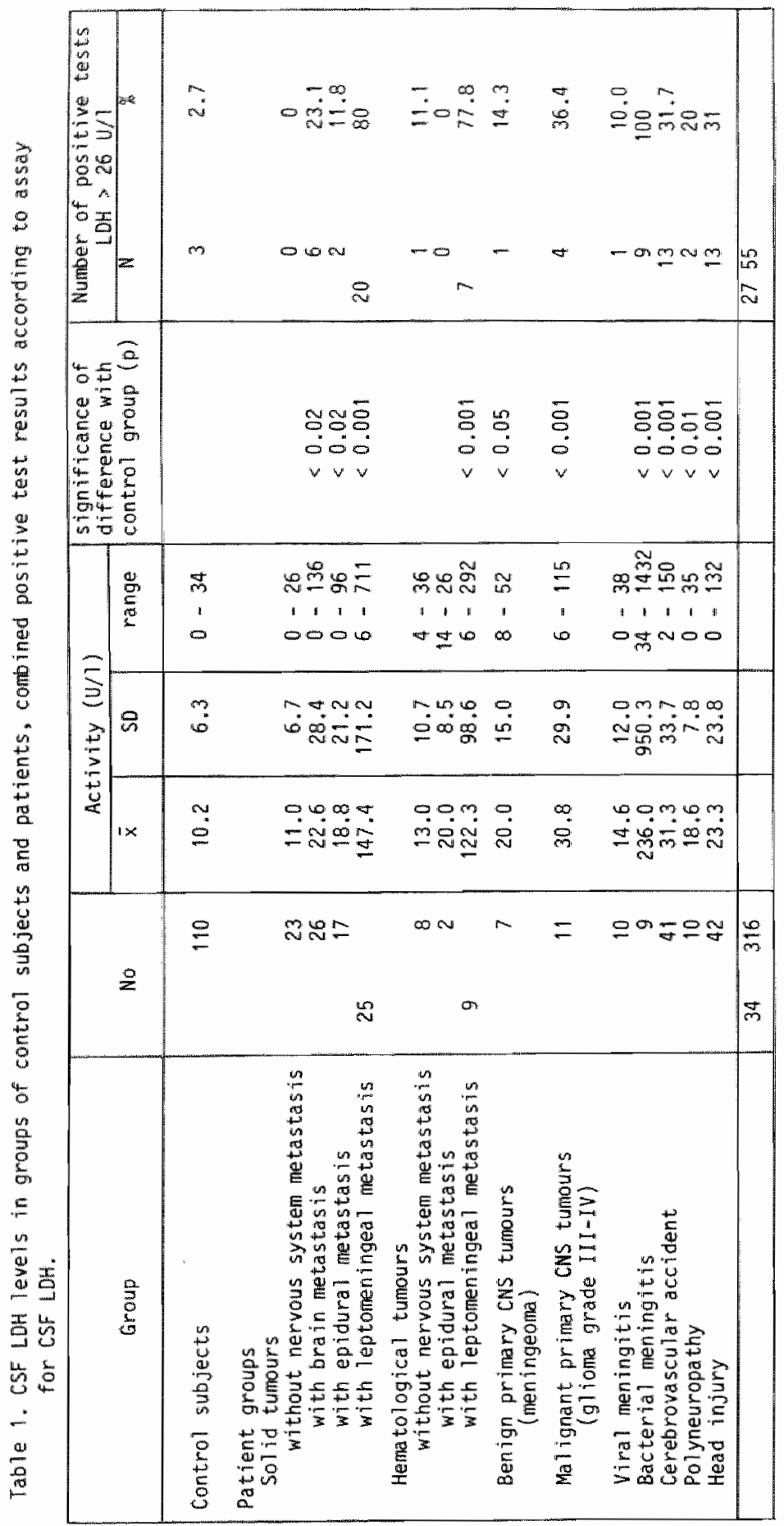


CSF analysis, nor CT brain scans or myelograms were indicative of CNS metastases. In 26 patients with brain metastases from solid tumours, the diagnosis was confirmed by CT brain scans. In 17 patients with solld tumours and in two with hematological malignancies, snyelagraphy confimed the diagnosis of spinal cord compression by epidural metastasis. In 34 patients with clinical evidence of leptomeningeal metastases, 25 with solid and mine with hematological tumours, this diagnosis was confirmed by positive CSF cytology or positive postmortem studies. In nine patients bacterial meningitis was demonstrated by gram stain and culture. In ten patients the diagnosis of viral meningitis was established by usual clinical and laboratory criteria such as menangeal irritation, uncomplicated clinical course, CSF mononuclear pleyocytosis, negat ive bacterial cultures, gram stains and nomal CSF glucose and CSF total protein levels. The lumbar CSF of seven patients with meningeoma and 11 with malignant primary brain tumours (glioma grade III-IV) were aiso studied.

In 24 (Table 2) of the 34 patients with leptoneningeal metastases from solid and hematological malignancies we were able to measure the LDH in lumbar and ventricular CSF subsequently, in the same session. These patients were treated with intraventricular methotrexate (MTX) via an ommaya reservair (13). The CSF was withdrawn from the lumbar and ventricular spaces before treatment was initiated.

The patients with leptomeningeal metastases were divided into three anatomical categories based on their neurological signs and symptoms (Table 2): I. brain, II * cranial nerves, and III. spine. The extent of the tumour growth was indicated by different neurological signs and symptoms, belonging to one or more anatonical category. We have treated the patients with ieptomeningeal metastases with intraventricular MT or wh th whole brain radiation followed by intraventricular MTX (13).

The criteria: improved, stable and progression were used for tumour response. Improved was defined as the disappearance of all signs and symptoms: disappearance of malignant cells was not necessary. stable was defined as no changes in neurological signs and symptoms during therapy.

Progression was defined as an increase of neur logical signs and symptons or the appearance of new lesions. The duration of the response was determined from the onset of the treatment to relapse. 


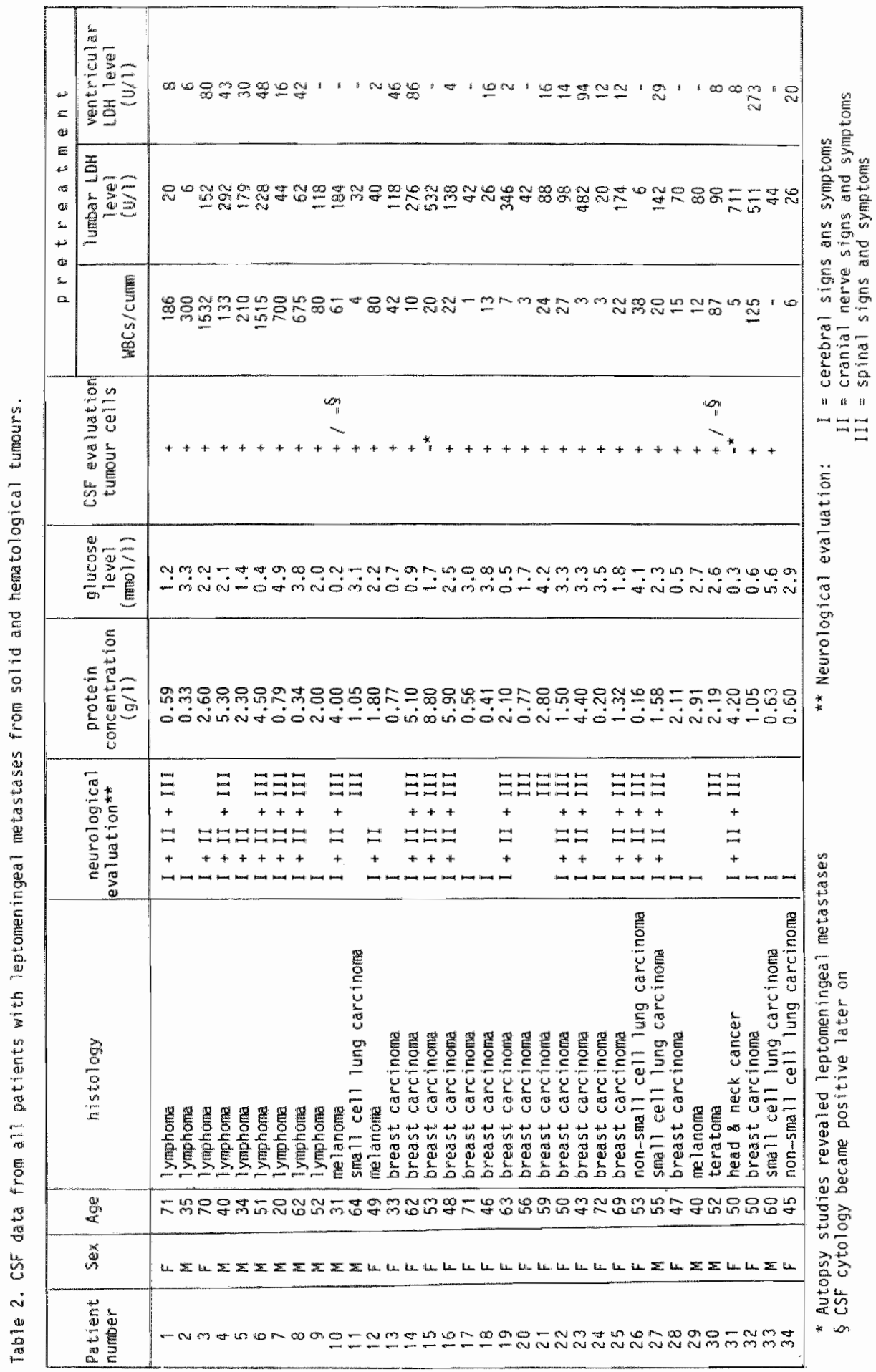


LDH Revels were determined in CSF using commercially availlable tests (14). The test methodology of the ACA (Dupont Company, Clinical systems, Wilmington DE, USA) is a modification of the enzymatic lactate to pyruvate procedure modified by Gay, McComb and Bowers (15). As the method described by the Deutsche Gesellschaft für Kl inische Chemie (14) in our laboratory is considered to be the reference method, the ACA method was cal ibrated to give results comparable with this method.

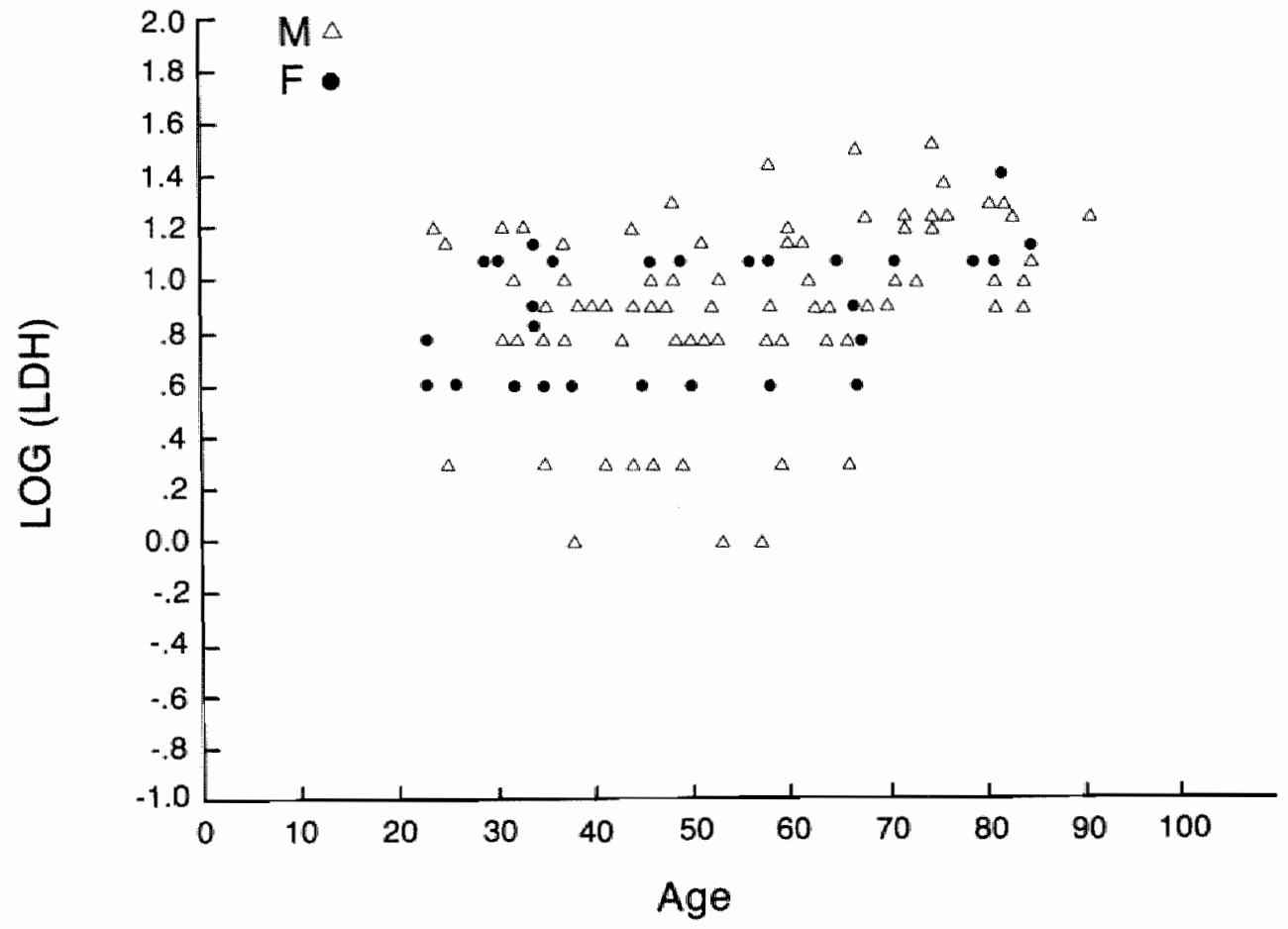

Fig. 1: CSF $\log (\mathrm{LDH})$ in 110 control subjects ranging in age from 23-81 years. Log LDH levels increased significantly with age for the group aged 70 years and older $(p<0.002)$.

\subsection{Statistics}

From the results of preliminary anallysis, it was decided to transform the LDH logarithmically prior to the final statistical analysis in order to get a closer approximation of the variation of observed values by the 
nomal distribution in all groups. Ordinary linear regression analysis was used to detemine the relationship between the log LDH level and sex and age. To test the statistical distribution of values for normality, the Shaptro and Wik test was used. Standard methods of statistical analyses were used to evalluate the results, including Student's $t$ test and andysis of variance and covariance. The sensitivity and specificity were calculated according to Griner et a1. (16). Nomal walues were estimated from patient data using a Bhattacharya plot as described by Maus et al. (17).

Table 3. Sensitivity, Specificity and Predictive Value Examinations for Leptomeningeal Metastases.

\section{Disease}

Present Absent

27

55

82

Test

Positive

Negative $\frac{7}{34} \quad \frac{261}{316} \quad \frac{268}{351}$

Negative $\frac{7}{34} \quad \frac{261}{316} \quad \frac{268}{351}$

Sensitivity $=\frac{27}{34}=79 \%$

Predictive walue Positive test $=\frac{27}{82}=33 \%$ Negative test $=\frac{261}{268}=97 \%$

\subsection{Results}

The data obtained from controls and patients are summarized in Tables 1 and 2. Reference Walues for I Umbar CSF LDH were calculated from results obtained in routine CSF analyses during a period of 34 months. Based upon 1949 patients we found a reference range from $0-26 \mathrm{U} / 1$ (18). The mean CSF LDH levels of the control subjects were $10.2 \mathrm{U} / 1$ with a standard deviation of 0.63 units. In this group statistical analyses were carried out to detect relationships between CSF LOH activities and age or sex. From ordinary linear regression anallyses we found a non 1 inear relationship between CSF 109 LDH and age (p quadratic 0.036) (figure 1). Inspection of these figures suggests a difference between CSF LDH and the age groups of $<70$ years and $\geqslant 70$ years. In subjects aged 70 years and older we measured no CSF LDH less than $5 \mathrm{U} / 1$. This estimated difference 
between the two age groups was not related to $\operatorname{sex}(p=0.94)$. We found no relationship between fenales and males and CSF $\log L D H \quad$ avel $5(p=0,067)$, and we calculated a deviation from normal in the contral subjects at a level of $p<0.01$. The upper nomal limit for CSF LDH activity was established as $26 \mathrm{U} / 1$. In the controls the CSF LOH was elevated in three cases. Table 1 ists the positive results in patients with metastases and primary CNS tumours and non malignant neurological diseases according to assay for CSF LDH. The catalytical activity of total LDH was elevated in 27 of the 34 patients with leptomeningeal metastases from solid and hematological tumours, but also in 55 of the 317 patients without leptomeningea? metastases. On the basis of these data, the sensitiwity of the test for leptomeningeal metastases was $79 \%$, and the specificity $83 \%$. The predictive values of positive and negative LDH tests were $33 \%$ and $97 \%$, respectively (Table 3 ).

We simultaneously measured the LDH activities in lumbar and ventricular CSF (Table 2) and found a mean concentration of LDH in the lumbar CSF of $177.88 \mathrm{U} / 1$ and in the ventricular CSF of $38.13 \mathrm{U} / 1$. The calculated mean lumbar LDH activity was approximately five times greater than the ventricular CSF LDH activity.

Table 4. Relationship between the lumbar and ventricular CSF LOH and the anatomical site of the leptomeningeal metastases.

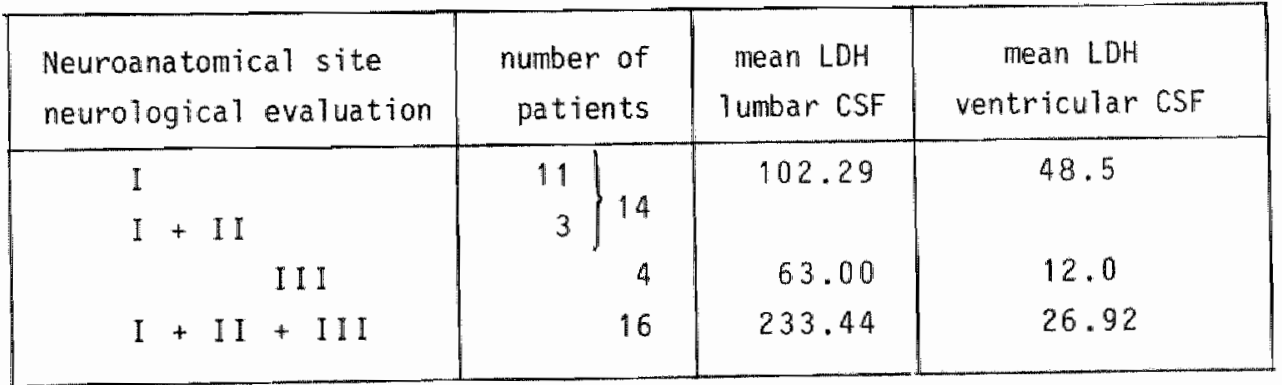

In Table 4 we show the relationship between lumbar and ventricular CSF LoH and the different area of the neuraxis involved in the leptomeningeal disease. Greater tumour size (including the anatomical area I+II+III) correlated with higher levels of the CSF LDH at the lumbar space. There was no association with the ventricular CSF level. When only the area of the spine is clinically involved (III), the lumbar CSF LDH concentration 
was greater than the ventricular CSF LDH concentration ( $p<0.03)$. In clinical involvanent of the leptomeninges of the brain and cranial nerves (1 + 11) the ventricular CSF LOH level was higher than the ventricular CSF, taken from patients with spinal leptomeningeal metastases larea III).

The CSF LDH activities in several types of primary tumours are summartzed in Table 5. There was no relationship between the CSF LDH level and the histology of the primary tumours.

Table 6 gives the relationship of serial LDH levels in the ventricular CSF to the pretreatment value and clinical response to therapy. A good correlation between decreasing LDH levels and response to chemotherapy was suggested. CSF LDH levels returned to nomal values in $11(69 \%)$. In five patients with decreased CSF LDH levels we found a progression of the clinical signs and symptions. The CSF LDH increased in three of the 11 non-responders. In five unchanged CSF LDH levels there was a progression of the neurological disease in three cases.

Table 5. Relationship between the lumbar $\mathbb{L O H}$ CSF level and the histological type of the primary tumour in patients with leptomeningeal metastase

\begin{tabular}{|c|c|c|c|c|c|}
\hline \multirow{2}{*}{ primary tumour } & \multirow{2}{*}{ No } & \multicolumn{4}{|c|}{ LDH } \\
\hline & & \multicolumn{2}{|c|}{ elevated } & mean & range \\
\hline breast & 15 & $12 / 15$ & $80 \%$ & 192.87 & $20-582$ \\
\hline non-Hodgkin's Iympho眼a & 9 & $7 / 9$ & $78 \%$ & 122.33 & $6-292$ \\
\hline Tung & 5 & $3 / 5$ & $60 \%$ & 50.00 & $6-142$ \\
\hline mella noma & 3 & $3 / 3$ & $100 \%$ & 101.00 & $40-184$ \\
\hline various & 2 & $2 / 2$ & $100 \%$ & 405.50 & $90-711$ \\
\hline $\begin{array}{l}\text { reference range } \\
\text { mean } \pm 50\end{array}$ & & & $0-2$ & & \\
\hline
\end{tabular}

\subsection{Discussion}

Leptomeningeal metastasis has been reported with an increasing frequency, especially in breast and lung cancer and 1 ymphoma (19-23), probably because of better control of early systemic disease and accompanying prolongation of survival by combination chemotherapy (24). 
Table 6. Relation of serial ventricular CSF lactate dehydrogenase (LDH) change with criteria of response to therapy in patients with leptomeningeal metastases.

\begin{tabular}{|c|c|c|c|c|}
\hline \multirow[b]{2}{*}{$\begin{array}{l}\text { relation with } \\
\text { pretreatment LDH }\end{array}$} & \multirow[b]{2}{*}{$\begin{array}{l}\text { number of } \\
\text { patients }\end{array}$} & \multicolumn{3}{|c|}{ correlation with clinical disease status } \\
\hline & & improved & stable & progression \\
\hline ventricular LDH level & & & & \\
\hline decreased & 16 & 11 & 0 & 5 \\
\hline unchanged & 5 & 1 & 1 & 3 \\
\hline increased & 3 & 0 & 0 & 3 \\
\hline & 24 & 12 & 1 & 11 \\
\hline
\end{tabular}

The diagnosis of leptomeningeal metastasis is based upon the demonstration of malignant cells in the CSF. However, the incidence of positive CSF cytology findings in the first sample may only be $40-60 \%$ (25) and in approximately $4-5 \%$ of patients even repeated llumbar CSF examinations fails to demonstrate malignant cells. Because of negative cytological findings, the diagnosis may be delayed. Early diagnosis, however, is particularly important since there is evidence that early treatment may improve results of treatment $(1,13)$.

The application of tumour markers has been discussed for the diagnosis leptomeningeal metastasis $(4,26-28)$. We have previously reported on the usefulness of the biochemical CSF markers B-glucuronidase, B2-microglobul in and carcinoembryonic antigen (29-31) in the detection of leptomeningeal metastasis. Reports concerning the presence of LDH in the CSF of various neurological diseases, including primary and metastatic CNS tumours, have been published since 1956 (6, 9, 11, 33). However, those studies are not unform. Methodologies of measurements do not always meet with the optimal recommendations of to-day $(34,35)$.

More recent studies $(36,37)$ only dealt with CSF LDH activities of affected patients and did not incorporate an adequate control group. For a proper diagnostic test control subjects should reflect the group of patients with a high probability of having the disease in question. In patients with leptomeningeal metastases the differentiation must be made 
from cerebral metastases $(38-40)$ and several types of infectious meningitis. In patients with spinal symptoms caused by leptomeningeal Involvement from malignancies the differentiation must be made from bone and epidural metastases and non mallignant conditions such as polyneuropathy, root lesions caused by herniated intervertebral disc and the Guilliain Barré syrudrome.

Gallen and Gambino (41) have published criteria for the evaluation of clinical laboratory tests used for diagnostic purposes. This madel may only be applied when sufficient data are available for the calculations of sensitivity, specificity and predictive value of the test.

In the previous reports, the reference populations used to calculate the limits, were not always free of disease. Moreover, few authors adjusted the normal range for the factors that might influence the test results other than disease. Nomal values of many variables are affected by the age of the subjects. Al though the earliest studies of CSF LDH did not separate nomal values by age $(6,42)$, later studies $(43,45)$ showed, that normal walues were age related. Ha in et a 7 . (44) reported a 1 inear incirease of LDH with age. This increase was linear to the age of 70 and then it remained constant through the age of 90 years. Spolter et al. published a study of age related LDH activities and found a CSF LDH increase with increasing age of patients. We found, however, a non linear relationship between CSF LDH activities and age. This relationship was based upon the absence of CSF LDH activities $<5 \mathrm{U} / 1$ in the patients aged 70 years and older. In the patients aged 70 years and older the CSF LDH increased significantly $(p=0.002)$. Because our group consisted of three patients over 70 years of age only, we did not standardize for age.

We found elevated CSF LDH levels in leptomeningeal disease from solid and hematological malignancies and in malignant primary bra in tumours. The number of patients with leptomeningeal metastases, who had negative cytologic results, have been evaluated. We found two patients with persistently negative cytology but highly elevated LoH activities. The diagnasis leptaneningeal metastasis was confirmed at autopsy. In non malignant conditions the CSF LDH was elevated in cerebrovascular accidents, in head injuries and in bacterial meningitis. Except the patients with bacterial meningitis, the degree of elevation of CSF LDH activity in leptomeningeal metastases was usually more than five times 
the non malignant conditions. These data indicate that an elevated CSF LOH level of approximately five times the mean activity of the control group is highly related to the diagnosis leptomeningeal metastasis.

The differentiation of leptoneningeal metastasis and bacterial meningitis might be made by the CSF white blood cell counts and culture. The CSF white blood cell counts in leptomeningeal metastases from sol id tumours are usually less than 100 per cubic millimeter, while in bacterial meningitis they are greater than 100 , usually in the range of 1000 to 10.000 per cubic millimeter (46).

We found that the I umbar CSF LDH concentration was about five times greater than ventricular CSF LDH concentration. These differences in 1 umbar and ventricular CSF LDH at these different levels of the neuraxis have mat previously been described. A possible explanation might be a higher concentration of LDH in the CSF in proximity to the leptomeningeali site of involvement.

Virtually no data are available regarding changes in CSF LDH activity as a function of clinical statu's or treatment in patients with leptomeningeal metastases. Efficacy of treatment can be evaluated by clinical parameters and following the presence of tumour cells in the CSF. Frequently the clinical evaluation may be difficult especially if neurological improwement cannot be expected to occur due to irreversible damage to the nerwous tissue. In these patients tumour response will be assessed by following CSF parameters including tumour cells. However, CSF levels of protein, glucose and malignant cells can differ at different anatomical levels of the neuraxis in patients with leptomeningeal metastases. This means that ventricular CSF may be negative while at the same time lumbar CSF contains tumour celis. We therefore analyzed the relationship between the serial ventricular CSF LDH in patients with leptomeningeal metastases and the results of treatment. Our analysis shows a moderate correlation between serial ventricular CSF LDH level changes and positive response to therapy or progression of disease.

This study indicates that the LDH assay of cerebrospinal fluid can be used as an adjunctive diagnostic test for leptomeningeal metastases if the clinical condition is carefully evaluated and appropriate caution is exercised in interpretation. Furthemore, serial ventricular CSF LDH measurements may be useful for monitoring the response to therapy. 
More studies are needed to evaluate the use of multiple sequential tumour markers in the CSF, in monitoring patients with leptomeningeal metastases from solid and hematological tumours.

\subsection{Summary}

Lactate dehydnogenase activities were measured in cerebrospinal filuid in 350 patients with various neurological diseases to establish the sensitivity and specificity of the CSF LDH as a marker for the diagnosis of leptomeningeal metastases. Slight elevations of CSF LDH were observed in nomalignant diseases, while marked elevations were observed in a considerabie number of patients with bacterial meningitis. We calculated a sensitivity of $79 \%$ and a specificity of $83 \%$. In the 34 patients with leptomeningeal metastases from solid and hematological tumours, we measured the LDH in lumbar and ventricular CSF simultaneously. The lumbar CSF LDH concentration in patients with leptomeningeal metastases was about 5 times greater than that in the ventricular CSF. No relationship was found between the CSF LDH and histology of the primary tumour. A good correlation was demonstrated between the lumbar CSF LDH and the effected area of the neuraxis. Serial deteminations of CSF LDH showed a relationship between level changes and responses ta therapy or progression. The findings of this study indicate that measurement of LDH in CSF can be used as an adjunctive diagnostic test for leptomeningeal metastases and in monitaring the efficacy of treatment.

\subsection{References}

1. Schold SC, Wasserstron WR, Fleisher M, Schwartz MK, Posner JB: Cerebrospinal fluid biochemical markers of central nervous system metastases. Ann Neur ol 1980; 8: 597-604.

2. Persijn JP, Korsten CB, Batteman JJ: Chemical significance of urinary CEA estimations during the follow-up of patients with bladder carcinoma or previous bladder carcinama. J Clin Biochem 1976; 14: 395-399.

3. Loewenstein MS, Rittgers RA, Feinerman AE: CEA assay of ascites and detection of malignancy. Ann Int Med 1978; 88: 635-638.

4. Wasserstrom WR, Schwartz MK, Fleisher M, Posner JB: Cerebrospinal fluid biochemical markers in central nervous system tumours: A review. Ann Clin Lab Sc i $1981 ; 11$, no. 3 . 
5. Jakoby RK and Jakoby WB: Lactic dehydrogenase of cerebrospinal wid in the differential diagnosis of cerebrovascular disease and brain tumour. \Neurosurg 1958; 15: 45-51.

6. Fleisher GA, Wakin KG, Goldstein MP: Glutamic-oxalacetic tramsaminase and lactic dehydrogenase in serum and cerebrospinal fluid of patients with neurologic disorders. Mayo Clin Proceed 1957:32: 188-197.

7. Green JB, 01 dewurtel HA, 0'Doherty DS, Forster FM: Cerebrospinal fluid transaninase and lactic dehydrogenase activities in neurologic disease. Arch Neurol Psychiat 1958; 80: 148-156.

8. Wroblewski F, Decker B, Wroblewski R: The clinical implications of spinal fluid lactic dehydrogenase actiwity. N Engl J Med 1958; 258: $635-639$.

9. Nelson PV, Carey WF, Pollard AC: Diagnostic significance and source of lactate dehydrogenase and its isoenzymes in cerebrospinal fluid of children with a variety of neurological disorders. J Clin Path 1975 ; 28: $828-833$.

10. Beaty HN, Oppenheimer S: Cerebrospinal fluid lactic dehydrogenase and its isoenzymes in infections of the central nervous system. N Engl J Med 1968; 279: 1197-1202.

11. Davies-Jones GAB: Lactate dehydragenase and glutamic oxalacetic transaminase of the cerebrospinal fluid in tumours of the central nervous system. J Neurol Neurosurg Psychiat 1969; 32: 324-327.

12. Dharker SR, Dharker RS, Chaurasia BD: Lactate dehydrogenase and asparate transaminase of the cerebrospinal fluid in patients with brain tumours, congenital hydrocephalus and brain abscess. J Neurol Neurosurg Psychiat 1976; 39: $1081-1085$.

13. Angerboer de Visser BW, Somers R, Nooyen WH, Heerde P van, Hart AAM, MCVie $3 G^{*}$ Intraventricular methotrexate therapy of leptaneningeal metastasis from breast carcinoma. Neurology 1983; 33: 1565-1572.

14. Empfehlungen der Deutschen Gesellschaft für Kl inische Chemie. Standardisierung von Methoden zur Bestimmung von Enzymaktivitäten in biologischen Flüssigkeiten. Experimentelle Begründung der optimierten Standardbedingungen. J Cl in Chem Clin Bfochem 1972; 10: 182-189.

15. Gay RJ, McComb RG, Bowers Jr GN: Optimum reaction conditions for human Tactate dehydrogenase enzymes as they affect total lactate dehydrogenase activity. Cl in Chem 1968; $14: 740-753$. 
16. Griner PF, Mayewski Ru, Hushl in AI, Greenland P: Selection and interpretation of diagnostic tests and procedures. Ann Intern Med $1981 ; 94: 553-592$.

17. Naus $A J$, Borst $A$, Kuppens PS: The use of patient data for the calculation of refierence values for some hematolagical parameters. J Clin Chem Cl in Biochen 1980; 18: 621-625.

18. Zanten van AP, Twijnstira A, Hart AAM, Ongerboer de Visser BW: Cerebrospinal fluid lactate dehydrogenase activities in patients with central nervous system metastases. Submitted Cl in Chim Acta.

19. Buschoff A: Erfahrungen mit der Tumorzelldiagnostik im Liquor cerebrospinalis. Acta Neurochir 1961; 9: 510-524.

20. Sayk J, Olischer RM: Fortschritte der Liquorzytologie bei der Diagnostik bösartiger Hirngeschwul ste (3. Mitteilung). Psychiat Neurol Med Psychol (Leipzig) 1967; 19: 88-89.

21. Hirsch FR, Paulison OB, Hansen HH, Uraa-Jensen J: Intracranial metastases in small cell carcinoma of the 1ung. Cancer 1982; 50: 2433-2437.

22. Brereton HD, O"Donne11 JF, Kent CH, Matthews M, Dunnick NR, Jahnson RE: Spinal mentingeal carcinomatosis in small cell carcinoma of the lung. Ann Intern Med 1978; 88: 517-519.

23. Nugent JL, Bunne PA Jr, Matthews MJ, Ihde DC, Cohen MH, Gazdar A, Minna JD: CNS metastases in small bronchogenic carcinoma. Increasing frequency and changing pattern with lengthening survival. Cancer $1979 ; 44: 1885-1893$.

24. 01 son ME, Chernik NL, Posner JB: InfiTtration of the leptomeninges by systemic cancer: A clinical and pathologic study. Arch Meurol 1974; 30: $122-137$.

25. Glass JP, Melamed M, Chernik ML, Pasner JB: Malignant cells in cerebrospinal fluid (CSF): The meaning of a positive CSF cytology. Neurology $1979 ; 29: 1369-1375$.

26. Dearnaley DP, Patel S, Powel TJ, Coombes RC: Carcinoembryonic antigen estimation in cerebrospinal fluid in patients with metastatic breast cancer. Oncodevel Biol and Med 1981; 2: 305-311.

27. Shuttleworth EC, Allen N: CSF-B-glucuronidase assay in the diagnosis of neoplastic mening itis. Arch Neurol 1980; 37: 684-687.

28. Koch Th R, Lichtenfeld KM, Wiernik PH: Detection of central nervous 
system metastases with cerebrospinal fluid B2-microglobulin. Cancer $1983 ; 52: 101-104$.

29. Zanter van AP, Twijnstra A. Benthem van V, Hart AAM, Ongerboer de Visser BW: Cerebrospinal fluid B-glucuronidase activities in patients with central nervous system metastases. Clin Chim Acta 1985; 147: $127-134$.

30. Twijnstra A, Nooyen WJ, Zanten van AP, Hart AAM, Ongerboer de Visser BW: Cerebrospinal fluid beta-2-micraglobulin: a study in controls and patients with metastatic and non metastatic neurological diseases. Eur J Cancer \& CAin Oncol 1986 (in press).

31. Twijnstra A, Nooyen WJ, Zanten van AP, Ongerboer de Visser BW, Hart AAM: Cerebrospinal fluid carcinomembryanic antigen in patients with metastatic and non metastatic neurological diseases. Arch Neurol fin press).

32. Marton LJ, Heby 0, Wil son CG: Increased polyamines concentration in the CSF of patients with brain tumors. Int J Cancer 1974; 14: $731-735$.

33. Goldman KO, Kaplan NO, Hall TC: Lactic dehydrogenase in human neoplastic tissues. Cancer Res 1964; 24: $389-399$.

34. Buhl SN and Jackson KY: Optimal reaction conditions and comparison of lactate dehydrogenase catalysis of the lactate-to-pyruvate and pyruvate-to-lactate reactions at 25,30 and $37^{\circ} \mathrm{C}$. Cl in chem $1978 ; 24$ : $828-831$.

35. Sharpe DM, Wilcock AR, Goldberg DM: Automated kinetic spectrophotometric assays of enzyme activities of human cerebrospinal fluid: methods and reference values. C1 in chem 1973; 19: 240-247.

36. Fleisher M, Wasserstrom WR, Schold S, Schwartz MK, Posner JB: Lactate dehydrogenase isoenzymes in the cerebrospinal fluid of patients with systemic cancer. Cancer 1981; 47: 2654-2659.

37. Rabbow L, Kristensson $K$ : Changes in lactate dehydragenase isoenzyme patterns in patients with tumours of the central nervous system. Acta Neurochir 1977; 36: $71-81$.

38. Rosen ST, Aisner J, Makuch RW, Matthews MJ, Ihde DC, whittacre MRN, Glatstein EJ, Wiernik PH, Lichter AS, Bunn PA: Carcinomatous leptomeningitis in small cell lung cancer: a clinicopathologic review of the National Cancer Institute Experience. Medicine 1982; 61: 45-53. 
39. Greenberg HS, Deck MDF, wikram B, Chu FCH, Posner JB: Metastasis to the base of the skull: Clinical findings in 43 patients. Neurology $1981 ; 31: 530-537$.

40. Max MB, Deck MDF, Rottenberg DA: Pituitary metastasis: Incidence in cancer patients and clinical differentiation from pituitary adenoma. Neurology 1981; 31: 998-1002.

41. Galen RS, Gabino SR: Beyond Nomality: The predictive value and efficiency of medical diagnosis. New York: Wiley, 1975.

42. Wrablewski F, Decker B, Wrablewski R: Activity of lactic dehydrogenase in spinal fluid. Am J Clin Pathol 1957; 28: 269-271.

43. Spoliter H, Thompson HG: Factors affecting lactic dehydrogenase and glutamid oxallacetic transaminase in cerebrospinal fluid. Neurology $1962 ; 12: 53-59$.

44. Hain RF, Nutter $\mathrm{d}$ : Cerebrospinal fluid enzymes as a function of age. Arch Neurol 1960; 2: $331-337$.

45. Yap BS, Yalp HY, Benjamin RS, Freirich EJ: CSF CEA in breast cancer patients with meningeal carcinomatosis. Proc Am Assoc Cancer Res/Am Soc Clin Oncol 1978; 19: 98.

46. Morgenroth J, Deisseroth A, Wimokur S, Schein Ph: Differentiation of carcinomatous and bacterial meningitis. Neurology 1972; 22 : $1240-1242$. 
Sensitivity and Specificity of Single and Combined Tumour Markers in the Diagnosis of Leptomeningeal Metastasis from Breast Cancer *

Albert Twijnstra, Anton P. wan Zanten, Willem J. Nooyen and Bram W. ongerboer de Visser.

\subsection{Introduction}

In recent years the diagnostic incidence of leptomeningeal metastases from breast carcimoma has steadily increased $(1,2,10,15)$. This has been attributed to longer survivals achieved with more effective treatment and to better neurological diagmostic procedures. Cytologic evaluation of the cerebrospinal fluid (CSF) is the principle modality to confirm the diagnosis of leptomeningeal metastases. With the cytocentrifuge technique, however, cytology will only be positive in $60 \%$ of the patients and in $4 \%$ there is a false positive result (3). This has. greatly contributed to the inability to make an early diagnosis of leptomeningeal metastases in breast cancer (3-9).

In previous studies we measured the levels of CSF B-glucuronidase $(B-g l u c),. B 2-m i c r o g l o b u l i n(B 2-m)$, carcinoembryonic antigen (CEA) and lactate dehydrogenase (LDH) in CSF of patients with a variety of metastatic and nonmetastatic diseases (11-13).

The most important points to consider in the evaluation of a tumour marker are the specificity and sensitivity of the various tests. By specificity is meant the ability of the test to discriminate those individuals who do not have the disease. Sensitivity refers to the abil ity of the test to detect all patients with the disease.

CSF B-gluc. appeared to be an accurate marker for leptomeningeal metastases fran solid tumours and $B 2-m$ the most useful for the detection of leptomeningeal spread from hematological tumours $(11,12)$. CSF CEA assay possesses a low sensitivity but a high specificity in establishing the diagnosis of leptomeningeal metastasis from solid tumours (13).

* To be published in: J Neural Neurosurg Psychiatry, 1986. 
We al so found that CSF LOH was a useful marker for leptomeningeal metastases, however, in contrast to the other tests the CSF LDH was elevated in warious nonmetastatic diseases (11).

The purpose of the present study was to determine whether in patients with breast cancer a combination of B-gluc., B.2-m, CEA and LDH measurements is more effective than the use of one of these single tests in the detection of leptomeningeal metastasis.

Table 1. Positive test results in breast cancer patients with and without CNS metastases, according to assay for B-g7uc., B2-m, CEA and LDH.

\begin{tabular}{|c|c|c|c|c|c|}
\hline \multirow[t]{2}{*}{ Group } & \multirow[t]{2}{*}{$\begin{array}{l}\text { No of } \\
\text { Patients }\end{array}$} & \multicolumn{4}{|c|}{$\begin{array}{l}\text { No of } \\
\text { positive tests }\end{array}$} \\
\hline & & B-gluc. & $\mathrm{B} 2-\mathrm{m}$ & CEA & $\mathrm{LDH}$ \\
\hline $\begin{array}{c}\text { Breast cancer with } \\
\text { CNS metastases }\end{array}$ & 41 & 16 & 13 & 12 & 17 \\
\hline leptomen ingea 1 & 15 & 13 & 9 & 9 & 14 \\
\hline spinal & 14 & 1 & 3 & 3 & 1 \\
\hline parenchymatous & 12 & 2 & 1 & 1] & 2 \\
\hline $\begin{array}{l}\text { Breast cancer without } \\
\text { CNS metastases }\end{array}$ & 16 & 0 & 1 & 0 & 0 \\
\hline neuropathy/plexopathy & 8 & 0 & 1 & 0 & 0 \\
\hline Tumbar disc disease & 4 & 0 & 0 & 0 & 0 \\
\hline headache & 3 & 0 & 0 & 0 & 0 \\
\hline cerebrovascular accident & 1 & 0 & 口] & 0 & 0 \\
\hline reference range \pm 2 SD & & $\begin{array}{l}9-27 \\
m \sqcup / 1\end{array}$ & $\begin{array}{c}0.65-2.2 \\
\mathrm{mg} / 1\end{array}$ & $\begin{array}{l}0.8-4 \\
\mathrm{ng} / \mathrm{ml} 1\end{array}$ & $\begin{array}{r}0-26 \\
0 / 1\end{array}$ \\
\hline
\end{tabular}

\subsection{Patients and methods}

CSF levels of B-glucuronidase, B2-m, CEA and LDH were measured in 57 woman with breast cancer and neurological disorders referred to the Antoni van Leeuwenhoekhuis during $1981-1983$. Their ages ranged from 30 to 78 years (mean, 57 years). In all patients diagnostic procedures included: CT brain scan, bacterial culture and cytologic examinations of CSF. 
They we divided into two groups (Table 1). Group I comprised 41 patients with chs metastases, of whon 15 had leptomeningeal metastases confirmed by positive CSF cytolagy in 13 and by postmortem findings in two. Group II comprised 16 patients with neuralogical disorders, but without demonstrable metastases to the central nervous system (CNS).

\subsubsection{Samples}

CSF samples were centrifuged for cytological examinations and immediately analysed for LOH. The additional CSF samples were coded and stored at $-20^{\circ} \mathrm{C}$ until analyses. Lumbar puncture was performed as a part of clinical diagnostic procedures, and never for the measurement of the markers only.

\subsubsection{Assay methods}

CSF B-gluc. was measured as described earlier (11), normal values ranged from 9-27 m/l (Table 1). CSF B2-m was measured by radioimunoassay using the Phadebas Bamicro Test (Pharmacia Diagnostics, Uppsala, Sweden). B2-m increased significantly $(p<0.0001)$ with increasing age (12). No relationship was found for sex. Nomal values standardized for age ranged from 0.65 to $2.20 \mathrm{ng} / 1$ (Table 1). CSF CEA was measured by the method of Egan et al (19) with several modifications (13, 16); the upper limit of normal is $4 \mathrm{ng}$ per millilitre (Table 1).

For B-gluc. and CEA no relationships were found between test results and age or sex $(11,13)$.

LOH determinations were perfomed using a Dupont ACA, calibrated to give values corresponding with the method of the German Society for Clintcal Chemistry (18).

Our test results related to age $(p=0.036)$ and not to sex $(11)$. The upper 1 int of nomal is less than $26 \mathrm{U} / \mathrm{l}$ (Table 1 ).

\subsubsection{Statistics}

The analysis in this paper depends upon data from previous studies to estimate test sensitivity and specificity. The receiver operator curve is a graph, which has been constructed to correlate true- and false-positive rates for a series of cutoff points for four biochemical marker tests. This graph is used to decide the optimum cutoff point according to the purpose of the test. When two or 
more tests are avallable to pursue a dianostic consideration, the comparison of the receiver operator characteristic (ROC) of each will often show, where one test has an advantage ower the other test.

For B2-m and LDH values an unequal deviation was found, so that results were analysed using nomal quadratic analys is $(17,18)$. The sensitivity, specificity and the Roc curves were calculated according to Griner et al (14). Galen and Gambino published criteria for ewaluating markers in diagnosis and screening (16). The reference ranges for the four markers in nomal CSF were based on mean \pm 2 SD (Table 1) (11-13).

Table 2. True and false positive rates for four markers of leptomeningeal metastases from breast cancer.

\begin{tabular}{|l|c|c|c|}
\hline Test & cutoff value & $\begin{array}{c}\text { sensitivity } \\
\text { (true pos.rate) }\end{array}$ & $\begin{array}{c}1 \text { - specificity } \\
\text { (false positive rate) }\end{array}$ \\
\hline B-glucuronidase (mu/1) & 27 & 87 & 7 \\
B2-microglobulin (mg/1) & 2.2 & 60 & 12 \\
CEA (ng/mi) & 4 & 60 & 7 \\
LDH (U/1) & 26 & 93 & 7 \\
\hline
\end{tabular}

\subsection{Results}

Table 1 shows the positive results in groups of subjects with and without breast cancer for B-gluC., B2-m, CEA and LDH. True-positive i.e. sensitivity and fallse-positive rates for the four tumour markers using the upper limit of nomal as cutoff point are presented in Table 2. The sensitivities and specificities were established for the diagnosis leptomeningeal metastasis. B-gluc., CEA and LDH were found to be relatively specific giving a false positive rate of 7\%. CEA and B2-m had a similar sensitiwity but CEA was slightlymore specific than $B 2-m$; the false positive rates are 7 and $12 \%$, respectively. Both LDH and B-g1 UC. were the most sensitive markers. LDH gave a true-positive rate of $93 \%$ and $B-g l u c$. of $87 \%$ taking the mean plus standard deviation as the upper 1 imit of nomal as cutoff point. LoH showed a higher true-positive rate than the other tests, but it is quite difficult to compare these tests directly.

We are only able to do this under comparable conditions of the four tests. Therefore, we changed the decision level for each test to give 
specificities (true-negative rates) of $93 \%$ and $100 \%$ respectively (Table 3). We then compared the tests on the basis of the resulting true-positive rates; LOH was more sensitive than the other tumour markers at a specificity rate of 93 . At a specificity of $100 \%$, however, $B-g l u c$. is considerably more sensitive than LDH.

Table 3. Test characteristics for leptomeningeal metastases from breast cancer.

\begin{tabular}{|c|c|c|c|c|}
\hline Test & \multicolumn{2}{|c|}{ specificity 93} & $\begin{array}{l}\text { specific } \\
\text { cutoff walue }\end{array}$ & $\begin{array}{l}y=0 \% \\
\text { sensitivity }\end{array}$ \\
\hline B-glucuronidase $\quad(\mathrm{mu} / \mathrm{l})$ & 28 & 87 & 39 & 87 \\
\hline B2-microglobul in (AS) (mg/l) & 2.9 & 47 & 4.4 & 13 \\
\hline $\operatorname{CEA}(\mathrm{ng} / \mathrm{ml})$ & 4.05 & 60 & 12.05 & 33 \\
\hline $\operatorname{LDH}(\omega / 1)$ & 24 & 93 & 96 & 47 \\
\hline
\end{tabular}

If we chosed decision levels needed to give sensitivity rates of $93 \%$ or 100\% respectively (Table 4), then we found that $L D H$ was more specific than each of the other CSF markers. Table 5 shows data concerning the operating characteristics of B-gluC, and $L D H$ when used alone or in combination. The combined tests are most helpful when both markers are abnomal, the combined specificity is then higher, but the sensitivity is lower. In Figure 1 we constructed a graph that correlates all truem and false-positive rates for a series of cutoff points for different tests, 1.a. B-gluc., BZ-m, CEA and LDH. Such a graph is known as the receiver operating curve (ROC). The curve can be used to decide the optimum cutoff point according to the purpose of the test. A comparison of the ROC of each test will often show where one test has an advantage over the other test.

Table 4. Test characteristics for leptomeningeal metastases from breast carcinama.

\begin{tabular}{|lr|cc|cc|}
\hline \multicolumn{1}{|c|}{ Test } & \multicolumn{2}{c|}{$\begin{array}{c}\text { sensitivity } 93 \% \\
\text { cutoff value specificity }\end{array}$} & \multicolumn{2}{c|}{$\begin{array}{c}\text { sensitivity 100\% } \\
\text { cutoff value specificity }\end{array}$} \\
\hline B-glucuronidase & $(\mathrm{mU} / \mathrm{l})$ & 19 & 69 & 17 & 45 \\
B2-microglobulin (AS) $(\mathrm{mg} / 1)$ & 1.16 & 38 & 1.00 & 14 \\
CEA $(\mathrm{ng} / \mathrm{ml})$ & 2.05 & 72 & 2 & 26 \\
LOH $(\mathrm{U} / 1)$ & 24 & 93 & 23 & 78 \\
\hline
\end{tabular}


Table 5. Dperating characteristics of combination testing.

\begin{tabular}{|l|cc|}
\hline \multicolumn{1}{|c|}{ Test } & sensitivity & specificity \\
\hline B-glucuronidase (A) & 87 & 93 \\
LDH (B) & 93 & 93 \\
A or B positive & 99 & 86 \\
A and B positive & 81 & 99 \\
\hline
\end{tabular}

\subsection{Discussion}

A number of CSF markers have been suggested as potential tumour markers for leptomeningeal metastases in solid tumours $(3,4,11-13)$. For interpretation of these laboratory tests, sensitivity, and specificity calculations are necessary.

Our results regarding sensitivity and specificity for this patient group are summarized in table 2 . It shows the 1 imited diagnostic value of CSF CEA and B2-m with respect to other tests. We standardized the four tests by choosing cutoff points with which all tests had the same true-positive rates, the tests could then be directly compared with regard to their true-negative rates. When we fixed the specificity for the four tests at $93 \%$, then B-gluc. and LDH showed sensitivity rates from $87 \%$ and $93 \%$ respectively. However, when choosing decision levels needed to give a $100 \%$ specificity, then LDH was markedly less sensitive (47\%) than B-gluc. (Table 3 ).

A sensitivity of $13 \%$ at $100 \%$ specificity for B2-m makes B2-m of little value as a marker for leptomeningeal metastases from breast carcinoma. Its usefulness was not altered by the combination with the other tests. An elevated CSF CEA value had a $100 \%$ specificity, but the ability of this test to detect meningeal spread from breast carcinoma $(1,2,10)$ is low (sensitivity level $32 \%$ ) and was unaltered by combination of the test. The ROC curves represented in the figure correlate true- and false-positive rates (sensitivity and 1 - minus specificity) for a series of cutoff points for the respective test. Good clinical performance for a test is characterized by a high true-positive rate and a low false-positive rate.

B-gluc. was the only marker with a high sensitivity at a specificity level of $100 \%$. LDH on the other hand, appeared to have in this patient 
group a higher sensitivity when the specificity was fixed at $93 \%$, but it had a markedly reduced sensitivity of $47 \%$ at $100 \%$ specificity. To our knowledge no other study prowided statistical data of the usefulness to combine CSF markers. In patients at risk for leptomeningeal metastases, using the combination of the markers with the highest sensitivity and specificity i.e. B-gluc. and LDH respectively, we found an increase in specificity from 93 to $99 \%$ at a sensitivity of only 81 (Table 5).

In conclusion, when taking into account the factors of sensitivity and specificity in evaluating the four markers, the combined tests of CS: B-gluc. and LDH seen to be the most reliable markers for the detection of leptomeringeal metastases in patients with breast cancer.

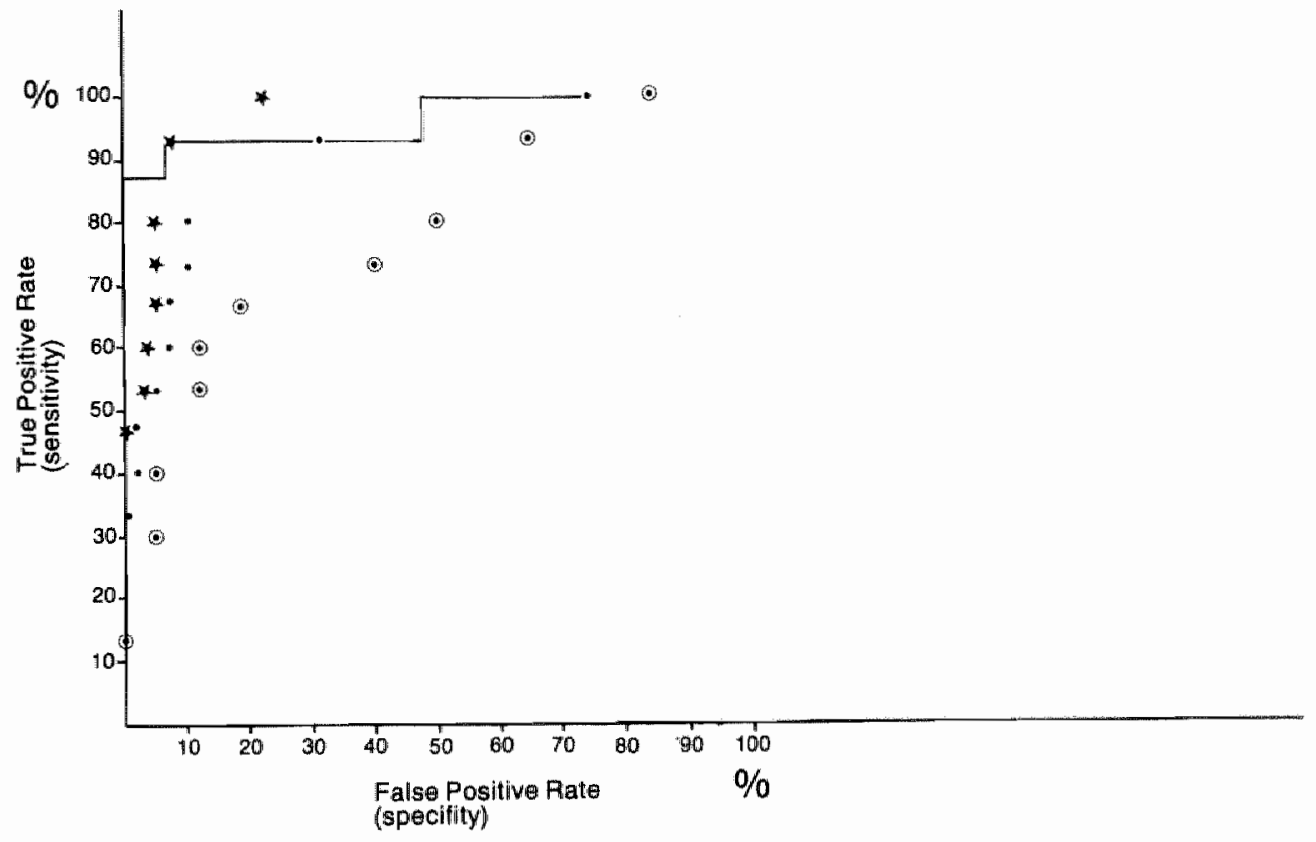

Fig. 1: A receiver operator characteristic for $B-g 7$ curonidase $B 2-m a \Theta \Theta, C E A \ldots$ and $L D H * \star * \star$ for patients with leptomeningeal metastases from breast carcinoma. 


\subsection{Summary}

We assessed the clinical efficacy of four laboratory tests in detecting leptomeninged metastases in 57 patients with breast carcinoma. The sensitivity and specificity of $B$-glucuronidase (B-gluc.), B2-microglobulin $(B 2-m)$, carcinoembryonic antigen (CEA) and lactate dehydrogenase (LDH) in cerebrospinal fluid were detemined. As a single test B-gluc. was the most sensitiwe (93\%) and specific (93\%) for discrilinating between leptomeningeal metastases and other cNS metastases from breast cancer. LDH was the next most useful marker. Both B2-m and CEA had a sensitivity of $60 \%$.

More specific results were achieved by combining B-glucuronidase and LDH. CSF B-glucuronidase may be useful by itself and in combination with LDH in the detection of leptomeningeal metastases from breast carcinoma.

\subsection{References}

1. Yap BS, Yap HY, Fritsche HA Jr, Blumenschein G, Bodey GP. Cerebrospinal fluid carcinoembryonic antigen in breast cancer patients with meningeal carcinomatosis. JAMA 1980; 244: 1601-1603.

2. Dearnaley DP, Patel S, Powels TU, Coombes RC. Carcinoembryonic antigen estimation in cerebrospinal filuid in patients with metastatic breast cancer. Oncodew Biol Med 1981; 2: 305-311.

3. Glass JP, Melamed N, Chernik NL, Posner JB. Malignant cells in cerebrospinal fluid (CSF). The meaning of a positive CSF cytology. Neurology (NY) 1979; 29: 1369-1375.

4. Schold SC, Wasserstrom WR, Fleisher M, Schwartz MK, Posner JB. Cerebrospinal fluid biochemical markers of central nervous system metastases. Ann Neurol 1980; 8: 597-604.

5. Shuttleworth E, Al len N. CSF B-glucuranidase assay in the diagmosis of neoplastic meningitis. Arch Neurol 1980; 37; 684-687.

6. Schaub C, Bluet-Pajot MT, Szikla G, Lornet-Videau C, Mounier F, Talairach w. Distribution of $B 2-m i c r o g l o b u t i n$ in cerebrospinal fluid and in cystic fluid of brain tumors. Path Biol 1978; 26: 381-385.

7. Mavligit GM, Stuckey SE, Cabanillas FF, Keating Mu, Tourtelotte WW, Schold SC, Freireich EJ. Diagnosis of leukemia or Tymphoma in the central nerwous system by beta-2-microglabulin detemination. N Engl J Med $1980 ; 7: 718-722$. 
8. Koch RT, Lichtenfeld KM, Wiernik PH. Detection of central nerwous system metastases with cerebraspinal fluid beta 2 -microglobulin. Cancer 1983; 52: 101-104.

9. Davies-Jones GAD. Lactate dehydrogenase and glutamic transaminase of the cerebrospinal fluid in tumours of the central nervous system. $J$ Neural Neurosurg Psychiat 1969; 32: 324-327.

10. Yap BS, Yap HY, Benjanin RS, Freirich FJ. CSF CEA in breast cancer patients with meningeal carcinomatosis. Proc Am Assoc Cancer Res/Am Soc Clin Oncol 1978; 19: 98.

11. Zanten AP van, Twojnstra A, Benthen $V$ van, hart AAM, Ongerboer de Visser BW. Cerebrospinal fluid B-glucuronidase activities in patients with central nervous system metastases. Clin Chim Acta 1985; 147: $127-134$.

12. Twijnstra A, Zamten AP van, Nooyen WJ, Hart AAM, Ongerboer de Visser BW. Cerebrospinal fluid beta2-microglobulin: a study in controls and patients with metastatic and non-metastatic neurological diseases.

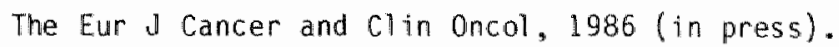

13. Twijnstra A, Nooyen WJ, Zanten AP wan, Ongerboer de Visser BW, Hart AAM. Cerebrospinal fluid carcinoembryonic antigen in patients with metastatic and non-metastatic neurological diseases. Arch Neurol 1986 (in press).

14. Griner PF, Mayewski Ru, Mushl in AI, Greenland P. Selection and interpretation of diagmostic tests and procedures. Ann Intern Med $1981 ; 94$ : $553-592$.

15. Ongerboer de Visser BW, Somers R, Noayen WH, Heerde P van, McVie JiG. Intraventricular methotrexate therapy of leptomeningeal metastasis from breast carcinoma. Neurology $1983 ; 33: 1565-1572$.

16. Galen RS and Gambino SR. Beyond normality: the predictive value and efficiency of medical diagnosis. New York: John Wiley \& Sons, 1975.

17. Shapiro SS, Wilk MB. An analysis of variance test for nomality (complete samples). Biometrika $1965 ; 52: 59 \%-596$.

18. Emfehlungen der Deutschen Geselischaft für KTinische Chemie. Standardisierung von Methoden zur Bestimmung von Enzymaktivitäten in biologischem Flüssigkeiten. Experimentelle Begründung der optimierten Standard Bedingungen. J C1 in Chem Cl in Biochem 1972; 10: 182-189.

19. Egan ML, Lautenschleger JT, Coligan JE. Radioimmune assay for carcinoembryonic antigen. Imunochemistry 1972; 9: 289-299. 

Serial Lumbar and Ventricul ar Cerebrospinal Fluid Biochentcal Marker Measurenents in Patients with Leptomeningeal Metastases from Solvd and Hematological Tumours *

Albert Twijnstra, Anton P. van Zanten, Wi llem $\mathrm{W}$. Nooyen and Grang Ongerboer de Visser.

\subsection{Introduction}

In previous studies $(1-4)$, we measured the levels of B-ghucurontage (B-gluc.), B2-microglobul in (B2-m), carcinoembryonic antigen (CEA), and lactate dehydrogenase (LDH) in the cerebrospinal fluid (CSF) of 197 patients with disorders of the central mervous system (CNS). We concluded that, of these CSF biochemical markers, B-gluc. and LDH were the most accurate markers of CNS metastases, especially in the detection of leptomeningeal metastases from solid tumours. The B2-m in CSF was found to be the most accurate in the detection of leptomeningeal metastases from hematological tumours. The diagnostic approach that was used could prove to be helpful to patients with leptomeningeal metastases.

The most effective treatment to date for patients with leptomeningea metastases from solid or hematological tumours consists of intratheca? administration of methotrexate (MTX) (5). The method of choice is injection of the drug directly into the ventricular system via an maja reserwair $(5,6)$.

A routine exanination of the protein, glucose, and tumour cells within CSF is valuable in the follow-up of patients with leptomeningeal metastases. However, the composition of CSF can differ markedly between different CSF sources, such as the Omaya reservoir or lumbar space (7), even in the absence of an extradural block. It has therefore been suggested that the response to treatment by serial examination of CSF obtained from the sites with the most marked pretreatment abnormality be monitored $(7,8)$. The now routine clinical use of intraventricular

* Manuscript submitted for publication, 1986. 


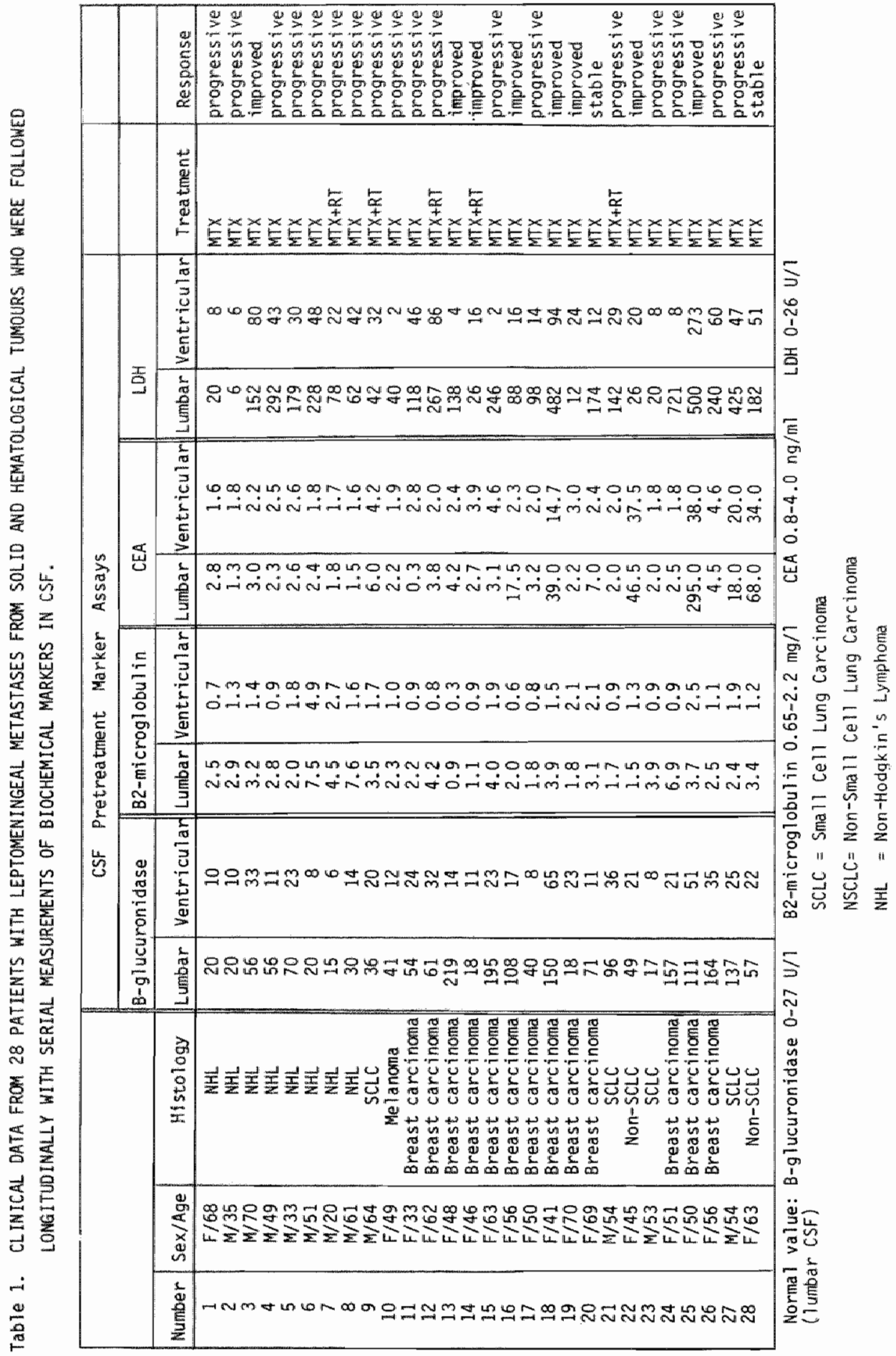


administration of chemotherapy wa the Omaya reservoir has made ventricular CSF more readily available for analysis. In this way, efficacy of treatment may be monitared by serial exanination of ventricular CSF. Al though numerous biochemical markers have been associated with leptomeningeal disease (9-11), as yet, mone has proven to be an adequate marker with clinical utility in monitoming this disease. We, therefore, studied the CSF levels of various potential biochemical markers in relation to treatment. To improve the utility of biochemical markers in the clinical setting, we investigated: (i) marker levels in ventricular and Iumbar CSF simultaneously, (ii) the correlation of marker levels with histology of the primary tumour, (iii) the correllation of marker levels with the most symptonatic area along the neuraxis, (iv) the correlation of marker levels with CSF cytology in the wentricular and lumbar spaces, and ( $w$ ) the correlation of marker levels with the disease status *

Attention was also directed to the potential influence of prophylactic chemotherapy on the level of the markers in the CSF examined.

In the current study, we utilized all of these approaches by simultaneous analysis of four biochemical markers in patients with leptomeningeal metastases from solid and hematological tumours.

\subsection{Patients and methods}

Between January 1981 and December 1983, 28 consecutive, unselected patients with leptomeningeal metastases from solid and hematological tumours, who had been referred to the Antoni van Leeuwenhoekhuis for treatment, had at least two assays of one of the following blomarkers: B-gluc., B2-m, CEA, and LOH. When clinically possible, serial assays from ventricular and llumbar CSF were performed just prior to each treatment, at intervals of one day or Ionger. Concurirentily, other routine biochemical, cytological, and cilinical reassessments of tumour activity were performed. The ages of the patients with leptomeningeal metastases ranged from 20 to 70 years (patients with 1 ymphama were between 20 and 70, and those with carcinoma between 37 and 70). A11 of the patients were treated for their leptomeningeal disease with intraventricular MTX, five patients in combination with cranial radiotherapy. The mediar length of surwival was three months and the range, 1 to 10 months; no patients are still being treated at this time. The diagnosis of leptomeningeal 


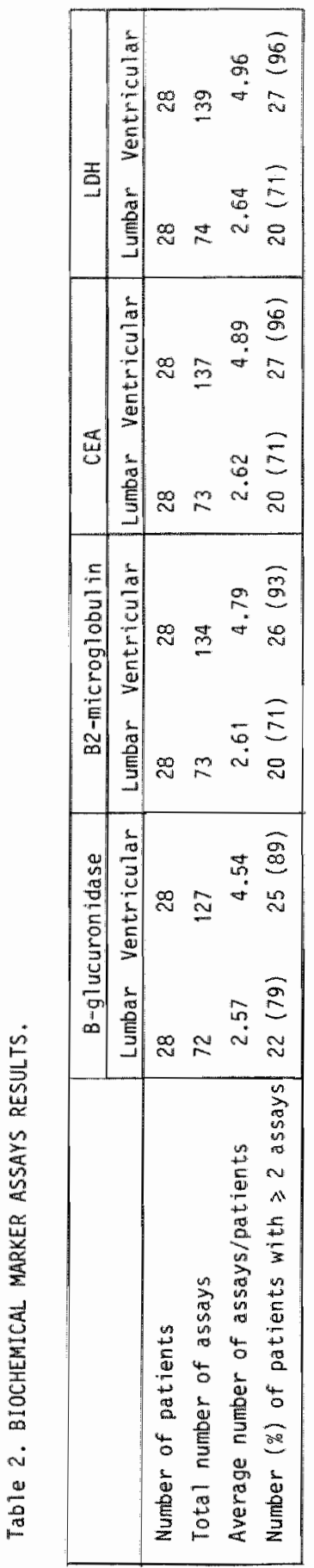


metastasis was made on the basis of clinical signs and symptoms, and was confimed by CSF cytology or autopsy findings. The initial staging work-up included, in some patients, computerized tomography (CT) scanning and myelography. The diagnosis of primary tumours was: breast carcinoma (13 cases), Iymphoma (eight cases), lung carcinoma (six cases), and melanoma (one case). There was no other documented reasun for any of the patients to have had abmormal biochemical marker levels. (Bacterial meningitis was ruled out by culture).

The criteria "improved" "stable", and "progressive" were used for tumour response. "Improved" signified the disappearance of all signs and symptoms (al though not necessarily the disappearance of malignant cells from CSF). "Stable" meant that there had been no changes in neurological signs and symptoms during therapy. "Progressive" indicated an increase of neurolagical signs and symptoms or the appearance of new lesions. The duration of the response was defined as the period of time from the onset of treatment to relapse.

The same tumour markers were al so measured in CSF from nine patients, five of whom had acute leukemia and four, a non-Hodgkin's lymphoma. These patients ranged in age from 16 to 59 years. All had been treated with prophylactic central nervous system intrathecal MTX.

\subsubsection{Cerebrospinal flluid sampling}

To obtain ventricular CSF, the Ommaya reservoir was entered with a 23 gauge butterfly needle; $3 \mathrm{ml}$ cerebrospinal fluid which had passed through the reservoir and tubing, was withdrawn and discarded. An additional $7 \mathrm{ml}$ was then removed and set aside for assay. Thus, no more than $10 \mathrm{ml}$ af cerebrospinal fluid was removed from the ventricle for purposes of sampling. One hour after the Ommaya sampling, a total of $10 \mathrm{mil}$ of CSF was al so removed from the lumbar regian. Both CSF samples were centrifuged for cytological examinations and immediately analysed for LDH. Additional samples were coded and stored at $-20^{\circ} \mathrm{C}$ for future analysis. Ventricular and lumbar punctures were performed as a part of clinicall, diagnostic, and treatment procedures, and never for the measurement of the markers al one. 


\subsubsection{Assay raethods}

Total pratein and LDH levels in CSF were determined using commercially avallable tests (i.e. the testing methodologies of the ACA, Dupont Company, Clinical System Division, Wilmington, DE. 19898, U.S.A.). The LDH measurement was calibrated to give values similar to the results abtained by the method used by the German Society for CTinical Chemistry (12). There was a nonlinear relationship between CSF, LOH, and age over 70 years. LoH increased significantly $(\rho<0.001)$ among patients 70 years and 01 der $(4)$. Since few cases were older than 70 years, normal values were not standardized for age. Glucose level was determined enzymatically by using comercially available glucose anallysis systems. The levels of CEA in CSF were estimated by the method used by Egan et al. with several modifications (13), and the upper nomal limit was $4 \mathrm{ng}$ per milliliter. B-gluc. in CSF was measured as described earlier (1). B2-m in CSF was measured by radioimnunoassay, using the Phadebas B2-microtest (Pharmacia Diagnostics, Uppsela, Sweden), and it was found to increase significantly $(p<0.001)$ with age $(2)$. No relationship was between $B 2-m$ level and gender. Normal values were standardized for age. The respective nomal values for these tumour markers in our laboratories were: B-gluc.: $9-27 \mathrm{mu} / 1 ; B 2-\mathrm{m}: 0.65-2.2 \mathrm{mg} / 1 ; C, E A: 0.8-4.0 \mathrm{ng} / \mathrm{ml}$; and LDH: $0-26 \mathrm{U} / 1$ of CSF obtained by lumbar puncture $(1-4)$.

Table 3. PRETREATMENT BIOMARKER ASSAYS IM LEPTOMENINGEAL METASTASES*.

\begin{tabular}{|c|c|c|c|c|}
\hline & B-glucuronidase & $B 2-\pi$ & CEA & LDH \\
\hline Breast: Carcinoma & $11 / 13(85)$ & $7 / 13(54)$ & $6 / 13(46)$ & $11 / 13(85)$ \\
\hline Small Cell Lumg Carcinoma (SCLC) & $(75)$ & $(75)$ & $(50)$ & $(75)$ \\
\hline Non-Sma 11 Cell Lung Carcinoma (NSCLC) & $(100)$ & $(50)$ & $(100)$ & $1 / 2$ \\
\hline Non-Hodgk in"s Lymphoma (NH.).) & $(50)$ & $7 / 8 \quad(88)$ & $0 / 8$ & $6 / 8$ \\
\hline
\end{tabular}

* Values = No elevated/total tested. The percentage is given between parentheses.

\subsubsection{Statistical methods}

Standard methods of statistical analysis were used to evaluate the results. One-way analysis of variance was perfomed on biochemical marker levels grouped by response category. The same analysis was also performed to determine the relationship between markers and the major symptomatic area and cytology of the CSF. 


\subsection{Results}

The clinical characteristics of the patients with leptomeningeal metastases are shown in Table 1 . We found no correlation between nomal pretreatment levels of the four biochemical markers and response to chemotherapy.

The total number of assays performed for each biochemical marker in the lumbar and ventricular CSF, and the number of patients from whom these assays were drawn, are shown in Table 2. The number of patients having two or more assays of a given marker are indicated separately. For each marker, more than $70 \%$ of the patients had two or more assays.

Table 4. BIOCHEMICAL MARKER LUMBAR/VENTRICULAR CSF RATIOS IN LEPTOMENINGEAL METASTASES.

\begin{tabular}{|l|c|c|c|c|}
\hline & \multicolumn{4}{|c|}{ Lumbar/Ventricular Ratio } \\
\cline { 2 - 5 } & mean & median & SE & range \\
\hline B-glucuronidase & 3.7 & 2.5 & 0.58 & $0.78-15.6$ \\
B2-microglobulin & 2.5 & 2.3 & 0.3 & $0.86-6.6$ \\
Carcinoembryonic Antigen & 1.7 & 1.2 & 0.3 & $0.11-7.8$ \\
Lactate Dehydrogenase & 12.9 & 8.8 & 5.2 & $50-123$ \\
\hline
\end{tabular}

The proportion of patients with increased levels of biochemical markers is shown in Table 3. Eleven of the thirteen patients with breast carcinoma had pretreatment levels moderately elevated over the control value; all but two had elevated B-gluc. and LDH. Of the eight NHL patients, none had elevated pretreatment CEA levels, and the pretreatment elevations of B-gluc. Were, in general, slight. In all lung carcinoma patients ( $S C L C$ and NSCLC), an increase in B2-m coincided with an increase in B-gluc. or LDH, or both. The mean, median, standard error, and range of the Tumbar:wentricular CSF ratio are shown in Table 4. Almost all ratios were greather than 1 , except the CSF:CEA ratio, which had nine values less than 1 , indicating that CEA was relatively more often elevated in the ventricular CSF than it was in the lumbar CSF. The site 
of invalvament was correlated with the pretreatment marker concentrations in lumbar ard ventricular CSF respectively (see Table 5).

The CSF:LDH ratio showed a significant correiation with the site of cNS involwement (1.e., at the spinal roots; $p<0.03$ ). For the other markers, no correlation was found.

Studying pretreatment levels of B-gluc., B2-m, CEA, and LDH in CSF with respect to the different histologic types, we found that patients with non-small cell lung carcinoma (NSCLC) had highly significant elevations of CEA in lumbar CSF $(p<0.01)$ (see Table 6). We did not find other significant differences among the various histological types. The small numbers, howevar, preclude definitive conclusions.

During treatment, the disappearance of tumour cells from the lumbar and ventricular CSF was correlated with the four marker concentrations in the lumbar and ventricular CSF. CSF cytology, during and after treatment, was described as one of the following: I. positive cytology in both Iumbar and ventricular CSF, II. negative lumbar and positive ventricular cytology, III. positive lumbar and negative ventricular cytology, or IV. negative cytology in both lumbar and ventricular CSF. The results are shown in Table 7. Group II contained only one patient and, therefore, was not evaluated. In each of the remaining groups, tumour cells and marker levels were detemined simultaneousiy. Statistically significant correlations were found only for the LDH walue in ventricular CSF ( $p<$ $0.01)$. No correlation was found between the presence or absence of malignant cells and levels of LDH in lumbar CSF or of B-gluc., B2-m, or CEA in lumbar and ventricular CSF.

Table 8 shows the means, standard errors, and numbers of patients for the respective biochemical markers which were divided into the three disease activities and pretreatment categories. A steady increase in the numerical values of means with increasing disease activity is apparent for ventricular B2-m (using Kruskal-wallis correlations of statistical significance; $p<0.08$ ). In addition, ventricular LDH showed a significant positive correlation with decreasing disease $(p<0.05)$. For all other markers, there was no correlation.

Clinical diagnoses of the nine prophylactically treated patients with acute leukemia and 1 mmphoma but without CNS disease are shown in Table 9. All of these patients received, in addition to systemic chemotherapy, cNS prophylaxis with intrathecal MTX. The CSF was examined just before CNS 


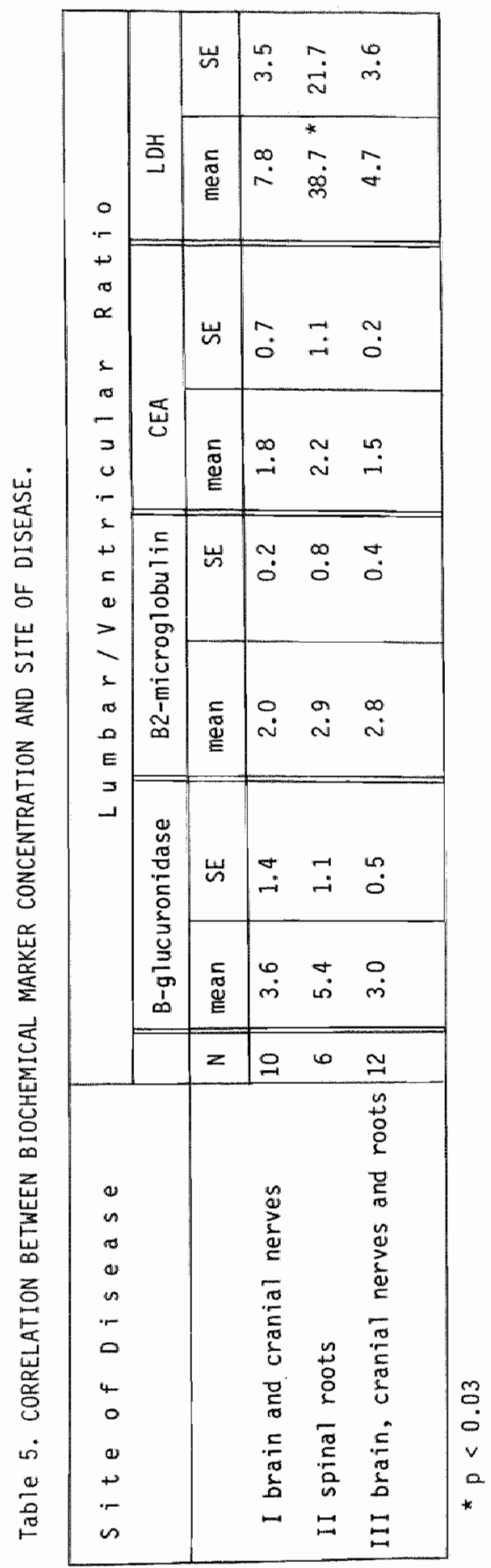




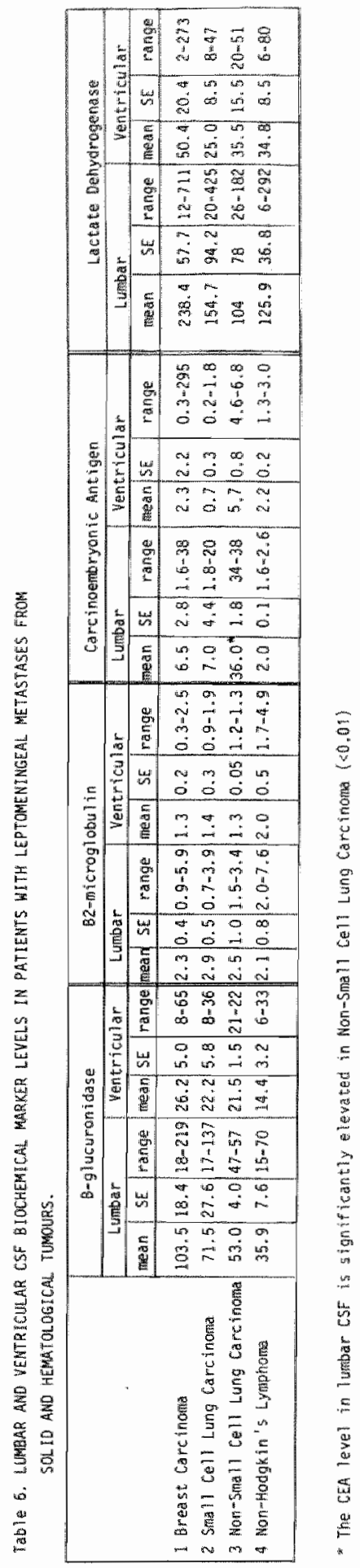




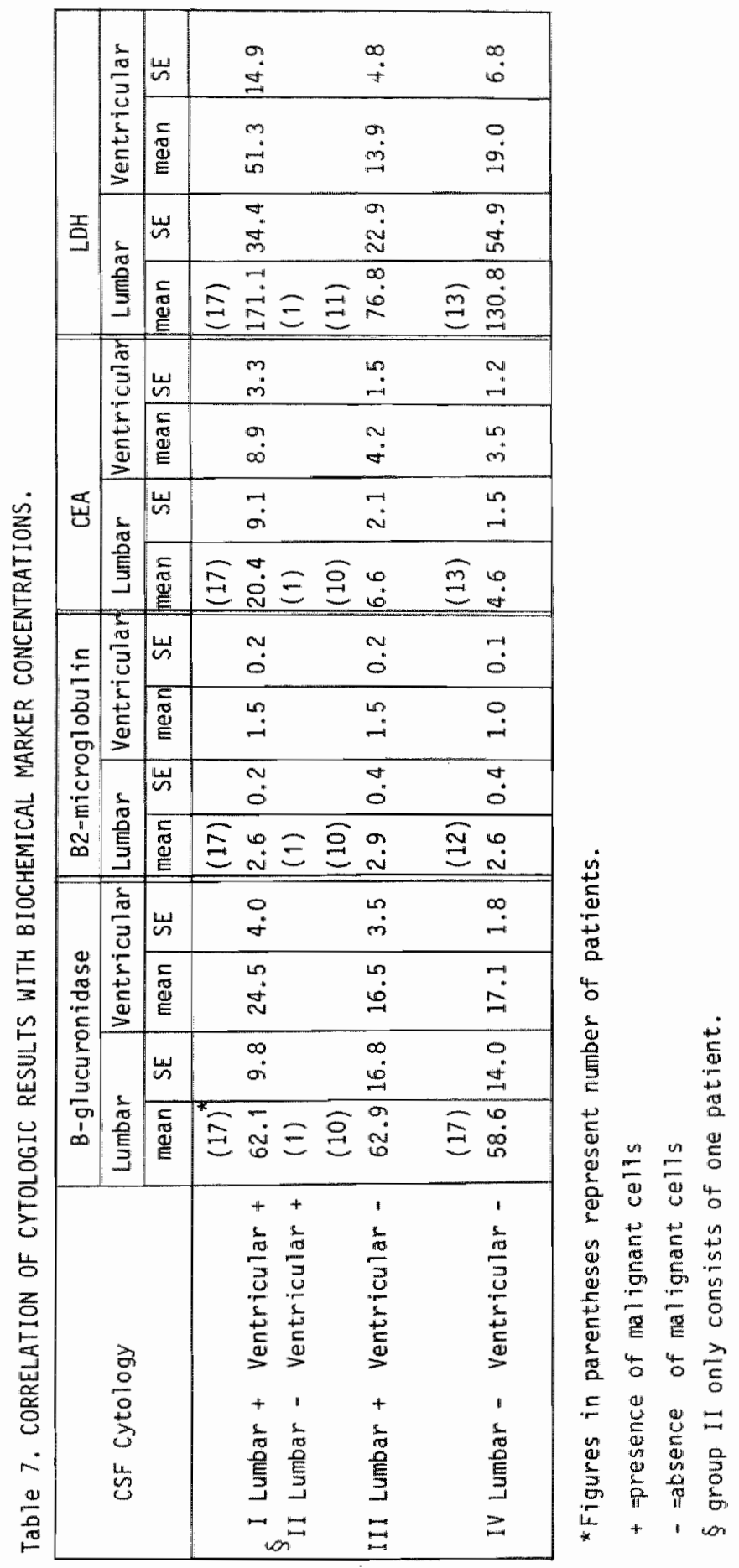




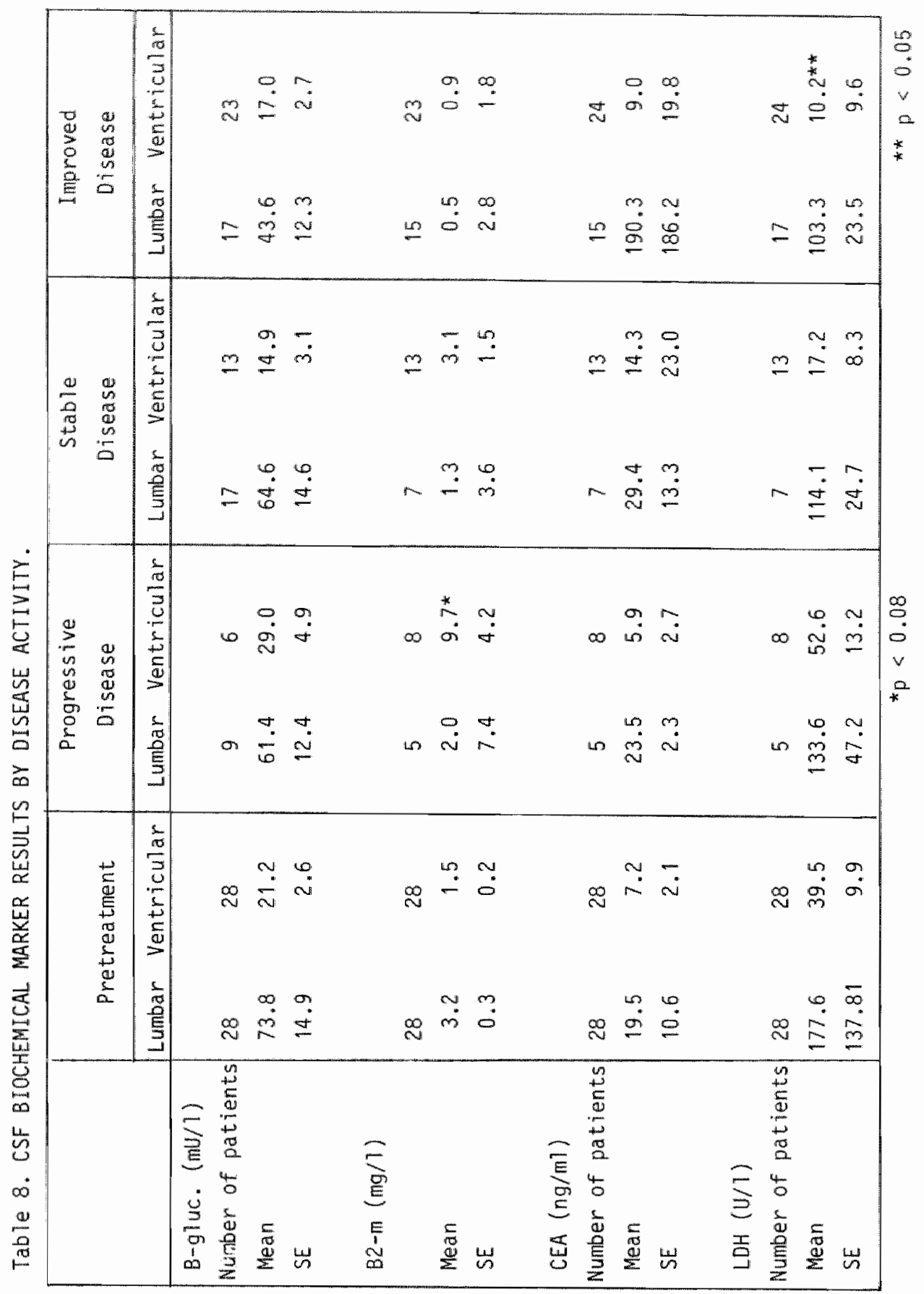




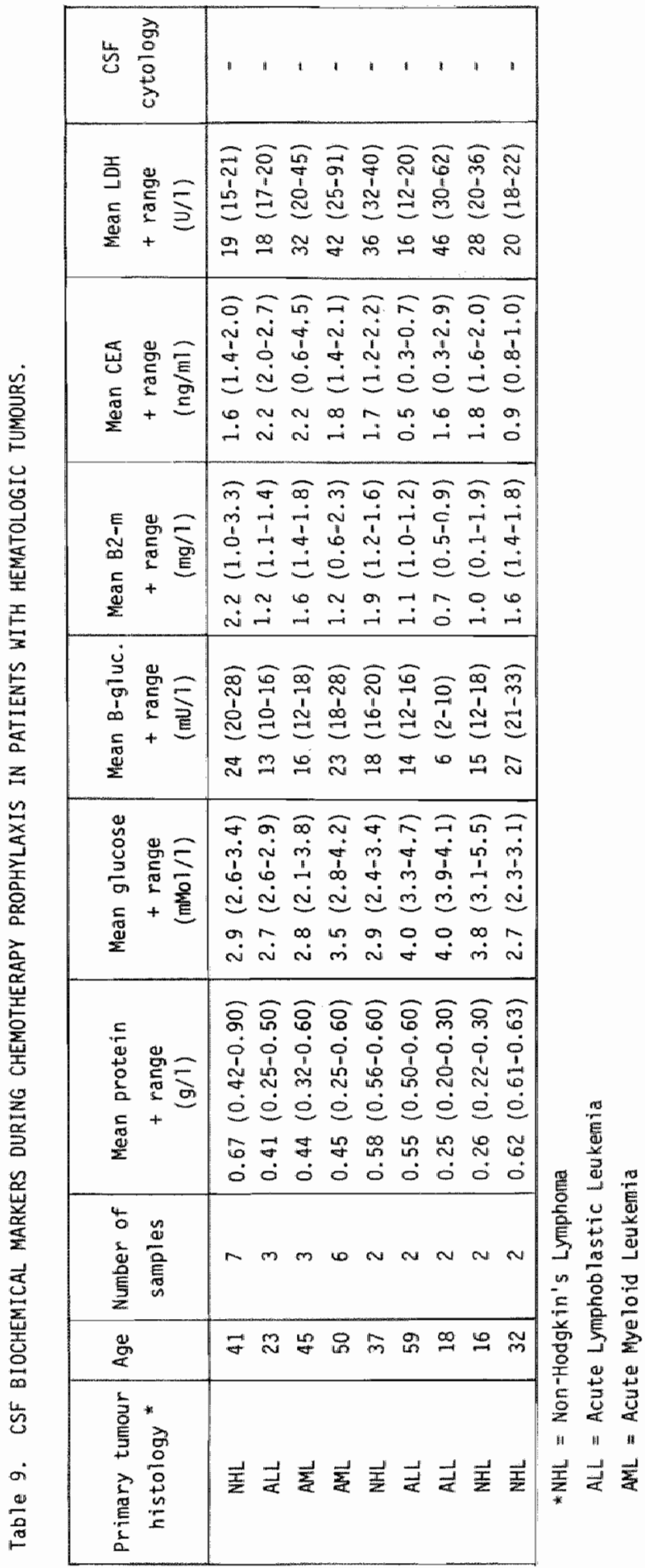


prophyl axe and at least one time during the treatment with intrathecal MT. These results are also shown in Table 9 . The glucose level in the CSF of these patients was nomal, but protein content rose during cas. chemotherapy. In some patients the LDH activities during CNS treatment were higher than nomal. Wone of the patients had CNS symptoms or signs during treatment. Our results show that prophylactic cNs chomotherapy does not conclusively produce biochemical changes of the CSF.

\subsection{Discussion}

There hawe been a number of studies showing lumbar CSF measurements of biochemical narkers as an aid in the diagnosis of leptoneningeal metastasis $(9-11)$. These markers, however, have less often been measured in ventricular CSF. Relatively few studies $(10,11,14)$ in leptameningeal metastases have focussed speclfically on the value of biochemical markers in CSF in monitoring and predicting the progression of disease. Those that have generally indicated that biochemical marker levels vary in accordance with changes in disease status; yet, little data has been analysed to indicate correlations between ventricular and lumbar CSF marker levels. To our knowledge, no studies in leptameningeal metastasis have evaluated the role of multiple, sequential biochemical markers in monitaring the efficacy of chemotherapy.

Intraventricular administration of chemotherapeutic agents via the Omaya reservoir is now the treatment of choice. Routine use of this device has made ventricular CSF readily available for analysis. However, it is difficult to evaluate treatment for patients with leptomeningeal metastases because standard criteria for respionse are lacking. Efficacy of treatment is determined by clinical parameters and with serial csf examination. Yet, clinical response to treatment cannot always be obtained, since irreversible damage to nerwous tissue cannot be corrected by anti-tumour therapy. Therefore, ventricular CSF is also used to assess response of CSF composition after treatment. Other points that should be considered during monitoring are false negative (15) and false positive cytologies in CSF. One such example is when brain tissue is transwersed by a catheter (Ommay device). Ventricular CSF can become contaminated by neurons or glia cells and these cells cam be mistaken for malignant cells (16). 
The composition of ventricular cSF can differ dramatically from that of lumbar CSF. It is known that a CSF protein gradient exists (7). Nomal vertericular protein levels in adults range fron 0.06 to $0.15 \mathrm{~g} / \mathrm{l}$, as compared with nomal values of 0.20 to $0.50 \mathrm{~g} / 1$ in 1 umbar CSF. This difference in protein concentrations has not been adequately explained. In addition, other CSF constituents, such as electrolytes, show no concentration gradients in nomal subjects. Differences in CSF composition make monitoring the efficacy of chemotherapy by routine cSF exaninations unreliable.

schold et al. (11) reported that the levels of $B-g / u c$. and CEA in ventricular CSF were always lower than those in lumbar CSF, with ratios ranging from 0 to 0.5 and from 0.2 to 0.5 , respectively. Our results are consistent with these findings. To date, in the literature, CSF ratios for B2-m and LDH have not been described; nor is the explanation for the marked variation in CSF from various regions along the neuraxis (ventricular: lumbar) clear. Obstructions to the flow of CSF were ruled out by myelograms. No relationship to age or specific diagnosis was apparent. However, the extent of active leptomeningeal involvenent of the CNS may have been important. A review of our own data reveals that most of the marker levels in CSF obtained near the major symptomatic area, were no higher than those obtained from other more distant sites. Only the level of LDH in the lumbar CSF was significantly higher when the spinal roots were involved. This means that when using the concentration of LDH in CSF to monitor disease activity, it is best to abtain CSF from the site along the neuraxis in which the most marked abnormality is detected.

Also analysed in our study was the relationship between maligmant cells in the different spaces and the marker levels. Only the LDH level in wentricular CSF showed a positive correlation with the CSF cytology. Although it has yet to be proven that CSF marker level elevation precedes other symptoms of CNS disease (cell shedding, neurological signs), it seems logical that marker levels could, indeed, precede the actual shedding of cells, which has been revealed through cytological study, the most effective test to date.

Drugs may very well influence the production, release, or elimination of the biochemical markers in CSF. Therefore, we al so analysed $B-g l u C ., B 2-m, C E A$, and LDH in the lumbar CSF of patients with acute 
leukenta or lymphona who recelved systemic and intrathecal MTX as prophylaxis. In sone patients only $L D H$ showed slight to marked elevations. Thus, the validity of the test in monitoring progression of disease was not affected by intrathecal MT:

As stated earlier, relatively few studies have focussed specifically on the walue of serial biochenical marker levels in monitoring the progression of disease vet, a number of those which have indicated that B-gluc. and CEA levels vary in accordance with changes in disease status $(10,11)$.

In our study, the B2-m and the LDH levels in ventricular CSF exhibited a positive relation with disease status. Such was not the case with any of the other markers. We agree with Mav1igit et a1. (14) that the B2-m level in CSF in monitoring treatment for patients with leptomeningeal metastases; however, he neglected to mention the source of the C.5F B2-m.

\subsection{Conclusion}

It appears that only the serial measurements of changes in the levels of B2-m and, LOH in ventricular CSF are valuable in the follow-up of patients with leptomeningeal metastases. Our findings indicate that routine measurements of $B 2-m$ in ventricular CSF may be reliable in monitoring the efficacy of chemotherapy and are independent of the most donomal site, histology of the primary tumours, and CSF cytology. This study has al so shown that the levels of these markers may vary in accordance with changes in disease status. The serial measurements of BZ-m and LDH in ventricular CSF may be of use in indicating the need for a change in therapy; however, prospective studies are needed to substantiate this hypothesis.

\subsection{Summary}

The serial biochemical markers B-glucuronidase (B-gluc.), B2-microglobul in $(B 2-m)$, carcinoembryonic antigen (CEA), and lactate dehydrogenase (LDH) were measured in lumbar and ventricular cerebrospinal fluid (CSF) in 28 patients with leptomeningeal metastases from sol id and hematological tumours. All of the patients were treated with methotrexate $(M T X)$; some al so received adjunctive cranial radiotherapy. The level of at least one pretreatment biochemical marker was elevated. Respomse rates were similar in patients with normal and abnomal pretreatment levels. 
The Tumbar and ventricular marker lewels were measured simultaneously. CSF levels of the four markers differed markedly at different sites along the neuraxis. Only LDH had a significant correlation with specific metastatic site $(p<0.03)$. Pretreatment CEA correlated well with the histology of the primary tumour for Non-Small Cel l Lung Carcinoma $6 p<$ $0.01)$. LDH level in ventricular CSF was significantly higher in CSF with positive cytolagy.

Increasing levels of B2-m ventricular CSF correlated with progressive disease $(p<0.08)$, and ventricular LDH showed a significant positive correlation with decreasing disease $(\rho<0.05)$.

\subsection{References}

1. Zanten van AP, Twijnstra A, Benthem van $V$, Hart AAM, Ongerboer de Visser BW: Cerebrospinal fluid B-glucuronidase activities in patients with central nervaus system metastases. Clin Chin Acta 1985; 147: $127-134$.

2. Twijnstra A, Nooyen WJ, Zanten van AP, Hart AAM, Ongerboer de Visser BW: Cerebrospinal fluid beta-2-microglobulin: a study in contrals and patients with metastatic and non metastatic neurological diseases. Eur $\mathrm{J}$ Cancer and Clin Oncol (in press).

3. Twijnstra A, Nooyen WJ, Zamten van AP, Ongerboer de Visser BW, Hart AAM: Cerebraspinal fluid carcinoembryonic antigen in patients with metastatic and non metastatic neurological diseases. Arch Neurol bin pressi.

4. Zanten van AP, Twijnstra A, Hart AAM, Ongerboer de Visser BW: Cerebrospinal fluid Tactate dehydrogenase activities in patients with central nervous system metastases. Manuscript submitted for publication, 1986.

5. Ongerboer de Visser BW, Somers R, Nooyen WH, Heerde $P$ wan, Hart AAM, McVie JG: Intraventricular methotrexate of leptomeningeal metastasis from breast carcinoma. Neurology 1983; 33: 1565-1572.

6. Shapiro WR, Young DF, Metha BM: Methotrexate: Distribution in cerebrospinal fluid after intravenows ventricular and lumbar injections. New Engl J Med 1975; 293: 161-166.

7. Murray JJ, Greco FA, Wolff SN, Hainsworth JD: Meoplastic meningitis marked variations of cerebrospinal fluid composition in the absence 
of extradural block. The Mmerican Journal of Medicine 1983; 75 : 289-294.

8. Sculier JP: Treatment of meningeal carcinomatosis. Cancer Treat Rewlews 1985; 12: 95-104.

9. Koch Th, R, Lichtenfeld KM, Wiernik PH: Detection of central nervous system metastases with cerebraspinal fluid $82-m i c r o g l o b u l i n$. Cancer $1983 ; 52: 101-104$.

10. Yap BS, Yap HY, Fritsche HA, BI umenschein G, Bodey GP: Cerebrospinal fluid carcinoembryonic antigen in breast cancer patients with meningeal carcinomatosis. JAMA 1980; 244: 1601-1603.

11. Schold SC, Wasserstron WR, Fleisher M, Schwartz MK, Posner JB: Cerebrospinal fluid biochemical markers of central nerwous system metastases. Ann Neurol 1980; 8: 597-604.

12. Emfehlungen der Deutschen Gesellschaft für Kl inische Chemie. Standardisierung won Methoden zur Bestimung von Enzymaktivitaten in biologischen Flüssigkeitem. Experimentelle Begründung der optimierten Standardbedingungen. J Clin Chen Cl in Biochen 1972; 10: 182-189.

13. Egan ML, Lautenschleger JT, Coligan JE. Radioimmune assay of carcinoembryonic antigen. Immunochemistry 1972; 9: $289-299$.

14. Mawligit GM, Stuckey SE, Cabanillas FF, Keating MJ, Tourtelotte WW, Schold S. Freirich EJ. Diagnosis of leukenia or 1 ymphoma in the centrali nervous system by beta-2-microglobul in determination. N Engl $J$ Med 1980; 303: 718-722.

15. Gl ass JP, Melamed M, Chernik NL, Posmer JB: Malignant cells in cerebrospinal fluid (CSF): the meaning of a positive CSF cytology. Neurology $1979 ; 29: 1369-1375$.

16. Mathios AJ, Nielsen SL, Burzett D, King EB: Cerebrospinal fluid cytomorphology: identification of benign cells originating in the central nervous system. Acta Cyto 1 1977; 21: 403-412. 


\section{Chapter 8}

Diagnosis of Leptomeningeal Metastasis

\section{1. Introduction}

This chapter consists of two parts. In the first part we present the diagnostic procedures for detection of leptomeningeal metastasis with particular emphasis on those advances that have increased the accuracy of the diagnosis.

In the second part of this chapter we analyze the usefulness of several tests in the diagmosis of leptomeningeal metastasis from solld and hematological tumours. The patients reported here were referred to the Antoni van Leeuwemhoekhuis Hospital, Ansterdam, and to the Department of Neurology at the University Hospital, Mastricht, from January 1981 to September 1985. We accepted those patients who had either the typical clinical findings (i.e. neurological dysfunction at multiple levels of neuraxis without radiographic evidence of either brain or epidural spinal metastases) or conclusive laboratory evidence supporting the diagnosis. i.e. malignant cells in the CSF.

Early diagnosis of leptomeningeal metastasis is particularly important because early treatment with intralumbar or intraventricular chemotherapy with or without radiotherapy may lengthen and improve the quality of survival in such patients (1).

\subsection{Definition of leptomeningeal metastasis}

Leptomeningeal metastasis is a form of metastasis of systemic cancer with focal, multifocal, on diffuse infiltration of the leptomeninges by cancer cells.

\subsection{Pathogenesis of leptomeningeal metastasis}

Tumour cells may infiltrate the subarachnoid or ventricular cavity by warious routes. It is thought that in the majority of cases tumour cells reach the leptomeninges via the blood stream. The cells pass the endothelium of leptomeningeal vessels and enter into the CSF. This mechanisin has been demonstrated in leukemia (2). In addition, this 
henatogenous entry into the leptomeninges is suggested by the presence of tumour cells in and around superficlal cortical vessels (3).

Meningeal infiltration from cerebral metastases to the leptomeninges is rare (4) because the fibrous reaction provoked by the invading tumour prevents free dissemination of tumour cells into the CSF. Subependymal metastases may, however" reach the ventricular surface because there is no fibrous scarring of the subependymal tissue (5).

Choroid plexus metastases $(6,7)$ form an important source of dissemination of tumour cells to the leptomeninges. The direct spread of a primary tumour in proximity of the CNS is a rarity because it is thought to be unusual for tumour cells to invade the dura $(5,8-10)$.

The spread from more distant foci along perineural I ymphatic wessels is controversial (11, 12). The infiltration of the leptomeninges via vertebral or paravertebral routes may occur in sone cases, but is probably rare $(7,13)$.

\subsection{Pathology}

Tumours which have seeded the leptomeninges may grow in a linear pattern, creating a thin layer of cells spread diffusely over the brain and spinal surfaces or leptomeningeal tumour may assume a nodular growth pattern involving the leptomeninges in a multifocal pattern with intervening tumour free areas.

In most cases theme is a slight leptomeningeal opacity over the sulci which is often more marked on the basal surface of the brain than on the convexity, particularly the chiasmatic cistern, the interpenduncular fossa and the cerebellopontine angles. Sometimes the infiltration may be confined to the spinal subarachnoid space $(7,11)$.

Microscopical1y, tumour cells may be found in most parts of the subarachnoid and perivascular spaces. The leptomeninges of the brain, the cranial and spinal nerves may be invaded by tumour cells or may be surrounded by a single layer of cells or a thick cuff of tumaur tissue. Invasion of the parenchyma of the nerve has been noticed in rare instances. The infiltration by tumour cells may also extend into the perivascular spaces of the perforating blood vessels. 


\subsection{Cl inical incidence and features}

The exact incidence of leptomeningeal metastasis is unknown, but the disease has been more frequently recognized in recent years, because of increased awareness, improved laboratory techniques and because of longer survival with combination chemotherapy.

The various series reported in the literature are not strictly comparable, as same include hematological tumours and even gliomas, while others confine themselves to carcinoma $(7,11,14)$. Tumours of the lung and breast and leukemias are the most frequently reported primary site (1). Approximately $30 \%$ of patients who die from systemic cancer have evidence of involvement of the central mervous system (CNS) at the time of autopsy, and an estimated two-thirds to three-fourths have experienced symptoms of their CNS lesions (1).

As longer 1 ife spans are achieved in various specific types of leukemia, Iymphoma and carcinoma by means of improved techniques of treatment, CNS relapse is becoming an increasingly common problem (11, $15,16)$.

In breast cancer and in small cell carcinoma of the lung the frequency is stated to be from $4 \%$ to $27 \%(17-21)$. The diagnosis of leptomeningeal metastasis from solid and hematological tumours is often difficult to establish because of a multitude of indefinite signs and symptoms (7). A definite diagnosis of leptomeningeal metastasis during life is based upon the demonstration of malignant cells in CSF. Several lumbar punctures may be necessary before tumour celys can be demonstrated and commonly one has to rely an indirect evidence (pleocytosis, elevated protein, low glucose and elevated intracranial pressure) in conjunction with clinical findings.

Leptomeningeal metastasis may occur in patients with longstanding cancer after many years of apparently good health. On the other hand, the 111 ness may be the first manifestation of cancer. The agle of the patients most $1 y$ reflects the age-incidence of cancer. Myelography and computerized tomography have occasionally been helpful in establishing the diagnosis $(26,27)$.

Neurological signs and symptoms may be minimal and at times concealed by polymeuropathy due to chemotherapy (1). In pattents with the intracranial form of leptomeningeal metastasis the differentiation must be made from cerebral metastasis $(22-24)$, specific infections and 
ardinary forms of meningitis $(7,23,26)$, i.e. neurosyphilits, sarcoidasis and tuberculosis which are al so important to consider in patients unknown to harbour a tumour $(25)$. An aneurysm ma be suspected when a patient presents with headache and ophthalmoplegia. In patients with spinal symptoms the differentiation must be made from bony and epidural metastases and nomalignant conditions such as herniated intervertebral disc..

The neurological symptoms and signs may be divided into three anatomic levels: $\mathbb{1}$. brain, IL. cranial nerve and III. spinal nerve roots $(1,11$, 12,28 ). Patients may have symptoms from one anatomic site only, while others have complaints referable to lesions in two or in all anatomical sites.

Onset of brain signs is often preceeded by a period of vague complaints such as dizziness, mental disorders, disturbed consciousness, nausea and apparantly unimportant headache or backache. Intracranial symptons are caused by meningeal irritation, hydrocephalus due to CSF passage disturbances and parenchymatous involvement.

The most frequent symptoms and signs referrable to cranial nerve palsies, are diplopia, facial numbness, facial palsy and weakness and loss of thearing.

The spinal form of leptomeningeal metastasis often presents with back pain, symptoms including weakness, usually affecting the legs, bladder and bowel dysfunction and radicular pain as their leading complaints. The referred symptoms and signs develop owing to compression and invasion of the cranial nerve spinal root and cauda equina $(11,12)$.

8.6. Laboratory findings

8.6.1. Cytopathology of cerebrospinal fluid

Cytologic examination of CSF is the major tool utilized in the diagnosis of patients with leptomeningeal metastasis. The diagnostic criterion of the disease is the presence of tumour cells in the cSF and all patients suspected of leptomeningeal metastases have to undergo a 1 umbar puncture for CSF analysis.

Four techniques are in use for the preparation of the CSF cell smears:

(i) Simple centrifugation and coverslip smears of the sediment. This 
method, howewer, does not yield high quality cytological preparations (29).

(ii) The Sayk technique; in the sedimentation chamber deweloped by Sayk, sediment cells are under gentle pressure while liquid is removed by paper filltration (18).

(iii) The cytocentrifuge technique has becone one of the most widely used methods of handling several CSF samples simultaneously. Cell morphology, however, may be altered by centrifugation (30).

(iv) The membrane filtration technique is a rapid method providing the best quantitative yield of cells but the cell morphology is not as well preserved as with the Sayk"s sedimentation technique $(31-33)$.

About sixty percent of the patients with leptomeningeal metastases have positive cytological findings. False positive results occur when inflammatory cells are mistakenly held for tumour cells or due to the contamination with peripheral blood or bone marrow from leukenic patients (34-36). Ventricular samples in which brain tissue is transversed by needles of catheters may also contaminated with neuron or glia cells, which can be mistaken for malignant cells $(34,35)$. This problem can be avercome by repeated cytological examinations. The false negative cytologies are more common when tumour cells are masked by reactive leukacytosis. The yield of CSF positive findings is generally lower in cases of primary brain tumour (15\% to 30\%), than in brain metastases (20\% to 50\%) (37). Autopsy studies, correlated with CSF findings, showed that: cells are rarely shed into the CSF by a deep parenchymal tumour. These results imply that the presence of tumour cells rather frequentiy indicates the invasion of the leptomeninges by a tumour (15).

\subsubsection{The role of CSF biochenical markers in central nervous system} (CNS) metastases

In chapter one we have extensively discussed the rolle of the biochenical markers in the CSF. With respect to leptomeningeal metastases, four potential markers in cerebrospinal fluid (CSF) have been studied, namely: $8-g l u c u r o n i d a s e ~(B-g l u c),. B 2-m i c r o g l o b u l$ in $(B 2-m)$, carcinoembryonic antigen (CEA) and lactic dehydrogenase (LDH) $(38-43)$. 


\subsubsection{The role of monoclonal antibodies in CSF cytology}

The diagnosis of leptomeningeal metastases by routine CSF cytological staining methods is frequently unsatisfactory and reported rates of detection of malignant cells vary between $40 \%$ and $60 \%$ of a 11 cases. This percentage may rise after multiple spinal taps (1,33). In the literature, studies are reported on efforts to deterine whether diagnostic accuracy in CSF examinations can be improved by performing monoclomal antibody inmunocytology $(44-46)$. Coakham et al. found that an important diagnostic contribution can be made by monoclonal reagents in CSF cytology. A diagnostic monoclonal antibody battery, which included markers for neural, epilthelial and Iymphaid differentiation antigens "was used in the detection of tumour cells in CSF. The monoclonal reagents were found to be of great value in the detection and characterization of neoplastic cells in CSF from patients with leptomeningeal metastases. Applying monoclonal immunocytology, the detection of malignant cells increased from $73 \%$ to $95 \%$ and the characterization of neoplastic cells from $16 \%$ to $95 \%$. These findings suggest that patients with leptomeningeal metastases may be spared prolonged investigation and inappropriate management by using batteries of monoclonal antibodies.

\subsubsection{Cytogenetic studies of cells in the CSF}

Reports of cytogenetic studies of cells in the CSF are very scarce. However, chromosome analysis of peritoneal and pleural fluid has been recognized as a useful tool in the diagnosis of neoplasia (47).

Baugham and Hirsch (48) first reported chromosome abnomalities in a post-mortem study of CSF of a patient known with malignant glioma.

Mastrangello et al. (49) demonstrated that chromosome analysis of CSF cells may be more accurate than cell cytology in the diagnosis of metastatic meningeal involvement of acute lymphoblastic leukemia. This technique has also been used as a diagnostic procedure in patients with leptomeningeal metastases from solid tumours where CSF cells with clearly abnormal karyotype were found (50). Sometimes chromosome analysis of CSF may be more accurate than cell cytology in the diagnosis of leptomeningeal metastasis, particularly in cases in which leptomeningeal metastases is the first clinical manifestation of malignancy. 
8.7. Radiological studies

8.7.1. Computerized tomography of leptomeningeal metastasis

Computer tomagraphy may be helpful in establishing the diagnosis of leptomeningeal metastasis. The characteristic CT-scan observations in leptomeningeal metastases have been described in 1976 (26, 51, 52). They include gyral enhancement, without edema, sulcal and basilar cisternal obliterations and ependymal-subependymal enhancement. Ventricular dilatation was a non-specific finding due to either comunicative or non-communicative obstruction.

8.7.2. Myel agraphy in patients with leptomeningeal metastases

Wasserstrom et a1. (1) studied the role of myelography in patients suspected of leptomeningeal metastases. He performed myelography an a total of 49 patients with leptomeningeal metastases secondary to a variety of sol id tumours. Twenty-two myelograms were nomal, 14 showed spinal epidural metastatic lesions, whereas only $13(26 \%)$ suggested reptomeningeal metastases. Pederson et al. (27) studied the use of myelography in diagnosing leptomeningeal metastases secondary to small cell carcinoma of the lung. Myelograms were suggestive of leptomeningeal metastasis in nine out of 20 patients.

The myelography is useful and complements CSF cytological examination in the evaluation of patients suspected of leptomeningeal metastases. The current policy is to perform a myelogram in patients suspected of leptomeningeal metastases and to regard a positive finding as diagnostic of the disease. Furthermore, therapy can be monitored by serial myelograms.

8.8. Clinical investigations and diagnosis in 41 patients with leptomeningeal metastases

The diagnosis of leptomeningeal metastasis is often difficult to establish despite the availability of various diagnostic tests.

In this part of the chapter we describe the results of these various tests in the aid of 41 patients with the diagnosis ieptomeningeal metastasis from solid and hematological tumours. 


\subsubsection{Clintcal findings}

Table 1. Leptomeningeal metastases from solid and hematological tumours in 41 patients: Vital Data.

\begin{tabular}{|c|c|c|c|}
\hline primary tumours & No & fenale/male & $\begin{array}{c}\text { age range } \\
\text { (years) }\end{array}$ \\
\hline Breast & 16 & $16 / 0$ & $37-70$ \\
\hline Lung & 12 & $1 / 11$ & $45-69$ \\
\hline adeno & 2 & $1 / 1$ & $45-69$ \\
\hline sma1l cell carcinoma & 6 & $0 / 6$ & $53-62$ \\
\hline epidermoid & 4 & $0 / 4$ & $50-69$ \\
\hline Malignant melanoma & 3 & $1 / 2$ & $31-49$ \\
\hline Non-Hodgk in's lymphoma & 9 & $1 / 8$ & $35-70$ \\
\hline M. Kahler & 1 & $1 / 0$ & 64 \\
\hline Tatal & 41 & $20 / 21$ & $31-70$ \\
\hline
\end{tabular}

In table 1 we show the histology of the primary tumours. There were 20 women and 21 men, ranging in age from $31-70$ years. Carcinoma of the breast was the most common primary tumour, accounting for 16 of the 41 patients. Carcinoma of the 1 ung was the primary tumour in 12 patients (six small cell carcinomas, four epidermoid carcinomas and two adenocarcinomas). Malignant melanoma was the primary tumour in three patients, whereas 1 ymphoma was the primary tumour in nine patients and multiple myel ana in one patient. The interval between the diagnosis of the primary malignancy and the diagnosis of leptomeningeal metastases varied from less than one day to more than ten years (Table 2). In one patient leptomeningeal involwement was the presenting complaint and the primary tumour was found subsequent to the CNS metastasis.

Fourteen patients had active disease outside the nervous system, including metastases to the rungs, liver and bone. Three patients had brain metastases, one had epidural metastasis and two had both brain and epidural metastases. In 21 patients metastases were 1 imited to the leptomeninges . 
Table 2. The interval after primary diagnosis in 41 patients with leptoneningeal netastases.

1: presenting signs

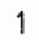

2: less than 6 months

12

3: $6-36$ months

19

4: 3-9 months

5: 10 more years
8

1

1

8.8.2. Symptoms and signs of patients with leptumeningeal metastases

All patients suspected for central nervous system metastases underwent a clinical evaluation by a neurologist. The neurological symptoms and signs were categorized into three anatomic levels (Table 3).

\subsubsection{Cerebral signs and symptans (T)}

Cerebral signs and symptoms occurred in 35 patients. Headache, mental change, nausea and vomiting were the most frequent. Three patients had severe headache, but no neurological signs.

\subsubsection{Cranial nerve signs and symptoms (II)}

Cranial nerve signs and symptoms occurred in 26 patients. The most frequent complaints were diplopia, facial numbness and weakness. Loss of hearing was found in three patients and nerve palsies were found in six. patients.

\subsubsection{Spinal signs and symptoms (III)}

Spinal symptoms and signs were noted in 27 patients. The most frequent were weakness, usually affecting the legs, paresthesias in the lower legs, and bladder and bowel dysfunction. The most frequent complaint was backache and radicular pain. These complaints developed during weeks to months before the diagnosis was established.

When signs and symptoms were considered together, 15 patients had signs and symptoms limited to one area, 5 patients to two and 21 patients to all three. 
Table 3. Neurological evalluation: CSF, myelography, CT-scan and autopsy findings in 41 patients suspected of leptomeningeal metastases.

\begin{tabular}{|c|c|c|c|c|c|c|}
\hline $\begin{array}{l}\text { patient } \\
\text { number }\end{array}$ & $\begin{array}{l}\text { neurological } \\
\text { evaluation* }\end{array}$ & $\begin{array}{l}\text { CSF } \\
\text { No }\end{array}$ & $\begin{array}{c}\text { evaluation } \\
\text { results }\end{array}$ & $\begin{array}{c}\text { Myelography at } \\
\text { results }\end{array}$ & CT-scant & Autopsy ${ }^{*}$ \\
\hline $\begin{array}{l}1 \\
2 \\
3 \\
4 \\
5 \\
6 \\
7 \\
8 \\
9 \\
10 \\
11 \\
12 \\
13 \\
14 \\
15 \\
16 \\
17 \\
18 \\
19 \\
20 \\
21 \\
22 \\
23 \\
24 \\
25 \\
26 \\
27 \\
28 \\
29 \\
30 \\
31 \\
32 \\
33 \\
34 \\
35 \\
36 \\
37 \\
38 \\
39 \\
40 \\
41\end{array}$ & 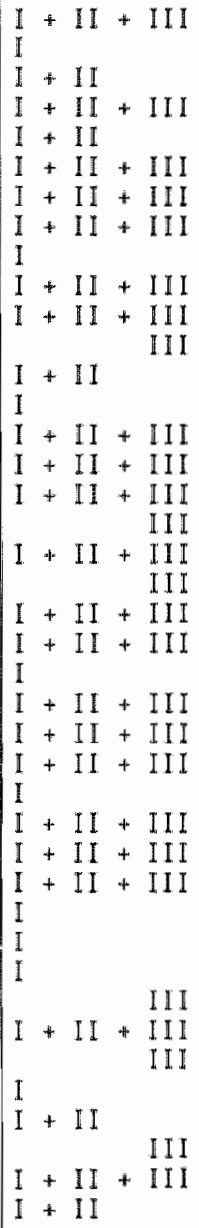 & $\begin{array}{l}1 \\
2 \\
1 \\
2 \\
1 \\
1 \\
1 \\
2 \\
2 \\
1 \\
1 \\
1 \\
1 \\
1 \\
2 \\
1 \\
1 \\
1 \\
4 \\
2 \\
3 \\
3 \\
2 \\
1 \\
1 \\
1 \\
1 \\
1 \\
4 \\
3 \\
1 \\
1 \\
1 \\
1 \\
1 \\
1 \\
1 \\
3 \\
2 \\
2 \\
1\end{array}$ & 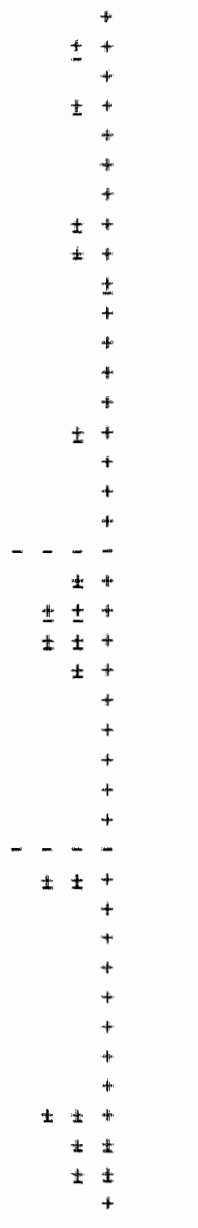 & $\begin{array}{c}0 \\
0 \\
0 \\
0 \\
\text { total stop } \\
0 \\
0 \\
0 \\
0 \\
0 \\
+ \\
0 \\
0 \\
0 \\
+ \\
0 \\
0 \\
0 \\
+ \\
- \\
+ \\
0 \\
0 \\
0 \\
0 \\
+ \\
- \\
0 \\
\text { total stop } \\
+ \\
0 \\
\\
0 \\
0 \\
+ \\
+ \\
0 \\
0 \\
0 \\
0 \\
0 \\
0 \\
0 \\
0 \\
0\end{array}$ & $\begin{array}{c}- \\
- \\
- \\
- \\
0 \\
- \\
0 \\
+ \\
- \\
\text { met. } \\
+ \\
0 \\
+ \\
+ \\
+ \\
\text { met. } \\
+ \\
+ \\
0 \\
0 \\
+ \\
+ \\
0 \\
+ \\
+ \\
+ \\
0 \\
+ \\
+ \\
\text { met. } \\
0 \\
0 \\
+ \\
0 \\
0 \\
0 \\
0 \\
\text { met. } \\
0 \\
\text { met. } \\
0\end{array}$ & $\begin{array}{l}0 \\
+ \\
0 \\
0 \\
0 \\
0 \\
0 \\
0 \\
0 \\
+ \\
0 \\
0 \\
0 \\
0 \\
+ \\
0 \\
0 \\
0 \\
+ \\
0 \\
0 \\
0 \\
0 \\
0 \\
0 \\
0 \\
0 \\
0 \\
+ \\
0 \\
0 \\
0 \\
0 \\
0 \\
+ \\
+ \\
+ \\
+ \\
+ \\
+ \\
+\end{array}$ \\
\hline
\end{tabular}




\section{Legend to Table 3}

* Neurological evaluation:

I : cerebral signs and symptoms

II : cranial nerve signs and symptoms

III : spinal signs and symptoms

** CSF evaluation :

* : malignant cells in the CSF

\pm : suspect cells or protein $>0.51 \mathrm{~g} / 1$, glucose $<2.0$ mnol $/ 1$, pressure $>18 \mathrm{~cm} \mathrm{H}_{2} \mathrm{O}$, leukocytes $>8 \mathrm{~mm}^{3}$

- : normal CSF

$\star \star \star$ Myelography :

+ : irregular filling of the subarachnoid space due to metastatic deposits

- : norma 1

0 : myelography not done

$\star \star \star *$ CT-SCan :

$+\quad$ : contrast enhancement and hydrocephalus

- : normal

0 : CT-scan not done

met : metastases

+ Autopsy: all autopsies are microscopic and include the spinal cord + : tumour cells have been found

- : no tumour cells have been found

0 : autopsy not done 


\subsubsection{Laboratory findings}

\subsubsection{Cytology of cerebrospinal fiuid}

All patients who had the typical findings of leptomeningeal metastases (i.e., neurological dysfunction at multiple levels of neuraxis without radiographic evidence of either brain or epidural spinal metastases) underwent a lumbar puncture. Cytological examination of CSF has become the most important diagnostical procedure in patients suspected of having meningeal spread of their tumour. CSF was examined in all patients of this study, many of them underwent several examinations before the diagnosis was established. The CSF findings were divided into three groups: a) a definite leptoneningeal metastasis if malignant cells are found (+); b) suspected leptomeningeal metastasis if atypical cells or changes compatible with leptomeningeal metastasis were found (protein > $0.51 \mathrm{~g} / \mathrm{l}$, glucose $<2.0 \mathrm{mmol} / 1$, leukocytes $>8 / \mathrm{mm} 3$, pressure $>18 \mathrm{~cm}$ CSF) $( \pm), c)$ not suspected in the absence of any of the above mentioned findings $(-)$.

The initial lumbar puncture (Table 3 ) was abnomal in all but two patients. Three patients neurologically suspected of leptaneningeal metastases had dubious CSF. In 50\% of the cases CSF pressure was above 18 $\mathrm{cm}$. The cell count was elevated in 26 patients. The inajority of these cells were mononuclear leukocytes, mostly 1 ymphocytes. The protein concentration was above $0.51 \mathrm{~g} / 1$ in 30 patients. In 19 patients the CSF glucose was less than $2.0 \mathrm{mmol} / 1$. Among the 41 patients with meningeal neoplasia the initial lumbar puncture was abnomal in $25(61 \%)$, the detection rate increased after multiple spinal taps (from $61 \%$ to $88 \%$ ). The CSF cytolagy remained persistently negative in two patients throughout the course of the disease. However, at autopsy leptomeningeal involvement of metastases were found.

\subsubsection{Biochemical markers in CSF as a diagnostic aid in}

\section{leptomeningeal metastasis}

We studied four biochemical markers in 41 patients with leptomeningeal metastases from carcinoma and 1 monphoma. B-gluc., B2-m, CEA and LDH were measured simultaneously on CSF samples from patients with CNS tumours and in patients with a braad spectrum of other neurological diseases.

CSF B-gluc., B2-m, CEA and LDH measurements were performed as reported 


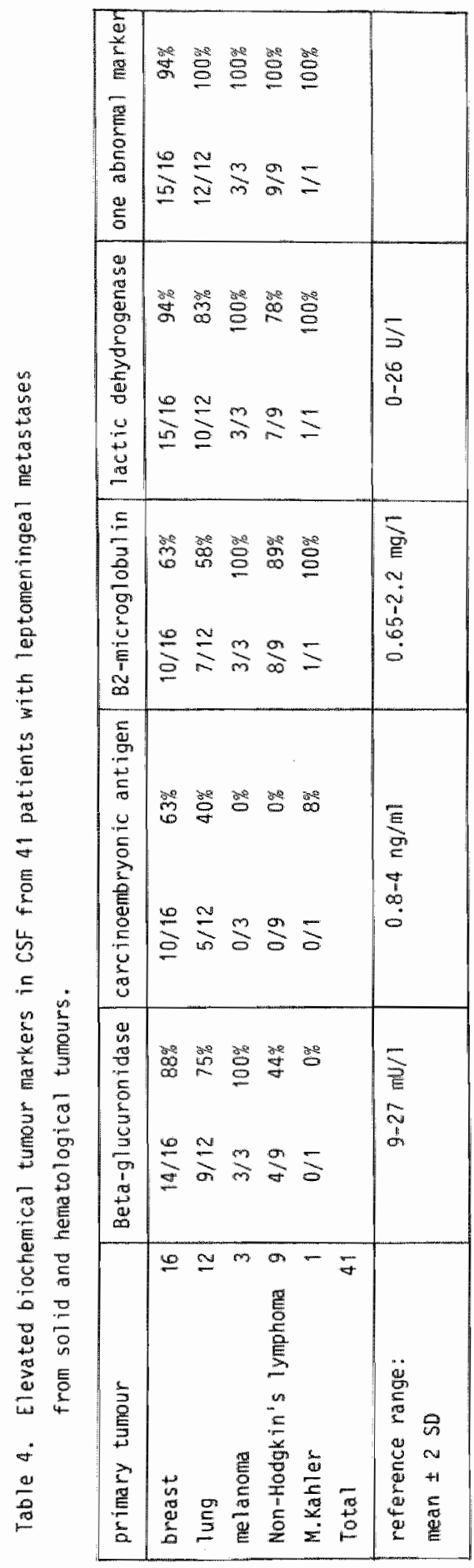


previous $1 \mathrm{y}$ (53-56). The reference ranges for the four markers in normal CSF were based upon man $\ldots 2$ SD (Table 5). B2-m increased significanty wh thereasing age (18). Using these reference ranges $B-g l u c$. and LDH were found to be the most frequent positive tests in patients with leptomeningeal metastases from solid tumours (breast carcinona, melanoma). For leptomeningeal metastases from hematological malignancy (1 ymphona and M. Kahler) $32-m$ was the most frequent positive (Table 4).

In one case with cytologic evidence of leptomeningeal metastases, the autopsy was megatiwe and there were almost entirely normal values of the CSF tumour markers. More common than these so-cal led 'false positive' cytologies is the failure to find malignant cells, when the clinical findings strongly suggest and autopsy revealed leptomeningeal metastases, the so-called 'false negative' cytologies. Of four patients, strongly suspected of leptomeningeal metastases, two patients had persistently negative CSF and two patients had suspicious CSF for tumour cells, however measurements of biochemical markers revealed elevated values with positive autopsy findings. Table 5 illusitrates the findings when the four markers are measured simultameously. Because these markers are sometimes elevated in different situations, measuring all of them often gives more information about the patient"s clinical diagnosis than measurement of either alone.

\subsubsection{Autopsy stuidies}

In 12 cases out of 41 patients with clinical leptomeningeal metastases a general autopsy and macroscopic neuropathological reports were investiglated, and a large number of slides of sections of various levels of the CNS were microscopically exanined. The infiltration of the leptomeninges by tumoum cells was focal in three patients, multifocal in four patients and in five patients diffuse. In three patients the infiltration by tumour cells was visible to the naked eye.

\subsubsection{Radiological studies}

8.8.4.1. Computerized tomography of leptomeningeal metastasis

In establishing the diagnosis of leptomeningeal metastasis computerized tomography (CT) may be helpful. We performed CT-scan in 26 


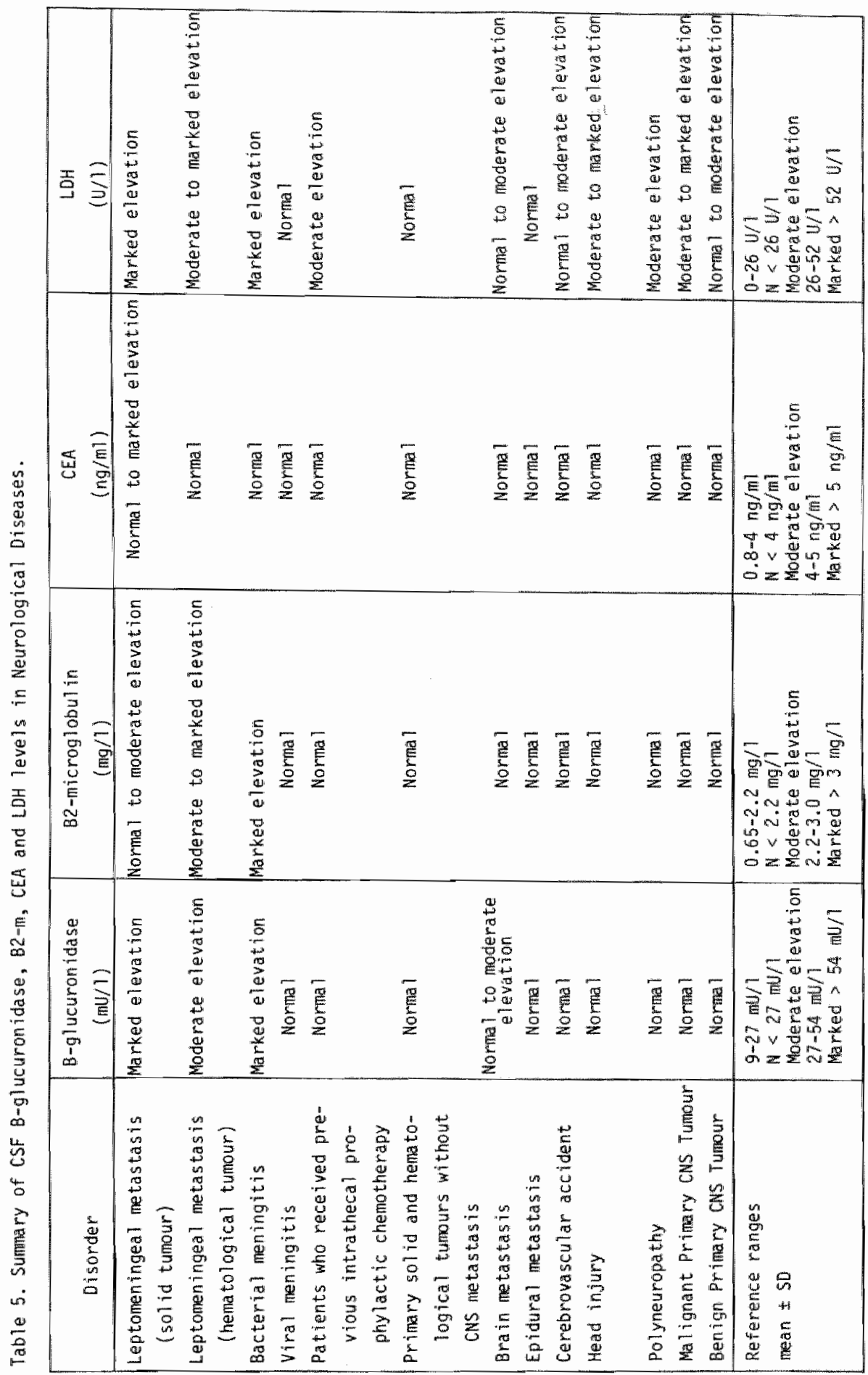


patients (Table 3) and found characteristic CT-abnomalities in 15 patients (58\%).

Findings were borderitine or suggestive in three patients (12\%). CT was nomal in eight patients (31\%). Enlargement of the entire ventricular system without an abstructing mass lesion was present in 15 of the CT-scans. Contrast enhancement in the basal cistern or cerebral gyri-sulci was present in 17 patients. Five scans showed evidence of parenchymal brain metastases.

\subsubsection{Myelography in patients with leptomeningeal metastasis}

In the present study we performed a myelography in 12 patients with leptomeningeal metastases and spinal root symtoms: all patients had mal igmant cells in their CSF (Table 3 ).

Two myelograms were nomal, two showed spinal epidural metastatic lesions, giving rise to a totall stop, whereas 8 patients $(64 \%)$ had a positive myelogram, with irregular fillings of the subarachnoid space due to thickening and nodosity of nerve roots, particularly of the cauda equina.

\subsubsection{Concluding remarks}

Leptomeningeal metastases are a clinically important complication of solid and henatological malignancies occurring with an increasing incidence.

The diagnosis can be established by the clinical signs and symptons and by appropriate laboratory and radiological examination. It has been suggested that symptoms more often stabilize than improve upon treatment; therefore early diagnosis may be important before symptoms are devastating.

The usefulness of the biochemical markers B-gluc., B2-m, CEA and LOH have been described as an aid in the diagnosis of leptomeningeal inetastasis.

Further studies are needed to establish other diagnostic methods such as the value of magnetic resonance for imaging leptomeningeal lesions and flow cytometry to measure the DNA index in CSF cells in cases of suspected leptameningeal metastases. 
1. Ongerboer de Visser BW, Somers $R$, Nooyen WH, Heerde P van, Hart AAM, MCVie JG: Intrawentricular methotrexate therapy of leptoneningeal metastasis from breast carcinoma. Neurology 1983; 33: 1565-1572.

2. Price RA, Johnson Wh: The central nervous system in childhood. Leukemia 1: The arachnoid. Cancer 1973; 31: 520-533.

3. Madow L, Alpers BJ: Encephalitic form of metastatic carcinona. Arch Neurol Psychiat 1951; 65: $161-173$.

4. Fried BW: Primary calcinoma of the 1ungs. Arch Intern Med 1925; 35 ; $1-41$.

5. Russell DS, Rubinstein LJ: Pathology of Tumours of the Nervous Systems. Fourth Ed. Baltimore, Williams and Wilkins, 1977.

6. Danisch F, Nedelmann E: Bösartiges Thyom bei einem $3 \frac{1}{2}$ jährigen kind mit eigenartiger Metastasierung ins Zentralnervensystem: Zugleich ein Beitrag zur Klinik und pathologischen Anatonie der Geschwul smetastasierung auf den Liquor(wege). Virchows Arch Pathol Physiol 1928; 268: $492-514$.

7. Ol som ME, Chernik NL., Posner JB: Infiltration of the leptomeninges by systemic cancer: A clinical and pathologic study. Arch Neurol 1974; 30: $122-137$.

8. Cairns $H$, Russel DS: Intracmanial and spinal metastases in gliomas of the brain. Brain 1931; 54: $377-420$.

9. Heffelfinger MJ, Dahl in DC, MacCarty CS, Beabout JW: Chordomas and cartilaginous tumors at the skull base. Cancer 1973; 32: 410-420.

10. Willis RA: The spread of tumours in the human body. Third Ed. London, Butterworths, 1973, 259-268.

11. Gonzalez-Vitale UC, Garcia-Bunuel R: Meningeal carcinomatosis. Cancer $1976 ; 37: 2906-2911$.

12. Parsons M: The spinal form of carcinomatous meningitis. Q J Med 1972; 41: $509-518$.

13. Kokkoris ChP: Leptomeningeal carcinomatosis. How does cancer reach the pla-arachnoid? Cancer 1983; 51 : 154-160.

14. Little JR, Dale A.JD, Okazaki $H$ : meningeal carcinomatosïs. Arch Neurol $1974 ; 30: 138-143$.

15. Glass JP, Melamed M, Chernik NL, Posner JB: Malignant cells in 
cerebrospinal fluid (CSF): The meaning of a positive CSF cytology. Meurology 1979; 29: 1369-1375.

16. Burn PA JR, Schein PS, Banks PM, DeVita VT Ur: Central nerwous system complications in patients with diffuse histiocytic and undifferentiated lymphoma: Leukemia Rew isited. Blood 1976; 47: 3-10.

17. Bischoff A: Erfahrungen mit der Tumorzelldiagnostik im Liquor cerebrospinalis. Acta Neurochir 1961; 9: $510-524$.

18. Sayk $d, 01$ ischer RM: Fortschpitte der Liquorzytologie bei der Diagnostik bösartiger Hirngeschwul ste (3. Mitteilung). Psychiat Neurol Med Psychol (Leipzig) 1967; 19: 88-89.

19. Hirsch FR, Paulson $O B$, Hansen $H_{H}$, Vraa-Jensen J: Intracranial metastases in smal'| cell carcinona of the lung. Cancer 1982; 50 : $2433-2437$.

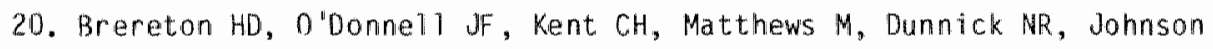
RE: Spinal meningeal carcinomatosis in small cell carcinoma of the lung. Ann Intern Med 1978; 88: 517-519.

21. Nugent JL, Bunn PA Jr., Matthews MJ, Ihde DC, Cohen MH, Gazdar A, Minna JD: CNS metastases in small bronchogenic carcinoma. Increasing frequency and changing pattern with lengthening survival. Cancer 1979; 44: 1885-1893.

22. Rosen ST, Aisner J, Makuch RW, Matthews MJ, Ihde DC, Whitacre MRN, Glatstein EJ, Wiernik PH, Lichter AS, Bunn PA: Carcinomatous leptomeningitis in small cell lung cancer: a clinicopathologic review of the National Cancer Institute Experience. Medicine 1982;61: $45-53$.

23. Greenberg HS, Deck MDF, Vikram B, Chu FCH, Posner JB: Metastasis to the base of the skull: Clinical findings in 43 patients. Neurology $1981 ; 31: 530-537$.

24. Max MB, Deck MDF, Rottenberg DA: Pituitary metastasis: Incidence in cancer patients and clinical differentiation from pituitary adenoma. Newrol ogy $1981 ; 31$ : $998-1002$.

25. Morgenroth J, Deisseroth A, Winokur S, Schein Ph: Differentiation of carcinomatous and bacterial meningitis. Neuralogy 1972; 22 : $1240-1242$.

26. Aseheral GF, Hilal SK, Brisman R: Computed Tomography of disseminated meningeal malignant neoplasms. Neuroradiology 1976; 12: 52 . 
27. Pederson AG, Paulson OB, Gyldensted C: Metrizamide myelography in patients with small cell carcinona of the lung suspected of meningeal Carcinomatosis. J Neura-0ncol 1985; 3: 85-89.

28. Wasserstrom WR, Glass JP, Posner JB: Diagnosis and treatment of leptameningeal metastases from solid tumors: experience with 90 patients. Cancer 1982; 49: 759-772.

29. Tourtelotte WW: Cerebrospinal fluid examinations in meningoencephalitis. Mod Treatm 1967; 4: 879-897.

30. Hansen HH, Bender RA, Shelton BJ: The cytocentrifuge and cerebrospinal fluid cytology. Acta Cytal (Baltimore), 1974; 18: $259-272$.

31. Barringer JR: A simpl ified procedure for spinal fluid cytology. Arch Neurol 1970; 22: 305-308.

32. Kreutz MJ, Dyken PR: Cerebrospinal fluid cytomorphology. Sedimentation vs filtration. Arch Neurol 1972; 26: $253-257$.

33. Bigner SH, Johnston WW: Cytopathology of cerebrospinal fluid. Acta Cytol 1981; 25: $461-479$.

34. McGarry P, Holmquist ND, Carmel SA: A postmortem study of cerebrospinal fluid with histologic correlation. Acta Cytol 1969; 13: $48-52$.

35. Mathios Ad, Nielsen SL, Barrett D, King EB: Cerebrospinal fluid cytomorphology: identification of benign cells originating in the central nervous system. Acta Cyto1 1977; 21: 403-412.

36. Spriggs AL, Boddington MM: Leukaemic cells in cerebrospinal fluid. Br J Haematol 1959; 5: 83-91.

37. Balhuizen JC, Bots GTAM, Schaberg A, Bosman FT: Value of cerebrospinal fluid cytology for the diagmosis of malignancies in the central nervous system. J Neurosurg 1978; 48: 747-753.

38. Schold SC, Wasserstrom WR, Fleisher M, Schwartz MK, Posner JB: Cerebrospinal fluid biochemical markers of central nervous system metastases. Ann Neurol 1980; 8: 597-604.

39. Wasserstrom WR, Schwartz NK, Fleisher M, Posner JB: Cerebrospinal fluid biochemical markers in central nervous system tumours: a review. Ann Cl in Lab Sci 1981; 11: 3: 239-251.

40. Shuttleworth EC, Allen N: CSF-B-glucuronidase assay in the diagnosis of neoplastic meningitis. Arch Neurol 1980; 37: 684-687. 
41. Koch ThR, Lichtenfeld KM, Wierfik PH. Detection of central nervous systen metastases with cerebrospinal fluid 82 -microglobulin. Cancer $1983 ; 52: 101-104$.

42. Dearnalley DP. Patel S, Powel Td, Coombes RC: Carcinaembryonic antigen estimation in cerebrospinal fluid in patients with metastatic breast cancer. Oncodevel Biol and Med 1981; 2: 305-311.

43. Fleisher M, Wasserstron WR, Schold 5 , Schwartz MK, Posner PB: Lactate dehydrogenase isoenzymes in the cerebrospinal fluid of patients with systemic cancer. Cancer 1981; 47: 2654-2659.

44. Garson JA, Coakham HB, Kamshead JT, Brownell B, Harper EL, Allan P, Bourne $S$ : The role of monoclonal antibodies in brain tumour diagnosis and cerebrospinal fluid (CSF) cytology. Neuro-oncol 1985: 3: $167-170$.

45. Coakhan HB, Garson JA, Browneli DB, Allan PM, Harper EL, Lane EB, Kamshead JT: Use of monoclonal antibody panel to identify maligmant cells in cerebrospinal fluid. Lancet $1981 ; 8386: 1095-1098$.

46. Coakham HB, Harper EL, Garson JA, Brownell DB, Lane EB: Carcinomatous meningitis diagnosed with monoclonal antibodies. Brit Med J 1984 ; 288: 1272 .

47. Dewald G, Dines DE, We 11 and LH, Gordon H: Usefulness of chromosome examinations in the diagnosis of malignant pleural effusions. $N$ Engl J Med 1976; 295: 1494-1500.

48. Baugham FA Jr, Hirsch B: Karotyping of cells from cerebrospinal fluid. Lancet 1963; 2: 417.

49. Mastrangelo R, Zuelzer WW, Ecklund PS, Thompson RJ: Chromosomes in the spinal fluid: evidence of metastatic origin of meningeal leukemia. Blood 1970; 35: 227-235.

50. Granbery-Oman JF. Andersson BI, Gupta $5 K$ : Chromosame analysis in meningeal carcinomatosis. Acta Neural Scand 1979; 60: 255-259.

51. Tadmor R, Davis K, Roberson G, Kleinman GM: Computed tomography in primary lymphomas of the brain. J Comput Assist Tomogr 1978; 2: $135-140$.

52. Enzmann DR, Norman D, Levin V, Wilson C, Newt an TH: Computed tomography in the follow-up of medullioblastomas and ependynomas. Radiology 1978; 128: 57-63.

53. Zanten AP vam, Twijnstra A, Benthem W wan, Hart AAM, Ongerboer de Visser BW: Cerebrospinal fluid B-glucuronidase activities in patients 
with central nervous system metastases. Cl in Chim Acta $1985 ; 147$ : $127-134$.

54. Twijnstra A, Zanten AP van, Nooyen WJ, Hart AAM, Ongerboer de Visser BW: Cerebrospinal fluid beta-2-microglobulin: a study in controls and patients with metastatic and non-metastatic neurological diseases. The Eur $\mathrm{J}$ Cancer and Clin oncol (in press).

55. Twijnstra A, Nooyen Wu, Zanten AP van, Ongerboer de Wisser BW, Hart AAM: Cerebrospinal fluid carcinoembryonic antigen in patients with metastatic and non-metastatic neurological diseases. Arch Neurol 1985 (in press).

56. Twijnstra A. Zanten AP van, Hart AAM and Ongerboer de Visser BW: Serial lumbar and ventricular cerebrospinal fluid lactate dehydrogenase activities in patients with leptomeningeal metastases from solid and hematologic tumours (submitted). 
In dit proefschrift worden de resultaten wan het onderzoek ower tumor merkstoffer in de liquor cerebrospinalis bij patienten met een leptomeningea le metastasering beschreven. De leptomeningea le metastasering is een ernstige neurologische complicatie van kanker, die vroeger zeldzaam was, mar tegenwoordig in stijgende frequentie wordt herkend.

Bij Jeptomeningeale uitzaaing is er sprake van een diffuse of multifocale uitzaaing van kanker naar de leptomeningen, warvan de diagnose veelal door het aantonen var tumorcellen in de liquor gesteld kan worden. De incidentie van leptomeningeale metastase wordt gesteld op 5-10\%. Het 1ijkt erop dat de incidentie van leptomeningeale metastase stijgt. Aangezien de kwaliteit en de duur wan overlewing zal toenemen bij het vroeg stellen van de diagnose, is het wan belang te kunnen beschikken over gevoelige tests voor de diagnostiek, die tevens kunnen beoordelen of de behandeling van een leptomeningeale metastase effect heeft gehad.

In hoofdstuk 1 wordt een literatuuroverzicht gegeven over de indeling en toepassing van tumor merkstoffen in de liquar. Het blijkt dat er nogal verwarrende gegevens zijn over de juiste beoordeling van de verschillende diagnostische tests. De tests zijn niet altijd op onafhankelijke wijze vergeleken met een gouden standaard voor de diagnose leptomeningeale metastase. 0ok bevatte de onderzochte groep patienten niet altijd de ziekte, die vaak verward werd met de ziekte in kwestie. De factoren die van invloed kunnen zijn op de normalwarden, zoals leeftijd en geslacht, werden dikwijls niet geanalyseerd.

De conclusie uit dit literaturroverzicht is, dat het bepalen van sommige tumor merkstoffen in de liquor duidelijk van waarde blijkt te zijn voor de diagnose en het meten van het effect van een behandeling. Echter voor een groot aantal tumor merkstoffen is de toepasbaarheid nog twijfelachtig. De potentiêle diagnostische en prognostische waarde is afhankelijk van de specificiteit en de gevoeligheid (sensitiviteit) van de tumor merkstof van de betreffende tumor.

Hoofdstuk 2 beschrijft de resultaten van een onderzoek naar de sensitiviteit en specificiteit van beta-glucuronidase in de 1 iquor. De relatie tussen hoogte vall de plasmaconcentratie en liquarconcentratie 
wordt nagegaan. Er blijkt geen verband te bestaan tussen de beide concentraties. Het blijkt dat B-glucuronidase sterk verhoogd is in de Viquor bij leptomeningeale metastasen van soliede tumoren en bacterièle ontstekingen, en minder verhoogd is bij leptoneningeale metastasen van hematologische tumoren.

Hoofdstuk 3 vermeldt de resultaten van beta-2-microglobuline (B2-m) in de liquor als diagnostische test voor het adntonen van leptoneningeale metastasen. Het blijkt dat de concentratie van $82-m$ sterk beinvloed word: door de leeftijd. Deze leeftijdsafhankelijkheid wan B2-m in de Tiquor is nog niet eerder beschreven.

De specificiteit en de sensitiviteit van 12 -m als tumor merkstof in de liquar zijn bepald. Voor het aantonen van leptoneningeale metastasen afkomstig van hematologische tumorem lijkt deze test het gevaeligst.

Hoofdstuk 4 beschrijft de bepaling wan het carcinoembryonal antigeen (CEA) in de liquor. Dok hier wordt geen duidelijk verband gevonden tussen de concentraties plasma CEA en 1 iquor CEA. De gevoeligheid van het CEA als tumor merker is voor het aantonen van de diagnose leptomeningeale metastase, afkomstig vam soliede tumoren, wrij laag. De specificitelit is daarentegen hoog. Er is meer onderzoek nodig naar de metastasen, afkomstig van die tumoren, die CEA produceren. Het is duidelijk dat de CEA bepaling in de liquor niet geschikt is voor de primaire diagnostiek, maar bij een onduidelijke diagnose bij een patient met een bekende maligniteit kan een CEA bepaling nuttig zijn.

Hoofdstuk 5 vermeldt de warde van de tumor merkstof lactat. dehydrogenase (LDH) woor de diagnose en het controleren wan het effect van een behandeling. Het LDH is gemetem in de liquor van een groot: aantal patienten met verschill lende neurologische ziekten. LaH in de liquor is weinig specifiek. Het kan verhoogd zijn bij primaire hersentumoren, bacteriële ontstekingen, trauma capitis en leptomeningeale metastasen. Echter als tumor merkstof is het toch belangrijk, ondat LDH goedkoop en in bijna ieder laboratorium gemakkelijk kan worden bepaald. ook geeft de LOH concentratie in de Tiquor een aanwijzing voor de tumorlocalisatie. Bij verwalg bepalingen wan LDH blijkt er een positief 
Verband tussen de concentratie wan LDH en de ziektetoestand op dat moment.

Hoofdstuk 6 beschrijft de kansen op het aanwezig zijn wan leptomeningeale metastase, berekend aan de hand van het verleggen van de grenzen van de normaalwarden en door het toepassen van een enkel woudige test of een combinatie van tests. Door het verlagen van de grenzen voor nomaal kan de sensitiviteit en de voorspellende warde van de negatieve test uitslag 100\% benaderen. Door het verhogen van de normaalwarden kan de diagnostische test worden gebruikt om de ziekte uit te sluiten.

Hoofdstuk 7 vermeldt de resultaten van de concentratie van B-glucuronidase, B2-m, CEA en LDH, die tegelijk in de ventriculaire en lumbale liquar zijn bepaald. De factoren die een rol spelen in de concentratie gradient tussen ventrikel en lumbale liquar, zijn onderzocht. Er blijkt een verband te bestaan tussen de liquor cytolagie en de LDH concentratie in de verschillende liquor ruimten. De mogel ijkheid om met tumor merkstoffen het effect van de behandeling te meten, is nagegaan. Wij vonden dat de ventriculaire B2-men LDH concentraties a $1 \mathrm{~s}$ parameters kunnen dienen on behandelingsresultaten te evalueren.

In hoofdstuk 8. wordt een literatuur overzicht gegeven van de verschillende tests, warmee de diagnose leptomeningeale metastase kan worden gesteld.

Bij 41 patienten met de $k 1$ inische verschijnselen, passend bij de diagnose leptomeningeale metastase, zijn een aantal van deze tests toegepast. Hieruit concluderen wij dat de tumar merkstoffen in de liquor een belangrijke rol kunnen vervullen in de diagnostiek wan de leptameningeale metastiasen.

\section{Conclusie}

Uit de resultaten van de studie over B-glucuronidase, B2-m, CEA en LDH bl ijkt dat deze tumor merkstoffen een bijdrage kummen leveren aan de diagnose leptomeningeale metastase. De toepassing van deze tumor merkstoffen on het effect $v$ an de behandeling te comtroleren is enigszins. teleurstellend. Al leen de ventriculaire B2-m en LDH concentraties kunnen 
a) 5 parameters gebruikt worden om het effect van de behandeling van de leptomeningeale metastasen te verwolgen.

Weer onderzoek is nodig naar de diagnostische en prognostische warden van de tumor merkstoffen in de liquor. 
Sumpary

The subject of this thesis is a clinical investigation of the value of biochemical tumour markers in cerebrospinal fluid (CSF) in the diagnosis and treatment of patients with leptomeningeal metastases from solid and hematological tumours.

Chapter 1 reviews the literature pertaining to the use of biochemical tumour markers in CSF and speculates on their role in the diagnosis and treatment of patjents with primary and metastatic tumours of the central nerwous system (CNS). Their classification and route of entry are al so discussed.

From the data in the literature it can be concluded that the detection of tumour markers may be of vallue in the early diagnosis of CNS tumours, particularly metastases to the leptomeninges. In addition, they may assist in the evaluation of the efficacy of treatment. An attempt is made to defime the principles of test selection and their use in the pracess of diagnosis. Most of the biochemical markers reviewed appear not to have been adequately studied. It is apparent that the problem of non-specificity is a major ane in the development of reliable cerebrospinal fluid markers of malignancy.

Chapter 2 presents the results of a study on B-glucuronidase in the CSF of patients suffering from various neurological diseases. Reference values are established as $9-27 \mathrm{mU} / 1$. A significant elewation of B-glucuronidase is observed with cytologically confinmed leptoneningeal metastases. Marked elevations are also observed in patients with bacterial meningitis. Moderate elevations are found in patients with leptomeningeal metastases from hematological mal ignancies.

In chapter 3 we study CSF beta-2-micraglabul in (B2-m) in contral subjects and in patients with a variety of neurological diseases to determine the usefulness of this marker test in the detection of leptomeningeal metastasis. In the literature, factors other than disease that can influence test results are not mentioned. We, however, find a highly significant correlation between $B 2-m$ in CSF and age $(p<0.0001)$. A 
sensitiwity of $70 \%$ for leptomeningeal metastases from solid tumours and of $90 \%$ for leptomeningeal matastases from hamatological malignancies is calculated. The specificity of this test is determined to be $93 \%$.

Chapter 4 deals with a study designed to ewaluate the usefulness of the assay of carcinoembryonic antigen (CEA) in the diagnosis of CNS metastases. In this study, determinations are made of CEA levels in the CSF of controls and patients with various neurological arseases in order to establish the sensitivity and specificity of CEA as a test for the diagmosis of leptomeningeal metastases. The sensitivity of the CEA test for the presence of leptomeningeal metastasis from solid and hematological tumours is rather low (31\%; $42 \%$ for solid tumours only); the specificity is $90 \%$.

In Chapter 5 determinations are made of the Vactate dehydrogenase (LDH) activities in the CSF of contral subjects and patients with various neurological diseases in order to establish the sensitivity and specificity of LDH as a test for the diagnosis of leptomeningeal metastases. Marked elevations of LDH in the CSF are observed in patients with leptomeningeal metastases from solid tumours and with bacterial meningitis. A sensitivity of $79 \%$ and a specificity of $83 \%$ are calculated.

LDH levels in CSF may help to define histologic type of tumours. In this study the LDH in ventricular and I umbar CSF from patients with leptomeningeal metastases is measured simultaneously during their treatment with chemotherapy. The LOH in CSF may al so help to differentiate the site of the leptomeningeal involvement of the neuraxis. Serial measurements of LDH in ventricular CSF show a positive correlation between LDH level changes and responses to therapy and progresston.

In chapter 6 the clinical efficacy of B-glucuronidase, B2-m, CEA and LDH in detecting leptomeningeal metastases from breast carcinona is studied. Through the application of multiple biochemical marker tests, simultaneously medsured in the CSF, we assess the diagnostic potential of combined testing. The sensitivities and specificities of these tests in the CSF are then evaluated. 
As a single test, B-gllucuronidase is the most sensitive $(93 \%)$ and specific (93\%) in discriminating between leptomeningeal metastases and other CNS metastases from breast carcinoma. More specific results are

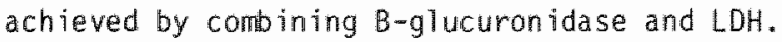

Chapter 7 describes the serial measurements of B-glucuronidase, B2-m, CEA, and LDH in lumbar and ventricular CSF. It is observed that the CSF tumour markers obtained from prophylactically treated patients with hematological malignancies are not influenced by chemotherapy. Response rates. are not associated with the pretreatment levels. A gradient is found between the four markers in ventricular and lumbar CSF. For most of the markers, this gradient cannot be explained by a difference in the site of leptomeningeal metastases. Only LOH in CSF exhibits a significant correlation with the metastatic area of the neuraxis $(p<0.03)$. The pretreatment levels of CEA in CSF correlates with the histology of the primary tumour (non-small cell Iung cancer; $p<0.01$ ). The LDH in ventricular CSF correlates with a positive CSF cytology. The B2-m and LDH in ventricular CSF appear to change with changes in disease status.

Chapter 8 reviews the diagnostic possibilities of establishing the diagnosis leptomeningeal metastasis. The clinical findings of leptomeningeal metastases from solid and hematological malignancies are analyzed. The role of CSF cytology and measurement of biochemical markers including B-gluc., B2-m, CEA, and LDH are evaluated. Computerized tomography and myelography also prove helpful in establishing the diagnosis of leptomeningea 1 metastases.

However, since no one of these tests is both highly sensitive and highly specific, tests are combined and evaluated for their combined diagnostic potential. Identification of B-gluc, $B 2-m$, and LDH with in the CSF appear to offer promise as an adjunct to the cytological analys is of CSF.

\section{Conclusions}

The results of the biochemical tumour marker studies described in this thesis demonstrate that measurements of B-gluc., B2-m, CEA, and LDH can assist in the diagnosis of leptomeningeal metastasis. The markers 
B-glucuronidase and LDH appear to be the most sensitive and specific in leptomeningeal meastasis from solid tumours. More specific results are achieved by combining the two. B2-microglobul in is found to be the most sensitive and specific marker in leptaneningeal metastases from hematological malignancies.

It appears that the serial measurements of changes in the levels of 82-m and, LDH in ventricular CSF are valuable in the follow-up of patients with leptomeningeal metastases. Moreover, our findings indicate that routine measurements of $B 2-m$ in ventricular CSF may be rellable in montoring the efficacy of chemotherapy. There are also indications that these measurements are independent of the most abnormal site of the neuraxis, histology of the primary tumour and CSF cytology. However, the role of the serial measurements of B-glucuronidase and CEA in monitoring therapy is smaller than what was anticipated and, therefore, somewhat disappointing.

The potential use of these biochemical markers in assessing early disease actiwity remains open for further investigation. 
This study was carried out at the Antoni wan Leeuwenhoek Cancer Hospital in Amsterdam, at the Sloterwart Hospital in Masterdam, and at the St. Annadal Hospital in Mastricht, University of Limburg, The Netherlands. I would, therefore, I ike to express my appreciation to menbers of the board of the Antoni van Leeuwenhoek Hospital, as well as to the neurologists of the Slotervaart Hospital, who generously put. their patients" filles at my disposal.

1 wish to acknowledge the foresight of Bram Ongerboer de Visser for making me aware of the importance of the field of neuro-oncology and for guiding the development of this thesis with his thoughtful advice and encouragement. I give heartfelt thanks to Prof.Dr. Jan M. Minderhoud, who introduced me as a student to the field of neuro-anatonical research and who offered me the opportunity to receive training at the Department of Neurology of the State University of Groningen.

I am especially indebted to my promotor, Prof.Dr. Paul van der luyt, both for giving me the opportunity to perform this work and for his advice during the preparation of the manuscript.

A major part of this thesis involved teamwork, and without the statistical assistance of Gulus Hart and the iaboratory assistance of Wi 11 em Nooyen and Anton van Zanten, who prepared an immense amount of data, I arn sure this study would have been impossible. For their critical review of the manuscript, special thanks are also due to Prof.Dr. Fré Bosmain, Dr. Geert Bl ijham, and Prof.Dr.. F.u. Cleton.

I would like ta thank Dr. P. van Heerde and Rob Visser for their cytologic examinations of the cerebrospinal fluid, Dr. D. Moffie for his neuropathologic examinations, and the radiollogists of the Antoni wan Leeuwerhoek Hospital, and of the St. Annadal Hospital for their radiological examinations. At the same time, I gratefully acknowledge the cooperation of the neurological residents of the St. Annadal Hospital, and Mrs. R. Schefman van Neer for their assistance.

Much of the routine, secretarial work was done by Mrs. Nancy Vandeberg and Mrs. Thera wan Lieshout. To them, and especially to Mieke Hamers, for heir accurate, intelligible typing and splendid cooperation, I express my sincere thanks, as I do to Chris Lawrence for his valuable English corrections. I am also grateful to my colleagues at the 
St. Amnadal Hospital for allowing me to spend the time 1 meeded to work on this thesis.

Last, but certainly not least, I must thank Karin, Rolf, and Titia for their tremendous patience, understanding, and support, whout which this work could not have been completed.

I am, indeed, grateful to you all. 
Curricul unitae.

Albert Twijnstra was born on June 27, 1944 in Meppel. The Netherlands. He attended high school in Zwolle and later situdied at the Medical Faculty of the University of Gromingen. During these years he was involved in clinical and research work at the Department of Neurology, under the supervision of Praf.Dr. J.M. Minderhoud.

After graduating in 1972, he worked as a general physician throughout the country. After obstetrical and urological residencies at the Department of Dbstetrics and Gynaecology, headed by Prof.Dr. Joosse, University Hospital of Groningen, and at the Department of Urology, headed by Dr. F.J. Felderhof, at the Leyenburg Hospital. The Hague, respectively, he worked from 1973 - 1975 as a resident in internal medicine at the Department of Internal Medicine, headed by Dr. L.W. Statius van Eps, at the St. El isabeth Hospital in Willemstad, Curacao, Netherlands Antilles.

In September of 1975 he returned to the Department of Meurology at the University of Groningen (chairman Prof.Dr. J.M. Minderhoud), to start his neurological training. In September of 1980 he completed his training, and in November of the same year, he became "chef de clinique" in the Department of Neurology, chaired by Prof.Dr. P.d.M. wan der Lugt, at the St. Annadal Hospital in Mastricht, University of Limburg. In November of 1981 he jointed the staff of the Department of Neurology at the St. Annadal Hospital, where he continues to work as a neurologist. 